\title{
The power of girls' schooling for young women's empowerment and reproductive health
}

\author{
Batool Zaidi \\ Zeba Sathar \\ Population Council \\ Minhaj ul Haque \\ Fareeha Zafar
}

Follow this and additional works at: https://knowledgecommons.popcouncil.org/departments_sbsr-pgy

Part of the Gender Equity in Education Commons, International Public Health Commons, and the Social and Behavioral Sciences Commons How does access to this work benefit you? Let us know!

\section{Recommended Citation}

Zaidi, Batool, Zeba Sathar, Minhaj ul Haque, and Fareeha Zafar. 2012. "The power of girls' schooling for young women's empowerment and reproductive health." Islamabad: Population Council. 


\section{The Power of Girls' Schooling for Young Women's Empowerment and Reproductive Health}

Authors:

Batool Zaidi

Zeba Sathar

Minhaj ul Haque

Fareeha Zafar
Contributors:

Maqsood Sadiq

Mumraiz Khan

Rehan Niazi

Hina Sheikh

Salaeya Butt 


\section{ACKNOWLEDGEMENTS}

Dr. Cynthia B. Lloyd was the advisor on this project. We thank her for her guidance, invaluable comments, and important contributions through all phases of this project, including the field study design and data analysis. Dr. Shahrukh Rafi Khan provided his expertise on the data analysis plan. We also thank all those who participated in our consultative meetings, especially Dr. Saba Gul Khattak, Dr. Aliya Khan, and Dr. Naushin Mahmood for their comments and feedback on the project's research findings and Dr. Nafisa Shah and Ms. Shahnaz Wazir Ali for chairing the meetings. This project was financially supported by the David and Lucile Packard Foundation, represented by Dr. Yasmeen Qazi in Pakistan. Dr. Fareeha Zafar and her team at the Society for the Advancement of Education (SAHE) carried out the program evaluation component. Dr. Zeba Sathar and Ms. Batool Zaidi undertook the final responsibility for writing the report. Ms. Pamela Ledbetter and Mr. Ali Pracha edited the report.

Design and Layout by Mr. Ali Ammad

Published: February, 2012 


\section{TABLE OF CONTENTS}

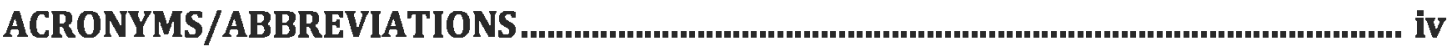

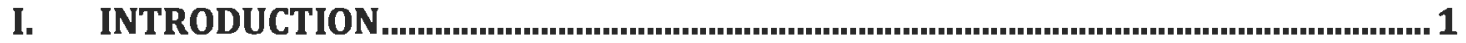

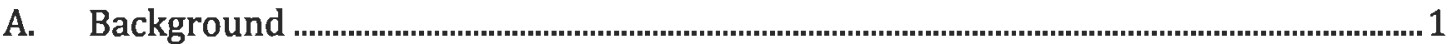

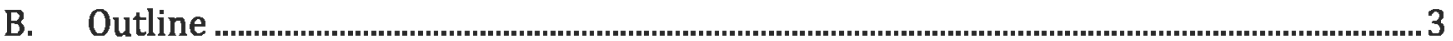

II. THE BIG PICTURE: STATUS OF GIRLS' SCHOOLING IN THE LAST 20 YEARS....... 7

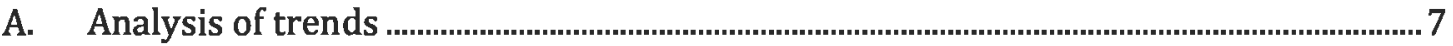

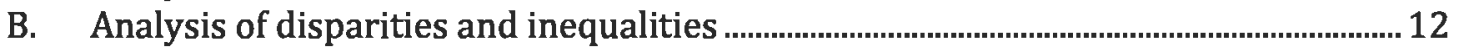

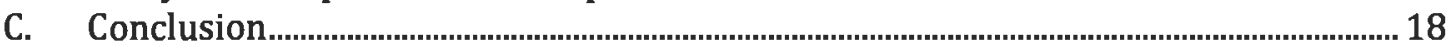

III. DO CHOICE, ACCESS AND QUALITY OF SCHOOLS MATTER FOR IMPROVING LEVELS OF GIRLS' SCHOOLING? ...........................................................................

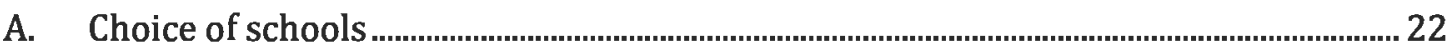

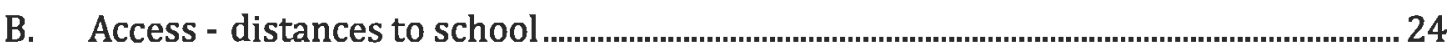

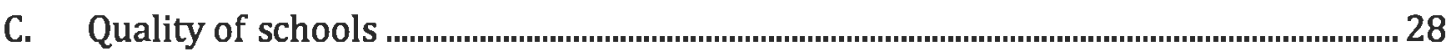

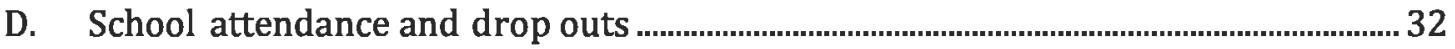

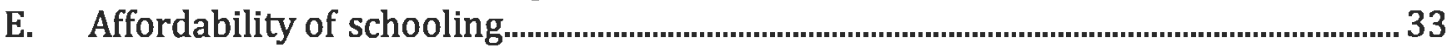

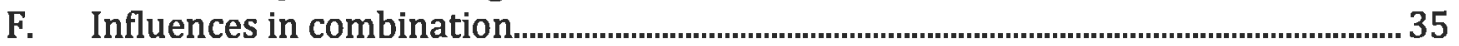

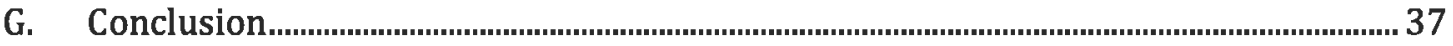

IV. AVENUES OF CHANGE IN YOUNG WOMEN'S LIVES: ROLE OF GIRLS'

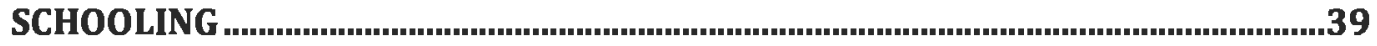

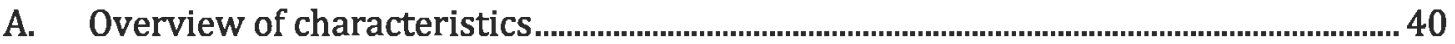

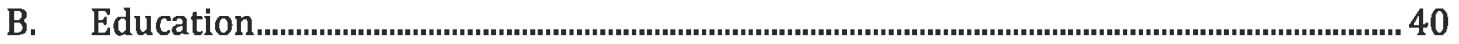

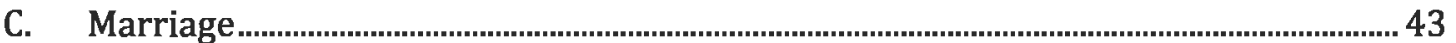

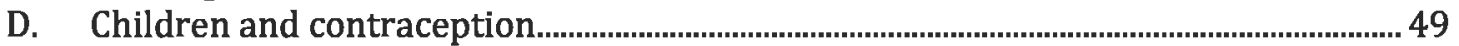

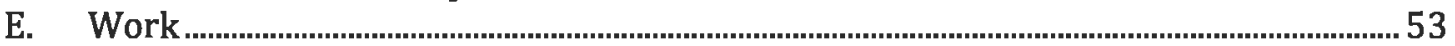

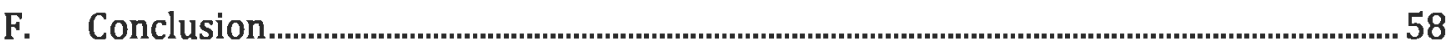

V. EVALUATING PROGRAMS: WHAT WORKED \& WHY IN GIRLS' EDUCATION

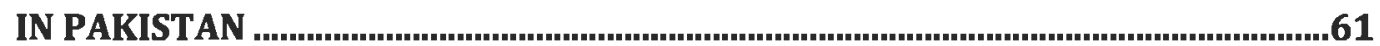

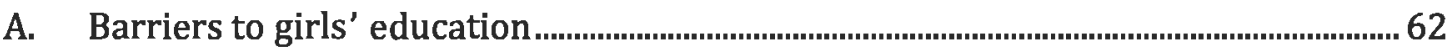

B. Government priorities: delayed agenda for girls?.........................................................6 63

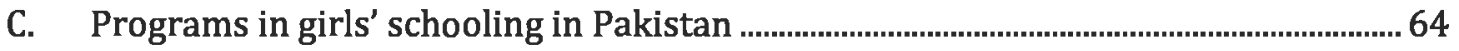

D. Key strategies that work to promote girl's education ....................................................66

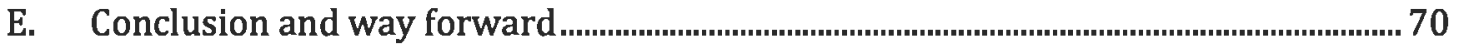

VI. SUMMARY AND CONCLUSIONS .............................................................................73

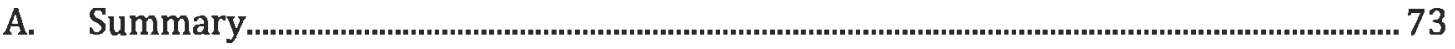

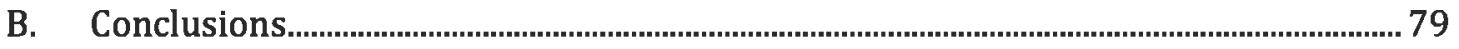

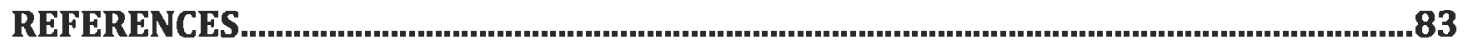

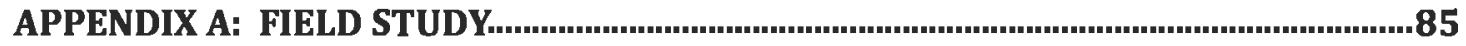

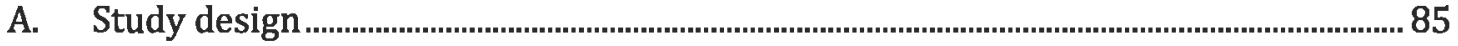

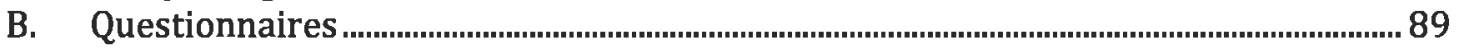

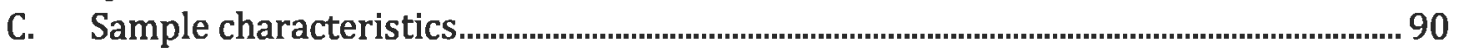

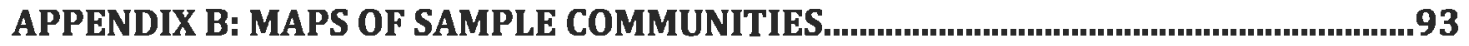




\section{ACRONYMS/ABBREVIATIONS}

\begin{tabular}{|c|c|}
\hline $\mathrm{ADB}$ & Asian Development Bank \\
\hline BHU & Basic health unit \\
\hline BPEP & Baluchistan Primary Education Project \\
\hline CBSP & Community-based school program \\
\hline DFID & Department for International Development (UK) \\
\hline EFA & Education for All \\
\hline ESR & Education sector reforms \\
\hline GDP & Gross domestic product \\
\hline GoP & Government of Pakistan \\
\hline Govt. & Government \\
\hline GPI & Gender parity index \\
\hline GPS & Global positioning system \\
\hline $\mathrm{HH}$ & Household \\
\hline $\mathrm{KP}$ & Khyber Pakhtunkhwa \\
\hline LFS & Labor Force Survey \\
\hline LHW & Lady health worker \\
\hline MDG & United Nations Millennium Development Goals \\
\hline MDG 2 & $\begin{array}{l}\text { United Nations Millennium Development Goal 2: achieve universal primary } \\
\text { education by } 2015\end{array}$ \\
\hline NCHD & National Commission for Human Development \\
\hline NER & Net enrollment rate \\
\hline NGO & Non-governmental organization \\
\hline NWFP & Northwest Frontier Province \\
\hline PDHS & Pakistan Demographic and Health Survey \\
\hline PIHS & Pakistan Integrated Household Survey \\
\hline PMSP & Punjab Middle-School Project \\
\hline PSLMS & Pakistan Standard of Living Measurement Survey \\
\hline PSU & Primary sampling unit \\
\hline PTA & Parent teacher association \\
\hline Pvt. & Private \\
\hline SAP & Social Action Program \\
\hline SBA & Skilled birth attendant \\
\hline SLI & Standard of living (index) \\
\hline SMC & School management committee \\
\hline SPEDP & Sindh Primary Education Development Program \\
\hline SWRHFPS & Status of Women, Reproductive Health, and Family Planning Survey \\
\hline UNESCO & United Nations Educational, Scientific, and Cultural Organization \\
\hline WB & World Bank \\
\hline
\end{tabular}




\section{INTRODUCTION}

\section{A. Background}

There is now global recognition that education is one of the smartest investments for development. The education of females has additional spinoffs that are pivotal for achieving developmental outcomes. Evidence from around the world shows that increased investment in girls' schooling is one of the most cost-effective ways of spurring socioeconomic development. 1

When world leaders gathered in Thailand in 1990 to discuss how to accelerate the process of achieving "Education for All" (EFA), the participation of girls and women in basic education programs was widely recognized as lagging far behind that of males. This was the beginning of global recognition that special attention needed to be accorded to actions designed to improve the participation of girls and women in primary and secondary education. This is now crucial to achieving national and international commitments to the gender-equity targets of both EFA and the Millennium Development Goals (MDGs).

Pakistan is a signatory to both the MDGs and EFA, among several other international and national commitments specific to the education of girls. The Government of Pakistan (GoP) has undertaken policy initiatives and implemented programs with strong components for improving girls' education nationwide, particularly in rural areas. In 1993-94, the GoP launched the Social Action Program (SAP), considered by many policymakers as the starting point of efforts directed towards improving the social sector, particularly education. The second phase of SAP (1998-2003) was to continue the momentum initiated under the previous phase and raise the status of human development. However, according to official and independent assessments and reviews, none of the phases achieved their targets or significantly improved indicators of participation, mainly due to weak implementation and failure to provide adequate and consistent incentives.

The National Education Policy (1998-2010) had objectives of reducing disparities and imbalances to promote gender equity; addressing issues related to the lack of access for

\footnotetext{
1 There are excellent and comprehensive reports that show how and why girls' schooling is important for each development outcome. Reports include: "Girls Count" (Levine et al. 2008), "Girl's Education in the 21st Century: Gender Equality, Empowerment, and Growth" (World Bank 2008) and "The State of the World's Children 2004 - Girls, Education, and Development" (UNICEF 2004).
} 
girls through formal and non-formal systems; and enhancing teachers' skills to increase quality. The National Plan of Action (1997) developed by the Ministry of Women's Development also focused on improving social indicators, particularly education for girls and women. The education sector reforms (2001-2005) also contained specific education targets related to gender.

Yet, despite the GoP's international and national commitments and the participatory role of multilateral and bilateral development partners toward promoting gender equity and quality in education, statistics indicate that targets, with some exceptions, are still not being reached. While there is national acknowledgment of the importance of improving girls' schooling in Pakistan, the close inter-linkages that girls' schooling has with other development indicators (e.g. economic growth, poverty alleviation, and maternal and child mortality) are not fully appreciated. This is one reason why girls' education is not provided with the resources required to make significant gains.

There has been some progress in Pakistan's education sector: for example, girls in particular have shown significant improvements in educational attainment since 2000 . While the recent pattern of enrollment growth since the millennium is encouraging, enrollment levels in rural areas, particularly for girls (less than $\mathbf{5 0}$ percent for the primary level), lag far behind urban levels. The pressing issue is how to accelerate this trend to be able to reduce the deficit of girls' primary schooling and to facilitate their transition to the secondary level, in the coming decade.

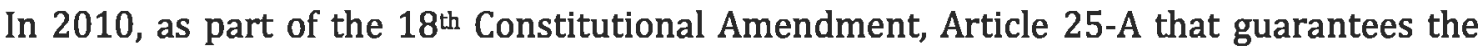
right to "free and compulsory education to all children of the age 5 to 16 years in such manner as may be determined by law", was included in chapter one (Fundamental Rights) of the Constitution of Pakistan. This historic step opened the door to providing completely free and compulsory education, requiring the provincial and federal governments to ensure that all children, including girls, are enrolled in school.

However, in order to guarantee this right, provincial governments need further legislation to define the rules for such provision. They also need to more than double the allocation of financial resources for meeting these education goals. Compared with other South Asian countries, Pakistan continues to have the lowest public expenditure on education as a percentage of gross domestic product (GDP), spending less public money on education than even Bangladesh and Nepal. Education spending amounted to 2.5 percent of GDP in 
$2006 / 07$ and has gradually decreased to an estimated 2.05 percent for $2009 / 2010$, much lower than the four percent recommended by UNESCO for developing countries.

Guaranteeing every child the right to an education and achieving universal primary education (MDG 2), will require deliberate effort that, in order for achieving the best results and where there is the greatest need, would first improve girls' schooling outcomes in rural areas, then boys' schooling outcomes in rural areas, then schooling outcomes for girls in urban areas, and finally, schooling outcomes for boys in urban areas. Only by committing to this effort will Pakistan be able to achieve full enrollment in a credible timeframe and reap the numerous benefits to be derived from educating its girls.

\section{B. Outline}

This report comprises evidence that will increase our understanding of girls' schooling in Pakistan. It will be useful for policymakers, donors, civil society, program/intervention designers, evaluators, and researchers, alike. The findings of this report should be used to guide points of influence and policies on girls' education in Pakistan. We look at girls' schooling from many directions in order to make that happen. We use a combination of secondary data analysis, primary data collection, and desk reviews of programs, policies and interventions in girls' schooling to shed more light on questions around girls' schooling. The following chapters ( $1 \mathrm{l}-\mathrm{V}$, details below) present information from primary and secondary data analysis on themes central to the discourse on girls' schooling.

Here is a condensed description of the chapters, indicating the central questions and sources of data that are addressed in each.

\section{- Chapter II. The big picture: status of girls' schooling in the last 20 years}

- How far has Pakistan come in providing education to all of its girls?

- Focus: We assess progress and areas of weakness in girls' schooling by looking at trends in major schooling indicators, analyzing changes in enrollment rates, focusing particularly on gender, geographical, and income gaps and how these gaps have changed over the last 20 years.

- Source: We use all rounds of the Pakistan Integrated Household Survey (PIHS) and the Pakistan Social and Living Standard Measurement Survey (PSLMS), from 1991 to the just-released 2010/11 survey, for our analysis. ${ }^{2}$

\footnotetext{
2 From 1991 to 1995/96 the PSLMS was known as the Pakistan Integrated Household Survey (PIHS).
} 
- Chapter III. Do choice, access, and quality matter for improving levels of girls' schooling?

- How do issues of access, quality, and affordability impact girls' schooling outcomes?

- Focus: We assess changes and differences in schooling environment (choice of schools, distance to schools, and quality of schools) and their relationship to schooling outcomes of girls in their communities.

- Source: We utilize primary data from field surveys conducted by the Population Council in 2011, 2004, and 1997 in 16 communities (12 were the same communities in all surveys; four communities were added in 2011). This chapter is based on information from the school and household questionnaires (176 schools and 1,191 households) from all 16 communities. We made observational visits at all identified schools to determine school quality, and recorded global positioning system (GPS) coordinates to measure physical road distances from sample households and community centers.

- Chapter IV. Avenues of change in young women's lives: role of girls' schooling

- What are the impacts of schooling on life outcomes for young women and how do they in turn influence incentives to educate girls?

- Focus: We test the strength of education's associations with these outcomes by looking at the three major transitions in a girls' life: the transition to marriage, the transition to motherhood, and the transition to work.

- Source: This chapter is based on information collected through the young women's questionnaire used in the field survey: there were 1,352 women respondents aged $18-35$.

- Chapter V. Evaluating programs: what worked and why in girls' schooling in Pakistan?

- Which policies, programs, and interventions in girls' schooling worked and why?

- Focus: The objective of this review is to analyze the success of the key initiatives undertaken by policymakers, development practitioners, governments, donors, and civil society organizations to develop sustainable future strategies to overcome barriers to girls' education in Pakistan. 
- Source: We carry out an extensive review of the literature available on the different programs on girl's education.

Chapter VI summarizes and brings together the central themes in girls' schooling in Pakistan in light of the report's findings and data analysis.

Appendices to the report contain details of the field survey design and methodology (Appendix A) and maps of our sample communities (Appendix B). 



\section{THE BIG PICTURE: STATUS OF GIRLS' SCHOOLING IN THE LAST 20 YEARS*}

In this chapter of the report, we look at how far Pakistan has come in providing education to all of its girls of school-going age. The purpose of this exercise is to provide an overview of where we stand in terms of girls' schooling, and more importantly, to highlight geographic and social pockets that require the most improvement in schooling outcomes for girls. We assess progress and identify areas of weakness by examining trends in major schooling indicators based on secondary analysis of national data sets. Utilizing all rounds of the PIHS and the PSLMS from $1991^{3}$ to the just-released 2010/11 round, we present trends in primary and secondary enrollment rates starting from the 1990s. While most of the trend analysis focuses on girls' enrollment, enrollment rates for boys are also shown to highlight trends in the gender gap in education. We also highlight changing trends in the distribution of enrollment across public and private schools, the stark differentials in enrollment rates across urban-rural areas and across provinces, and the relationship between poverty and school attendance. Issues and relationships discussed in this chapter will be further examined in the chapters that follow.

\section{A. Analysis of trends}

\section{Attendance and literacy}

Four years away from the MDG deadline, and after many gender-specific education policies and programs, boys (aged 5-14 years) continue to fare better with a higher proportion (75 percent, compared to 63 percent of girls) currently attending school. The good news is that girls are catching up - the gender gap in almost all education indicators has diminished. At the beginning of the 1990s, the difference between the proportion of boys and girls (aged 5-14) currently in school was 22 percentage points; this difference decreased to 15 percentage points by $2001 / 02$ and to 12 percentage points by $2010 / 11$.

The education status of Pakistani youth (aged 15-24 years) shows an even starker difference in improvements. While the proportion of young men with no education (never attended school) remained around 20 percent over the last 20 years, the proportion of young women with no education fell significantly (and consistently) from 60 percent in

\footnotetext{
* This chapter was authored by Batool Zaidi, Senior Program Officer and Maqsood Sadiq, Program Officer, at Population Council.

3 The PSLMS was known as the PIHS from 1991 to 2001/02.
} 
1991 to 37 percent by 2010/11. Therefore, the improvement in girls' educational attainment has been occurring since the early 1990s, and for multiple cohorts/generations. Youth literacy has also improved more rapidly for females than males. However, while the rates are increasing more rapidly for girls, the proportion of girls currently in school is now equal to the proportion for boys almost 20 years ago. The female youth literacy rate of 63 percent is now equal to the male youth literacy rate from 1991. Clearly, girls still have a long way to go.

With the MDG deadline for achieving universal primary education fast approaching, it would be expected that most girls aged 5-9 years would be enrolled in school. Unfortunately, the latest education data $(2010 / 11)$ show that 36 percent of these girls (compared to 27 percent of boys) have never attended school.

\section{Primary education}

The most widely used indicator for primary education is the net enrollment rate (NER) for grades 1-5 by children aged 5-9 years. Data on primary level net enrollment shows that while enrollment rates have improved since 1990, this improvement took place only after 2000 , for both boys and girls (Figure 2.1).

Figure 2.1: Primary net enrollment rate (NER), by gender and year

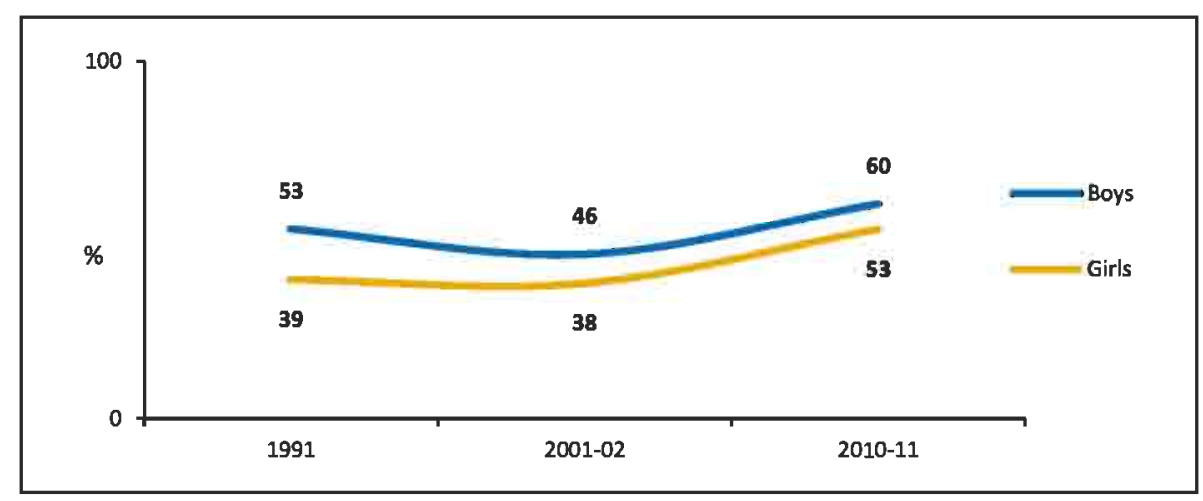

The decade of the 1990s saw no improvement, and in fact even a slight decrease in enrollment rates, particularly for boys. Since 2001/02, primary NER increased from 46 percent to 60 percent for boys and 38 percent to 53 percent for girls by 2010/11. Much of this increase occurred during the 2001/02 to 2005/06 period, with girls' primary NER increasing 13 percentage points in a five-year time period (Figure 2.2). In the next five years (2007 to 2011), however, increases in enrollment rates have stagnated, increasing only two percentage points in the same amount of time. The slowdown in the rise in 
enrollments post-2005 is also reflected in the slowdown in the expansion of the number of schools (AEPAM 2009).

Figure 2.2: Net enrollment rate (NER) for girls, by level and year

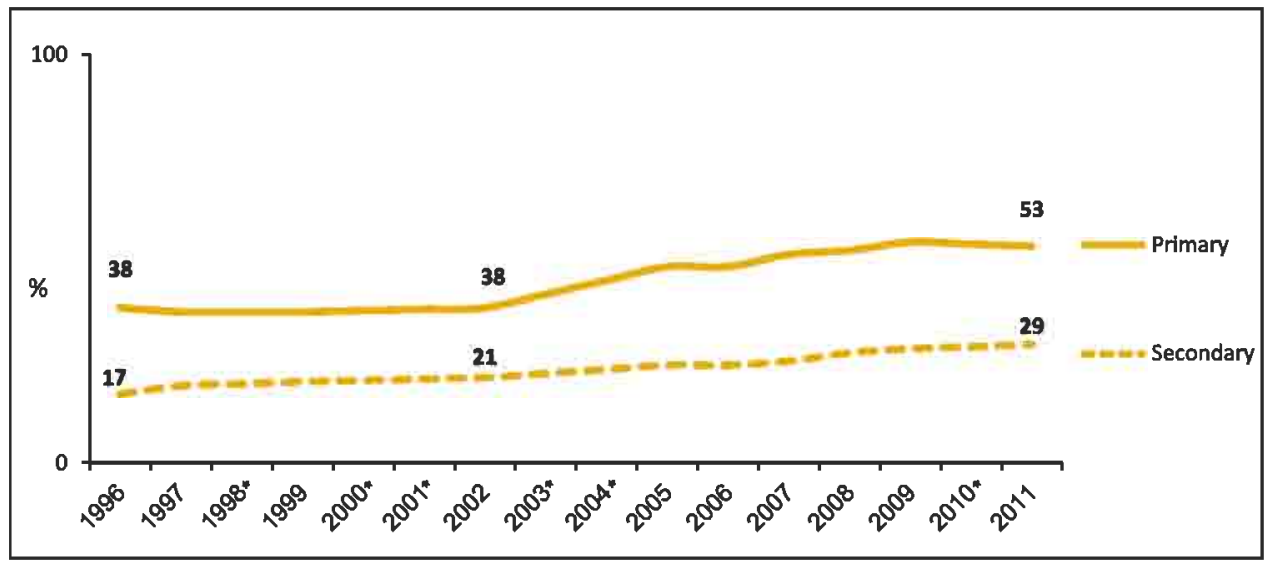

\section{Secondary education}

Given the poor state of primary education, it is not surprising that the state of secondary education is even worse, if not abysmal. Overall, the NER for the secondary level ${ }^{4}$ has increased only seven percentage points (from 25 percent to 32 percent) over the last 20 years. Breaking it down by gender, we find that girls' secondary NER saw some improvement, increasing from 17 percent in 1991 to 29 percent in 2010/11, but boys' secondary enrollment only increased from 32 percent to 34 percent in these 20 years (Figure 2.3). Similar to trends in primary education, there was almost no change in secondary NER during the 1990s (there was, in fact, a slight decline for boys). Since the turn of the century, secondary education has been increasing slowly for both boys and girls, with rates rising by almost one percent per annum for girls.

\footnotetext{
4 The NER at the secondary level refers to the number of students enrolled at the secondary level (grades 610) of required secondary level school age (10-14) divided by the number of children in the 10-14 age group.
} 


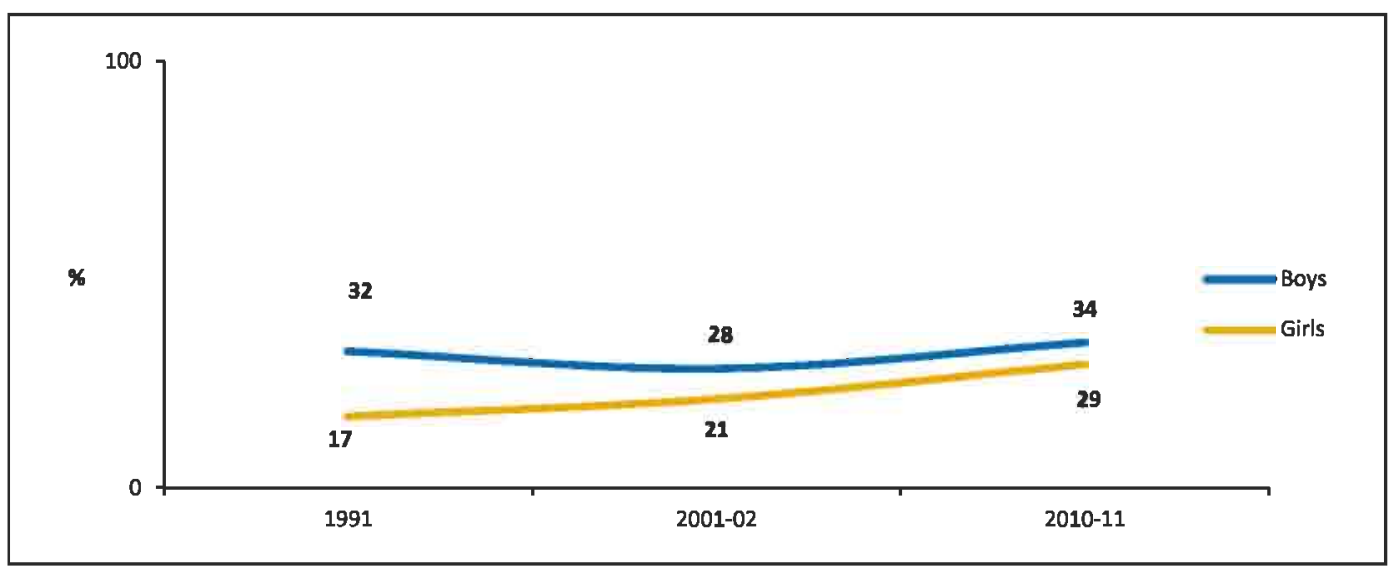

\section{Public-private enrollment}

During the start of the $21^{\text {st }}$ century, much of the discourse on education in Pakistan focused on the role of low-fee private schools in achieving universal primary education. The discourse on private schools fell under two broad categories: one was a debate on the extent to which the private sector could replace the state in providing education (Alderman et al. 2001; Andrabi et al. 2002), and the other focused on determining whether or not private schools were providing better education than their public counterparts (Andrabi et al. 2006; Khan et al. 2003; Kardar 1998). While it is now widely accepted that private schools offer better education (Campaign for Quality Education 2007), the private sector's capacity to fill in for the public sector in providing universal primary education remains doubtful.

Looking at PIHS/PSLMS data over time, we find that the sharp increase in primary enrollment rates during the first half of the last decade did, in fact, come primarily from increases in enrollment in private schools. Over this four to five-year period, public school enrollment increased by two percentage points each for boys and girls, while private school enrollment increased by nine and eight percentage points, respectively. The rise in private school enrollment has tapered off since 2005/06. In fact, the latest data show that private primary NER for girls has remained at 19 percent over the last five years (see Figure 2.4 for data on girls). 
Figure 2.4: Net enrollment rate (NER) for girls, by type, level, and year

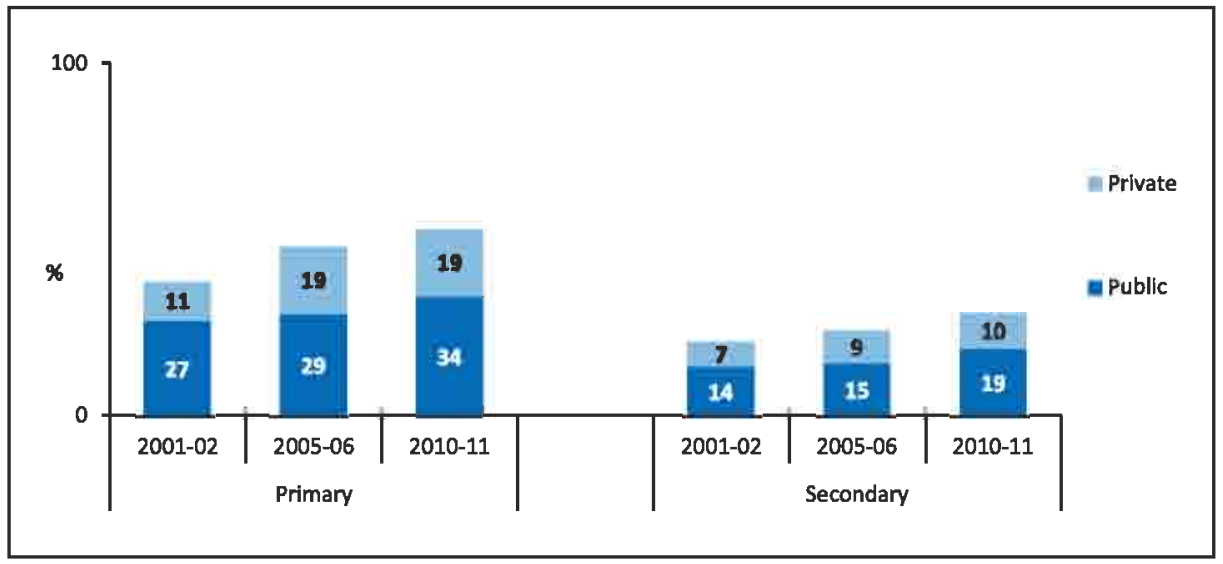

Private schools have played less of an important role in secondary schooling than they did in primary education. This is in line with previous findings that argued that private schools, with less qualified teachers, are more likely to be restricted at the primary level (Andrabi et al. 2006).

\section{Dropout rates}

Analyzing dropout rates of 15-19 year old boys and girls by grade shows that (a) dropout rates have decreased for both sexes over the last ten years with slightly greater improvement experienced among girls, and (b) dropout rates for boys remain slightly lower than for girls (Figures 2.5 and 2.6). More girls drop out after completing primary school than boys - 22 percent versus 17 percent. Another 11 percent of girls drop out after middle-school and an additional 11 percent after secondary school (class 10).

Figure 2.5: Dropout rates for girls (15-19), Figure 2.6: Dropout rates for boys (15-19), by grade and year by grade and year
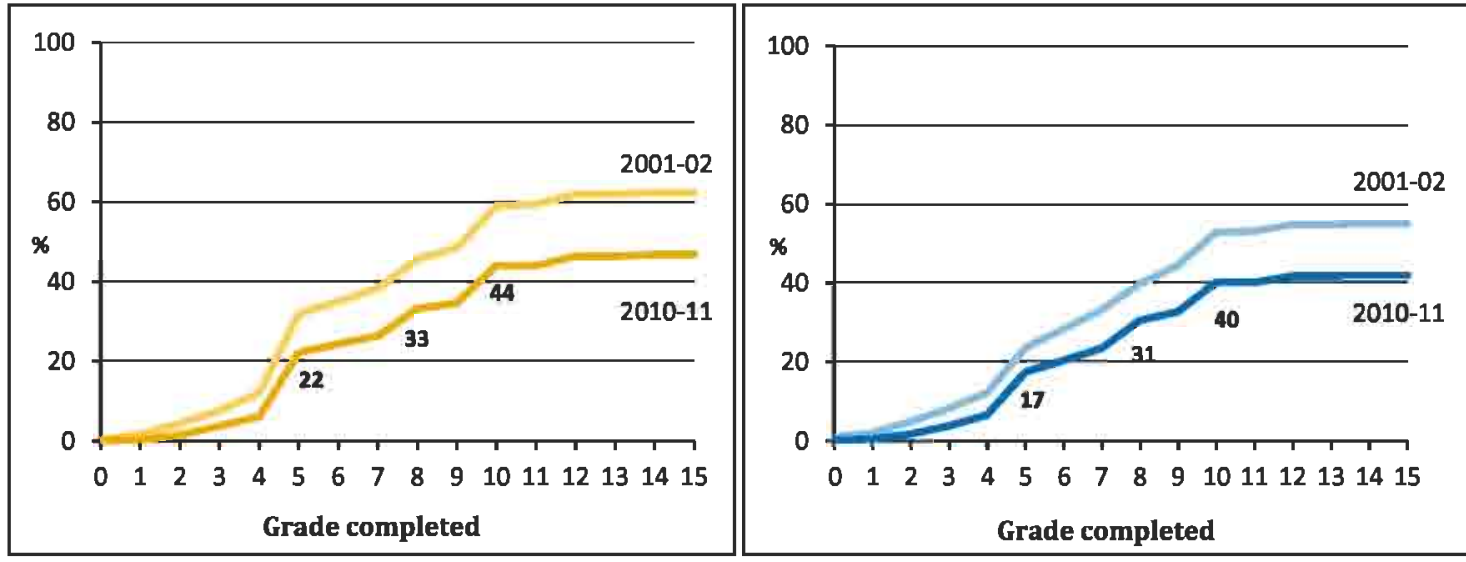


\section{B. Analysis of disparities and inequalities}

\section{Urban-rural differences}

Overall averages can often be misleading. Disaggregating the data by urban-rural residence presents a more realistic and informative picture. As expected, urban enrollment rates for both boys and girls are much higher than for their rural counterparts.

Figure 2.7 illustrates that the difference between urban and rural primary enrollment rates for girls has decreased over the years - urban rates increased by ten percentage points from 57 percent in 1991 to 65 percent in 2010/11, while rural NER increased 18 percentage points from 31 percent to 48 percent during the same period. Even though rural areas are catching up, the difference between primary NER for urban and rural areas remains considerable - rural primary NER for girls would need to increase by another 17 percentage points to reach the urban rate.

Figure 2.7: Primary NERs for girls, by residence and year

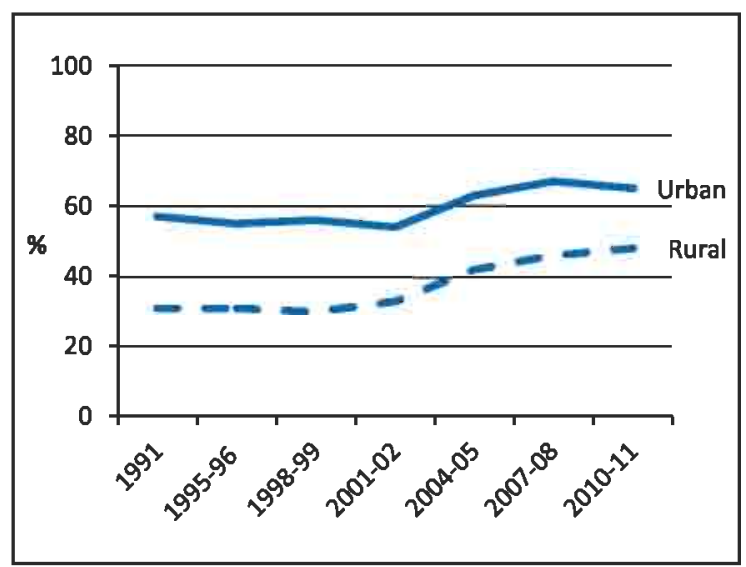

Figure 2.8: Secondary NERs for girls, by residence and year

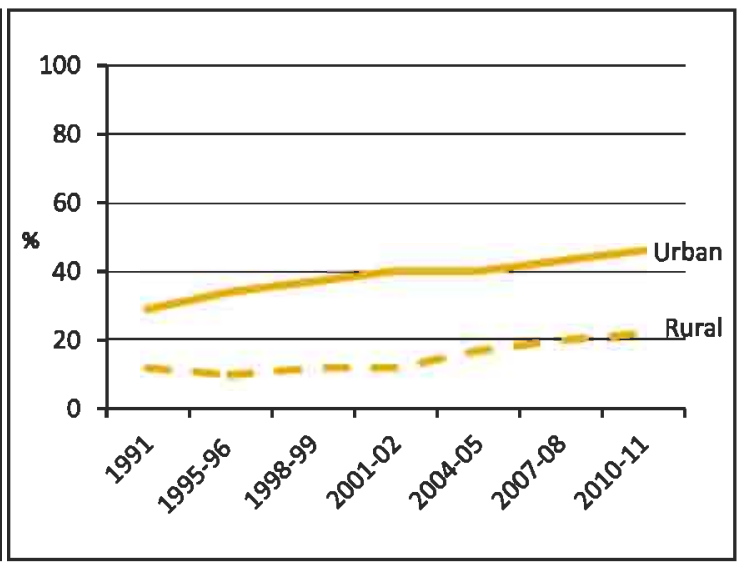

As expected, rural girls also fare worse than urban girls in secondary education. Urban NER is twice rural NER - 46 percent and 22 percent, respectively (Figure 2.8). This urbanrural gap between girls' enrollment in secondary school has widened since 1991 and was the largest around 2001/02. While most of the increase in secondary enrollment rates for urban girls took place during the decade of the 1990s, rural areas only started experiencing a positive change after 2000. Despite rural rates almost doubling from 12 to 22 percent, they would need to double again to match secondary education rates for girls in urban areas, and increase five times to become universal. 
The disparity in urban-rural female education extends beyond proportions attending school and gender inequality, to the type of education attained, as well. Both urban and rural areas have seen an increase in private schooling, however, in urban areas almost 60 percent of the girls enrolled in primary school attend a private school, compared to less than a quarter in rural areas. At the secondary level, 41 percent of the girls enrolled in secondary school in urban areas attend a private school compared to 27 percent of rural girls.

The gender parity index (GPI) - the ratio of female NER to male NER-is a widely used indicator to measure the disparity in enrollment rates by gender. The primary level GPI in urban areas has increased to 0.97 indicating that the gender gap is no longer a problem in urban areas. Like girls, boys also experience lower enrollment rates in rural areas, but to a smaller degree; urban-rural residence influences girls' primary education more than that of boys. Despite significant improvement, the rural GPI remains at 0.84 - for every ten boys that go to primary school, eight girls attend primary school. Therefore, not only do rural girls have the lowest levels of enrollment, but they also face the most gender discrimination in receiving primary education.

Although gender disparity in secondary education used to be a problem in both rural and urban areas at the start of the 1990s, urban girls experienced an increase in secondary education during the last decade, and the gender gap at the secondary level is now particular to rural Pakistan, only. Urban secondary NERs are the same, if not higher, for girls as they are for boys. Yet again, girls from rural areas get the shortest end of the stick despite improvements in both secondary NER and gender equality, only one in five girls (aged 10-14 years) in rural areas goes to secondary school.

There is no significant gender disparity in the type of school attended in both rural and urban areas. These trends indicate that girls suffer gender disparity in attending school depending on where they live - rural girls have a low chance of attending school, not only lower than their urban counterparts, but also lower than rural boys - but not in the type of school they attend. 


\section{Provincial differences 5}

As discussed, residence (urban-rural) leads to considerably different outcomes for girls' schooling. Even rural areas are not all the same: the proportion of girls attending school in rural areas differs vastly by province. Similarly, trends in the gender gap in primary and secondary education also vary by province. Pakistan's provinces have always been on different development trajectories. Using provincially disaggregated data is essential to understanding provincial trends/trajectories. The implementation of the $18^{\text {th }}$ amendment ${ }^{6}$ has made this even more central to developing meaningful policies.

Provincial data for primary education show several interesting patterns. The first is the variance in the speed of increases in enrollment rates. Over the last 15 years, ${ }^{7}$ Punjab has seen the highest increase in primary NER for girls (19 percentage points), closely followed by KP (17 percentage points), and then Sindh (nine percentage points). The change in primary NER for girls within these provinces has been differently distributed across urban and rural areas (Figure 2.9). In Sindh, urban girls' primary enrollment increased by only five percentage points compared to rural girls' enrollment, which increased by 15 percentage points. Therefore, the overall rise of girls' primary education in Sindh was mostly a rural phenomenon, while in Punjab and KP (to a lesser degree) both rural and urban areas experienced this increase relatively equally. But rural KP and Punjab differed in their time of change. The major portion of increase in enrollments in KP took place from 1995/96 to 2004/05. For rural (and urban) Punjab, most of the increase occurred during 2001/02 and 2006/07.

5 We excluded Baluchistan from our analysis because of data quality issues. Needless to say, the situation of girls' schooling in Baluchistan is the worst among the four provinces.

6 Passed in 2010, the $18^{\text {th }}$ Amendment to the Constitution of Pakistan has meant the devolution of authority in many government services from the national level to the provincial level.

7 Data are shown starting in 1995/96 because earlier datasets (1991) were not representative at the provincial level. 
Figure 2.9: Primary NER for girls across provinces, by residence and year
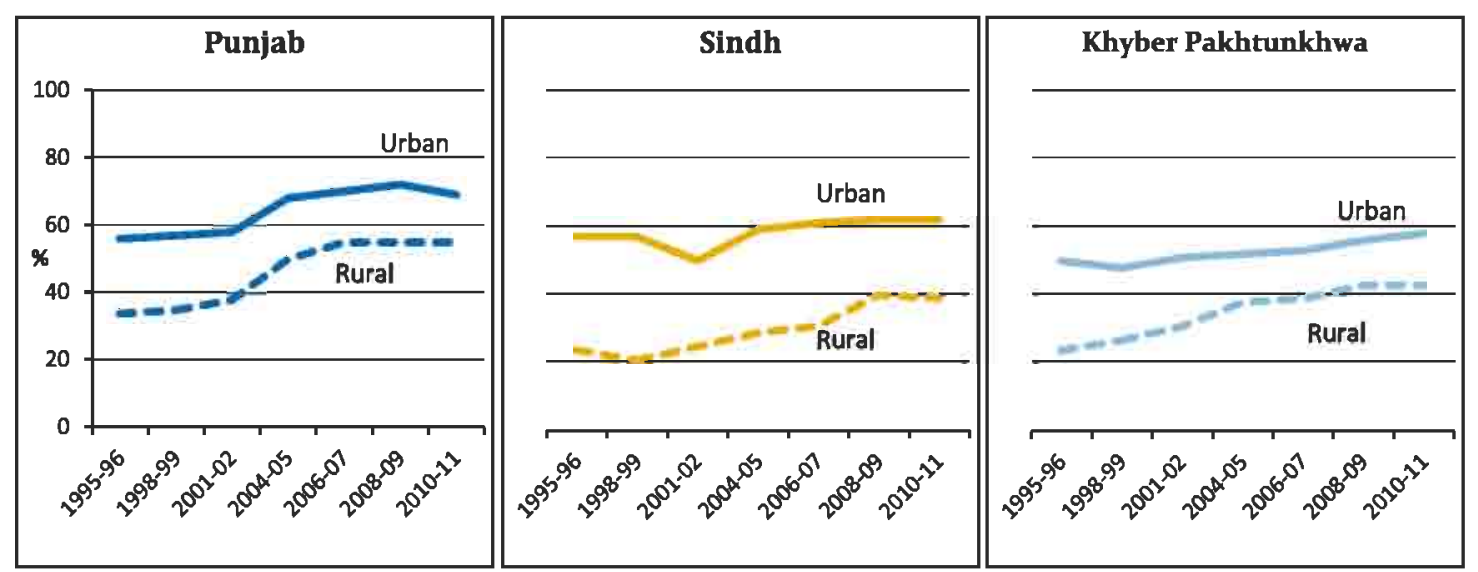

What is alarming is that despite the positive trend in rural Sindh, urban-rural disparity remains the widest here, and, not surprisingly, rural Sindh's primary NER for girls of 39 percent is the lowest among the three provinces. Gender disparity in education is also the highest in rural Sindh: for every five boys attending school, four girls attend school at the primary level and only two girls at the secondary level. As discussed at the national level, gender disparity is generally not a problem in urban Pakistan at either of these schooling levels. This trend is reflected in both urban Punjab and Sindh. However in urban KP, girls continue to face a slight disadvantage at both the primary and secondary level of schooling.

To summarize the situation for each province, we find that Punjab has the highest enrollment rates and lowest gender inequality in both rural and urban areas. Sindh has very different trends for its urban and rural areas - urban Sindh has high enrollment rates and low gender disparity, while rural Sindh has very low enrollment rates and very high gender disparity. In $\mathrm{KP}$, rural areas are catching up to urban areas in enrollment rates, but gender gaps are relatively high in both areas.

\section{Poverty}

Many studies looking at the status of schooling in Pakistan have highlighted income as a strong predictor of schooling (Sathar and Lloyd 1994; Khan and Ali 1999; Sawada and Lokshin 2001; Toor and Parveen 2004). Of these, a few have focused on poverty rather than just income level to explain the persistently low enrollment rates (Arif et al. 1999). 
We apply the national poverty line methodology to the PSLMS ${ }^{8}$ data to study variances in school enrollment across poor and non-poor households.

Poverty has played a big role in education levels for girls at both primary and secondary levels. Trends show that in both urban and rural areas, poor households have lower enrollment rates than non-poor households. In both areas, and for both boys and girls, the difference in primary enrollment between the poor and non-poor is around 20 percentage points (data not shown). In fact, the rural non-poor have higher (or equal) enrollment rates than the urban poor. Given that the availability of schools is much greater in urban areas, this trend indicates that affordability is a more important factor behind school attendance. However, looking at improvements over time, we find that in primary education, urban poor girls experienced twice the increase in enrollment rates (15 percentage points) of rural poor girls (seven percentage points) (Figure 2.10). In secondary education, enrollment rates for rural poor girls remained at seven percent for those six years, while rates for urban poor girls increased marginally (Figure 2.11).

Figure 2.10: Primary NER, by poverty status, $\quad$ Figure 2.11: Secondary NER, by poverty residence, and year status, residence, and year

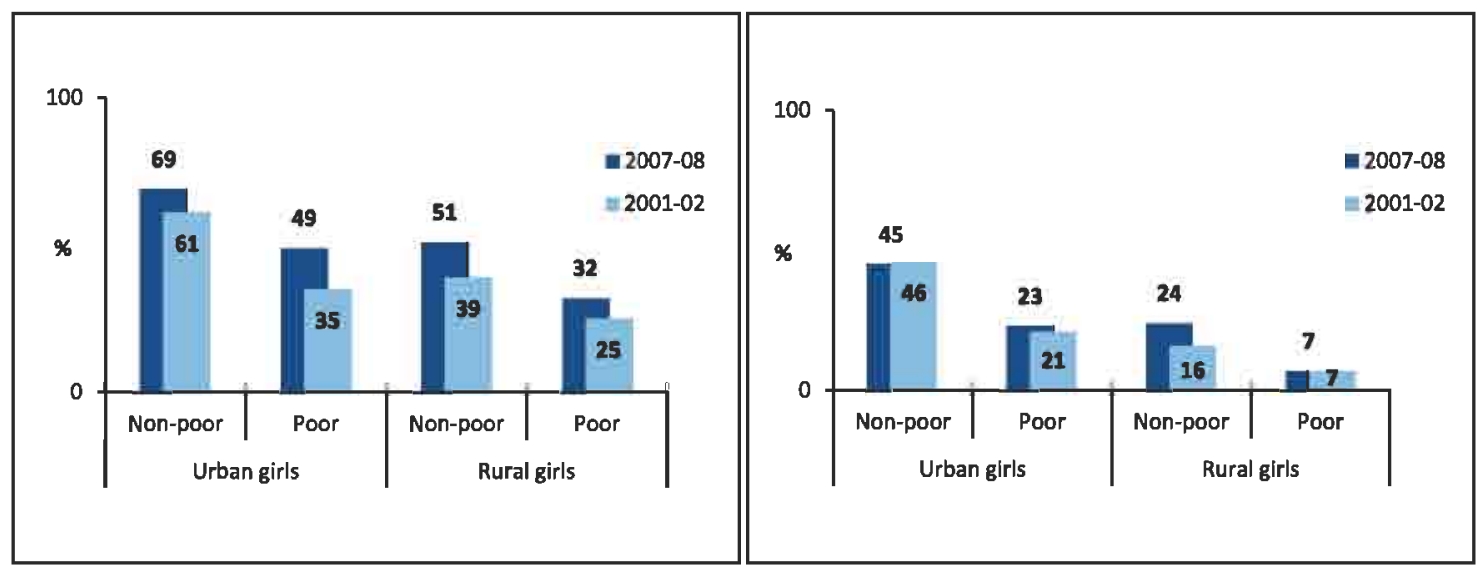

In terms of gender disparity, enrollment gaps remain the same for poor and non-poor indicating that poverty affects girls' and boys' enrollment similarly. This is true in urban areas where there is no gender gap in enrollment rates for both poor and non-poor, and in rural areas where both poor and non-poor households each have a gender gap in primary and secondary enrollment of ten percentage points.

${ }^{8}$ Consumption data used to construct poverty figures were collected in the 2010/11 round. However, this dataset has not yet been released for public use. Therefore, the poverty analysis in this paper uses 2007/08 survey data for the latest figures. 
Though poverty does not appear to aggravate gender disparity in enrollment, it is highly correlated with the type of school that children attend. In urban areas, with a larger supply of private schools, there are high differentials in the type of primary school that girls attend, by income (Figures 2.12 and 2.13). Sixty-one percent (42/69) of currently enrolled girls from non-poor households attend a private school, but this does not hold true for urban girls from poor households $(11 / 49=22$ percent $)$. The same negative relationship between poverty and private schooling holds true in rural areas $[15 / 51=29$ percent from non-poor households versus $3 / 31$ = ten percent from poor households).

Figure 2.12: Primary NER for girls, by type of Figure 2.13: Primary NER for girls, by type of school, poverty, and residence, 2001/02 school, poverty, and residence, 2007/08

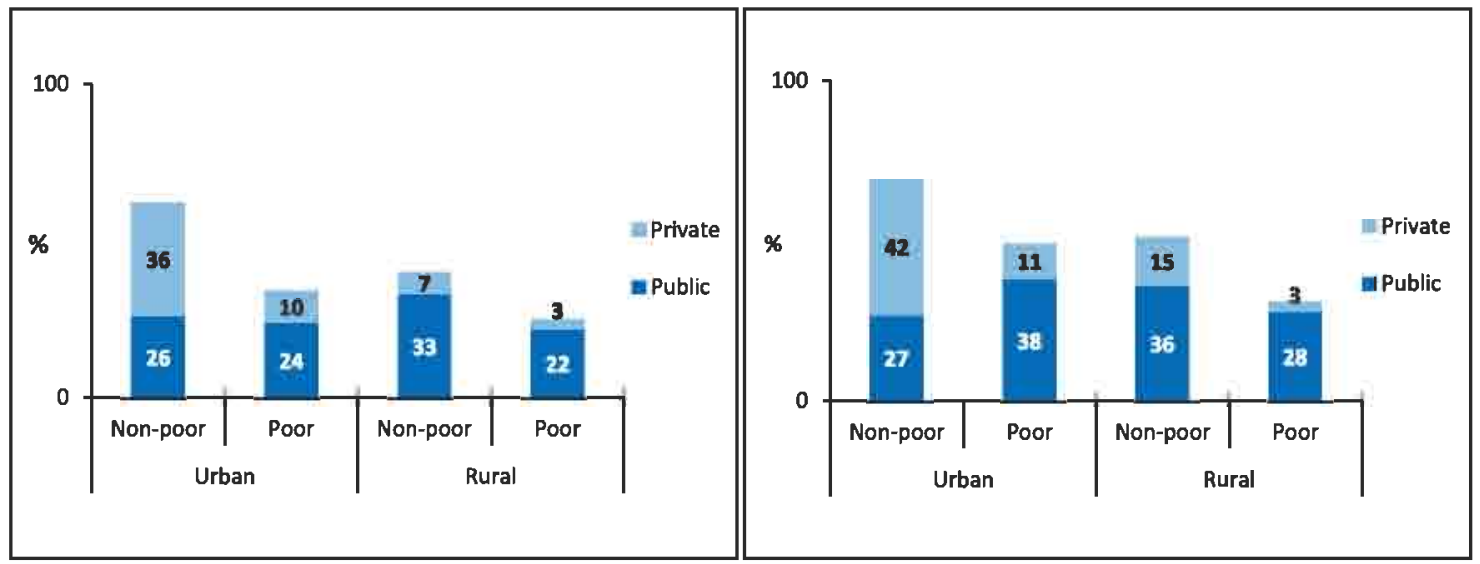

The distributions for 2001/02 show that over the following six-year time period, girls from non-poor households in both rural and urban areas benefited more from private enrollment, whereas almost all of the increase in enrollment rates for girls from poor households was due to an increase in public enrollment.

Similar to trends for the primary education level, private enrollment at the secondary level is highest among urban non-poor girls at 18 percent, followed by rural non-poor girls at nine percent (Figure 2.15). Comparing the latest figures to those from 2001/02, private secondary enrollment has not changed much in these six years, with the only significant increase taking place for rural girls from non-poor households (Figure 2.14). 
Figure 2.14: Secondary NER for girls, by type of school, poverty, and residence, 2001/02

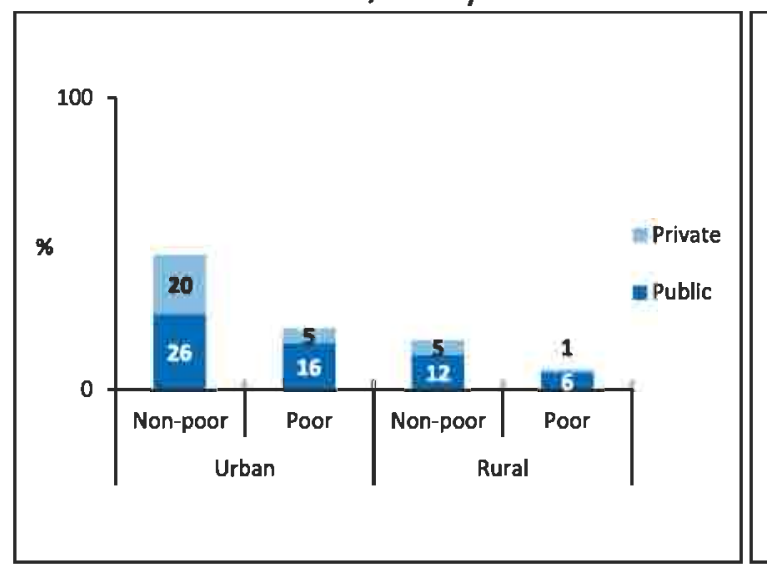

Figure 2.15: Secondary NER for girls, by type of school, poverty, and residence, $2007 / 08$

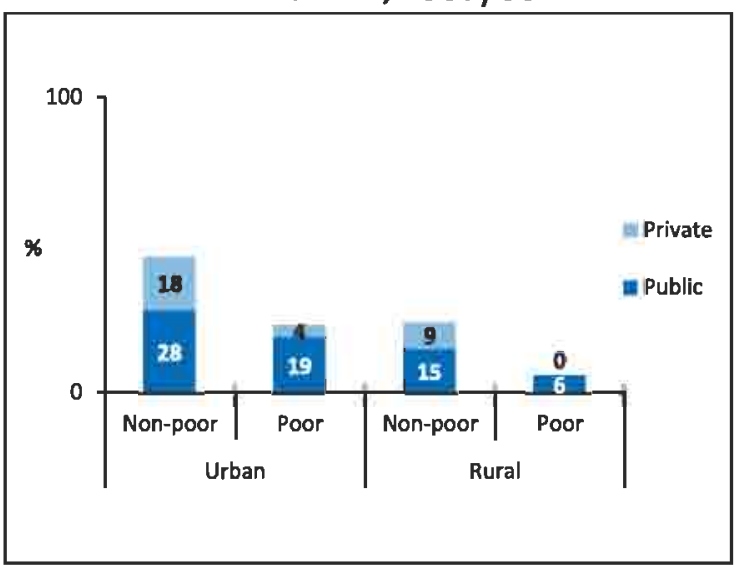

\section{Conclusion}

Despite mostly being criticized for ineffective implementation, the multitude of education policies and plans in the 1990s that heavily prioritized girls' schooling did make some difference when we look at trends over time. Much of the improvement in schooling outcomes, particularly at the primary level, took place after these policies were developed, and seems to have been more concentrated for girls than boys.

Even though girls' schooling saw greater improvement than that of boys over the last decade, the gender gap in education rates remains high and both boys and girls remain far from reaching universal levels. More worrying is the recent slowdown in improvements in education rates, particularly at the primary level. Unsurprisingly, even the limited data on the supply of schools shows a slowdown in the increase in the number of schools (AEPAM 2009).

When it comes to choosing the type of education, availability and affordability are the strongest determinants in sending children to private schools. Despite high hopes from low-fee private schools, a private education remains largely unaffordable for the poor and has a weaker presence in rural areas. The private sector, no matter how cheap, is restricted to the laws of demand and supply, and thus, cannot provide primary education to all children of school-going age. Therefore, it is imperative that the GoP continue its role in providing education to disadvantaged population groups, namely poor girls living in remote rural areas. 
Policy prescriptions need to take regional differentials into account. Education sector reforms in Punjab need to take into account the disparate situations between north/central Punjab and southern Punjab.

Plagued by ghost schools and recent natural disasters, rural Sindh is the worst off among all regions in the three provinces. The Sindh Government needs to prioritize effective provision of education, focusing on improving the political and administrative aspects of the education system.

The issues facing KP are somewhat different - girls' primary education in rural areas has made remarkable progress and KP has the smallest urban-rural differentials. However, gender disparities in the province remain high. In fact, KP is the only province among the three where the gender gap persists in urban areas. In the coming years, KP needs to place greater emphasis on addressing the increasing cultural barriers to educating girls.

If Pakistan hopes to reach universal primary education in the next decade even, immediate attention needs to be brought to the slowdown in improvement of education indicators over the last few years. Particularly worrying is the stagnation in the rise of private enrollment. There is an urgent need to understand why the growth in the education sector is slowing down - is it because of constraints faced by providers (both public and private) or by families themselves? Answering these policy-relevant questions requires further investigation, which will remain incomplete without a population census and education census that fully covers the private sector as well. 



\section{DO CHOICE, ACCESS, AND QUALITY OF SCHOOLS MATTER FOR IMPROVING LEVELS OF GIRLS' SCHOOLING?*}

In the coming decade, ensuring that acceleration of girls' primary schooling in rural areas and facilitating their transition to the secondary level, are top priority. To explore in more detail some of the findings of the previous section based on macro-level data, we focus on examining the factors related to lower enrollment rates for girls living in rural areas. We present an analysis of the schooling data and the full sample of girls aged 5-19 found in the household rosters of 1,191 households in 16 communities in Punjab, KP, and Sindh. We also take advantage of panel data from 12 communities (from Punjab and KP) and household rosters from 938 households.

We look at both supply and demand factors behind the low levels of girls' schooling in this comprehensive field study of rural communities across eight districts of Pakistan (see Appendix A for details on study design and methodology). Through this complex data design, we are able to link changes in community choices for schools, measure actual road distances to schools, and calculate community development indicators and link them to school attendance in households by their income levels. The broad analysis presented here is aimed at achieving operational answers to the following types of questions:

1. Does the number of schools in the vicinity have an impact on girls' attendance in school?

2. Does physical distance in terms of road access/transport affect attendance in school?

3. Does the quality of schools (particularly across private and public schools) — for example, teacher training/experience/presence, physical infrastructure, etc.-influence school choices for girls?

4. How do household income levels interface with school choice, distance, and quality in influencing educational outcomes for girls?

\footnotetext{
* The chapter was authored by Zeba Sathar, Country Director, Minhaj ul Haque, Senior Program Manager, Rehan Niazi, Program Officer, Maqsood Sadiq, Program Officer, and Mumraiz Khan, Senior Program Officer at Population Council.
} 


\section{A. Choice of schools}

There has been clear growth in the number of schools in these rural communities over the last decade. School access increased dramatically across the years, perhaps most notably after 2000. Earlier research has pointed toward increasing school choice as an important factor in improving enrollment, especially for girls. Similar expansion is seen in the microlevel data on primary-level schools in the 16 communities for which we have data on the year when the school was set up.

There were 176 schools in our 16 communities (in KP, Punjab, and Sindh). In addition to basic information about school attributes, we were able to ascertain the year in which the school was set up. Table 3.1 provides a breakdown over time by the number of schools available to the 16 communities located in the three provinces.

Table 3.1: Number of schools available to 16 communities, by type of school, students, and date of availability, 2011

\begin{tabular}{|c|c|c|c|c|c|c|c|c|}
\hline \multirow{2}{*}{$\begin{array}{l}\text { Date } \\
\text { established }\end{array}$} & \multicolumn{2}{|c|}{ School type } & \multicolumn{3}{|c|}{ Students } & \multicolumn{3}{|c|}{ Schooling level } \\
\hline & Public & Private & Boys & Girls & Co-ed & Primary & Middle & High \\
\hline Up to 1980 & 41 & 4 & 23 & 12 & 10 & 41 & 19 & 16 \\
\hline Up to 1985 & 51 & 7 & 29 & 16 & 13 & 53 & 23 & 19 \\
\hline Up to 1990 & 58 & 13 & 32 & 21 & 18 & 65 & 30 & 25 \\
\hline Up to 1995 & 69 & 28 & 37 & 27 & 33 & 89 & 47 & 36 \\
\hline Up to 2000 & 74 & 39 & 41 & 29 & 43 & 104 & 58 & 42 \\
\hline Up to 2005 & 94 & 66 & 49 & 40 & 71 & 142 & 92 & 59 \\
\hline Up to 2011 & 99 & 77 & 53 & 46 & 77 & 153 & 103 & 66 \\
\hline
\end{tabular}

There appear to be more dramatic increases in schools in the period 2000-2005. Public schools increased from 74 to 99 and private schools from 39 to 77 . The period 2005-2011 did not see as rapid an expansion in the number of schools. Another notable change is the clear growth of those schools that have primary classes, but also go up to higher levels (middle and higher). In 2000, there were 58 schools with middle schooling, they now number 103. In comparison, the schools providing primary education increased from 104 to 153 . The doubling of middle-level schools post-2000 is impressive as larger numbers of these schools have implications for greater retention of children attending primary classes, though middle-schools are usually located further from communities than primary schools. 
The emergence of private schools is visible post-1990, but really takes off post-2000. The number of girls' schools also increases more dramatically post-2000. In 1990, there were 32 boys' schools, 21 girls' schools, and 18 co-educational schools. In effect, boys had access to 50 schools and girls to 39. In 2011, in comparison, girls had access to 123 schools and boys to 130, reflecting expanding choices and attenuating differences in choice across gender.

The expansion of private schools is an interesting phenomenon and is reflective of the increased demand for schooling choices. But is this expansion occurring throughout the rural areas as it is visible in urban areas? In an effort to assess whether or not private schools are locating in major parts of rural areas, we looked at the association between development scores for the 16 communities and the numbers of private schools available. We found a positive association between the number of private schools and development scores (seen in Figure 3.1). Private schools are concentrated in 'more developed' communities, presumably where there is greater demand for such schools and greater ability to pay for higher education. In contrast, there is practically no such association between development scores and the number of public schools, indicating that the consideration for public school location is based on other factors. Private schools and those schools that had beyond-primary classes are more likely to be located in more developed communities. Thus, the recent expansion benefits those areas already wellendowed with schooling choices.

Figure 3.1: Development score ${ }^{9}$ of community by number of schools available
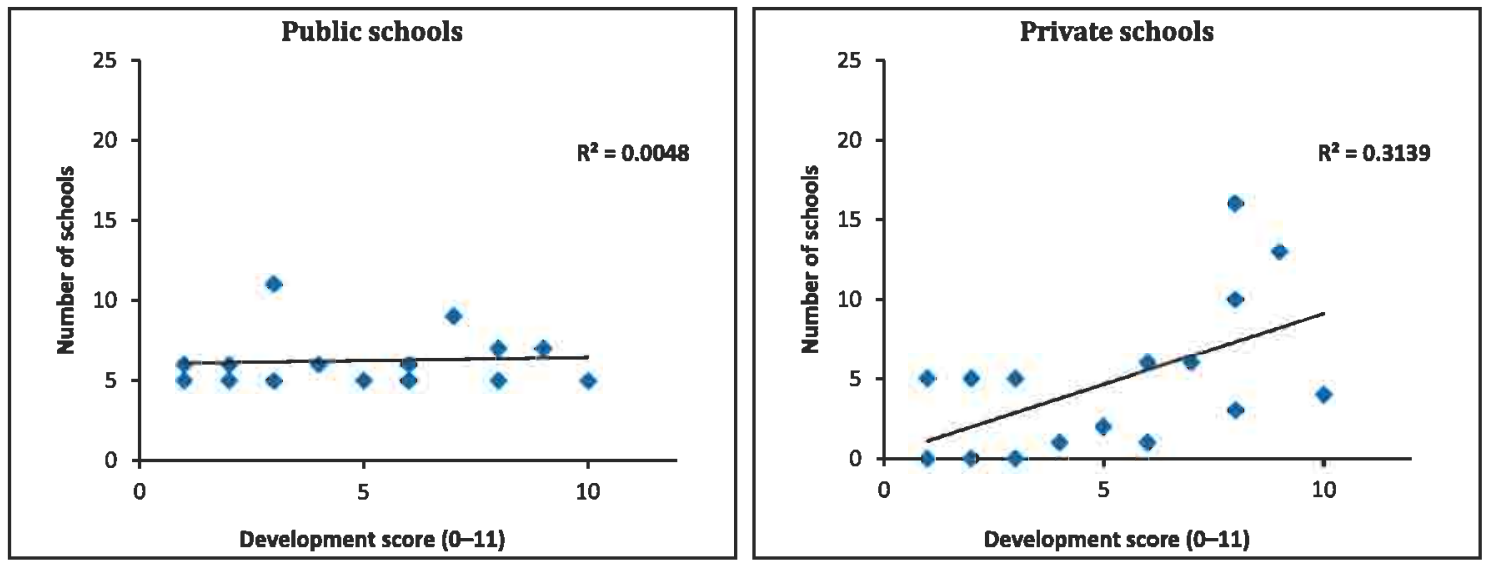

${ }^{9}$ See footnote 11 in Appendix A for details on how the community development score was computed. 
The expansion of schools is not uniform across all communities. In fact, changes in numbers of schools present interesting differences by province (Figure 3.2). The rise in private schools appears to be most dominant in Punjab where private schools have outnumbered public schools by 2011. While numbers of private schools are catching up in $\mathrm{KP}$, public schooling remains dominant there. In Sindh, there is no notable alternative to public schooling, with the exception of a few private schools.

Single-sex girls' schools in communities in Punjab outnumber boys' schools. The expansion of girls' schooling choices in that province are quite apparent (Figure 3.2). Equally important, the numbers for co-educational schools have surpassed the numbers of single-sex schools in both Punjab and KP. However, the numbers of single-sex girls' schools are much lower than boys' schools in our KP and Sindh communities. The expansion of middle or higher-level schools is also more dominant in Punjab, followed by $\mathrm{KP}$, but hardly apparent in communities in Sindh. 
Figure 3.2: Trends in availability (number) of schools by type, province, and date they were established
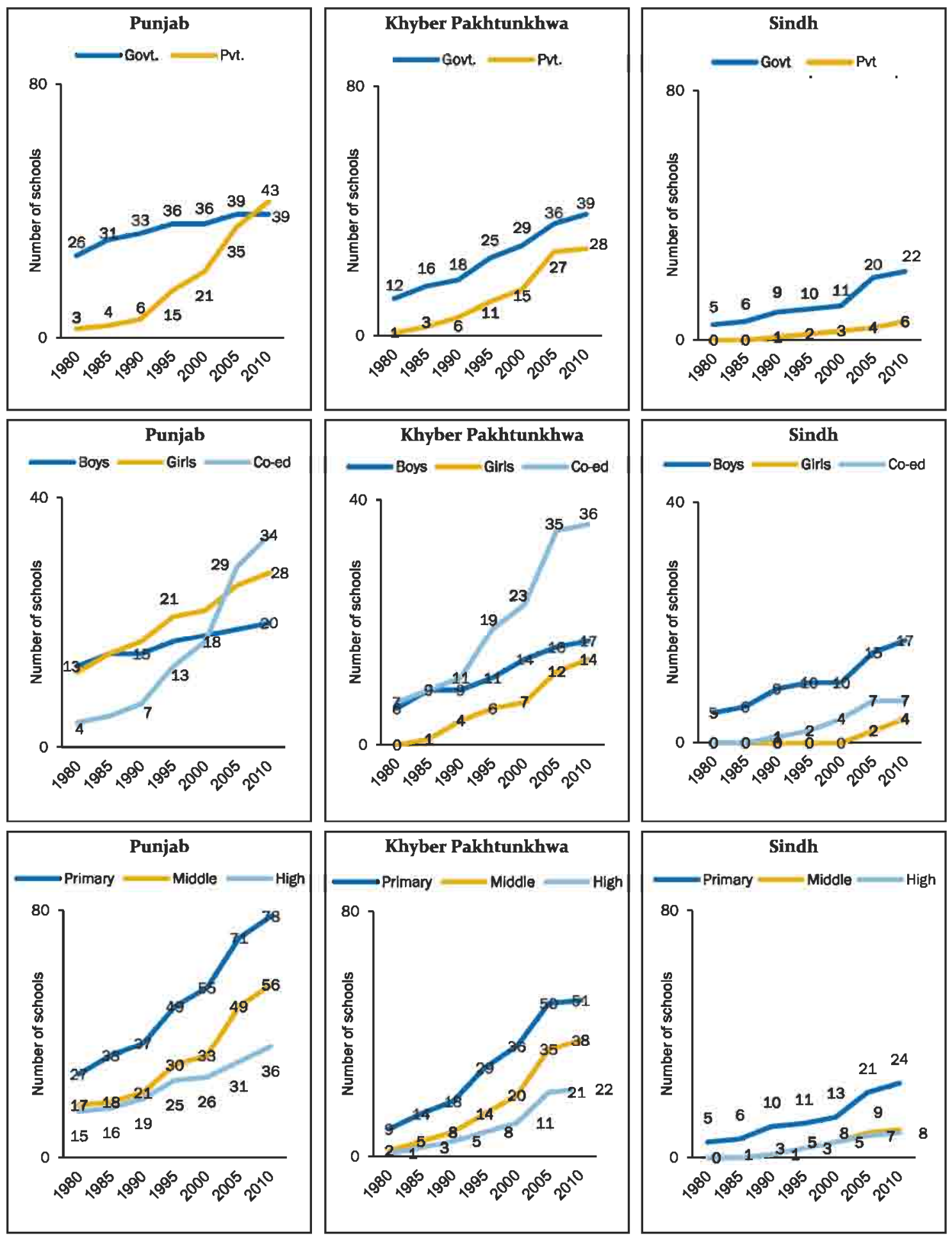

So how do the findings about choice play out for girls' enrollment rates? Are those living in areas with greater choice of public schools more likely to be enrolled? Is the response 
similar for private schools? We look at correlations between numbers of schools and school attendance by age of girls.

Table 3.2 shows the correlation matrix between girls' school enrollment and numbers of schools by levels and type. Clearly, girls' school attendance is more responsive to the availability of schools, especially for older girls. Attendance in school for the youngest age groups is most highly associated with the number of private primary schools available in the community, whereas attendance for 10-14 year old girls is correlated with both public and private school availability. However, attendance in school for older girls aged 15-19 bears the strongest association with the numbers of public schools that are most definitely single-sex schools. Increased choice of schools in both the private and public sector-but especially in the public sector-is very important for adolescent girls to continue their education.

Table 3.2: Correlation matrix of percentage of girls currently attending school, by age and available schooling level

\begin{tabular}{lrrr}
\hline & \multicolumn{3}{c}{ Age group } \\
Schoolinglevel & $\mathbf{5 - 9}$ years & 10-14 years & 15-19 years \\
\hline \hline Public primary level & .361 & na & na \\
Public above primary level & na & $.675^{* *}$ & $.862^{* * *}$ \\
Private primary level & $.725^{* *}$ & na & na \\
Private above primary level & na & $.737^{* *}$ & $.814^{* * *}$ \\
\hline \hline$* *$ Correlation is significant at the 0.01 level (two-tailed). & & & \\
na = not applicable & &
\end{tabular}

\section{B. Access - distances to school}

In this study, we were able to use advanced tools for measuring actual road distances to each school by using the distance from the center of the primary sampling unit (PSU) to the GPS position of each school identified by parents as one that children from the community are attending. While earlier studies use presence of schools reported to be inside and outside of communities, we are unaware of other studies for Pakistan utilizing such precise measures of distance.

It appears that road access has also improved with increased choice in availability of schools. Using GPS to measure the location of each school and the distance of each school from the center of the community, it is clear that overall distances to be travelled to school in the 16 communities have become shorter (Table 3.3). There may be a few communities 
that are an exception to these findings, such as those affected by floods or Taliban action (data not shown). On average, distance to public schools has remained much the same but the distance to private schools has become much shorter. Whereas girls' schools used to be much further than boys' schools, they are now comparable in distance. Due to the expansion in the numbers of both private schools and schools for girls, the average distances to schools are shorter.

Table 3.3: Trends In distance of schools from PSU centers, by type of school, students, and levels, in 16 communities in Punjab, KP, and Sindh (in kilometers)

\begin{tabular}{|c|c|c|c|c|c|c|c|c|c|}
\hline \multirow[b]{2}{*}{ Variable } & \multicolumn{3}{|c|}{ Type } & \multicolumn{3}{|c|}{ Students } & \multicolumn{3}{|c|}{ Lovel } \\
\hline & All & Public & Pvt & Boys & Girls & Co-ed & Primary & Middle & High \\
\hline \multicolumn{10}{|l|}{ By year } \\
\hline Up to 1995 & 2.5 & 2.2 & 3.1 & 2.2 & 2.7 & 2.6 & 2.3 & 3.6 & 4.0 \\
\hline Up to 2000 & 2.5 & 2.3 & 2.9 & 2.1 & 2.6 & 2.9 & 2.4 & 3.5 & 4.2 \\
\hline Up to 2005 & 2.5 & 2.3 & 2.6 & 2.1 & 2.6 & 2.6 & 2.4 & 3.1 & 3.7 \\
\hline Up to 2011 & 2.4 & 2.5 & 2.3 & 2.4 & 2.4 & 2.5 & 2.3 & 3.1 & 3.7 \\
\hline \multicolumn{10}{|c|}{ By province (to 2011) } \\
\hline Punjab & 2.4 & 2.8 & 2.1 & 2.4 & 3.1 & 1.9 & 2.3 & 2.8 & 3.3 \\
\hline $\mathbf{K P}$ & 1.8 & 1.7 & 1.9 & 1.4 & 1.6 & 2.0 & 1.6 & 2.2 & 2.5 \\
\hline Sindh & 4.2 & 3.5 & 6.5 & 3.4 & - & 8.1 & 3.9 & 8.3 & 9.1 \\
\hline
\end{tabular}

- No girls schools in three of four communittes; therefore, average cannot be computed.

Similar improvements in access are seen for higher than primary level schools. Middle schools are now 0.5 kilometers closer than they were in 1995. High schools are slightly closer than they were in 1995, though still 1.4 kilometers further than the schools with only primary sections. The closer location of middle and high school levels is expected to have a notable impact on attendance in primary school as parents and communities see greater possibilities for their children to continue beyond primary school when these levels are more accessible.

When we look at average distances that children have to travel to reach primary school by province, KP has the shortest distance, followed by Punjab, and then Sindh having the longest travel involved. While provincial distances for high schools also follow the same pattern, the differentials are much wider. The difference between distances to public and private schools is the largest for Sindh and is expected to be longest for girl's schools as well. 
In exploring the relationship between distances and their influence on school attendance among girls, we find the inverse association is much stronger for girls aged 10-14 than 59 year olds, reflecting greater issues with travelling long distances for girls as they approach and cross puberty. For 15-19 year olds, there is a strong negative correlation with distances to both public and private above-primary level schools. These associations are tested through regressions later in the chapter.

Table 3.4: Correlation matrix of percentage of girls currently attending school by nearest distance from school to PSU center (in kilometers)

\begin{tabular}{lrrr}
\hline & \multicolumn{3}{c}{ Age group } \\
\cline { 2 - 4 } Distance variable & $\mathbf{5 - 9}$ years & $\mathbf{1 0 - 1 4}$ years & $\mathbf{1 5 - 1 9}$ years \\
\hline \hline Nearest public primary level & $-.544^{*}$ & na & na \\
Nearest public above primary level & $\mathrm{na}$ & $-.626^{* *}$ & $-.515^{*}$ \\
Nearest private primary level & -.208 & $\mathrm{na}$ & $\mathrm{na}$ \\
Nearest private above primary level & $\mathrm{Na}$ & -.237 & $-.585^{*}$ \\
\hline \hline
\end{tabular}

**. Correlation is significant at the 0.01 level (two-tailed).

*. Correlation is significant at the 0.05 level (two-tailed).

na $=$ not applicable

\section{Quality of schools}

In addition to availability of schools, the quality of schools is expected to be an important factor in explaining the school attendance of girls. To explore this association, we looked at current quality or attributes of all schools from our sample of 16 communities.

While it is difficult to fully capture quality, for this study, we measured quality of schools primarily through school, teacher, and classroom attributes. During site visits, our teams observed and verified classroom size and availability of teachers and text books. We did not attempt to measure the quality of the teaching. While we collected information on a range of indicators, this discussion focuses on a few main indicators that we found to be important and variable across schools.

Table 3.5 summarizes the main differences in these measures across different types of schools: private and public; boys and girls; and primary and middle level. There are clear differences in the attributes of these three comparisons. Private schools fare much better than public schools in almost all attributes, especially infrastructure. Findings show that weak infrastructure-such as water, toilets, and furniture-was much more a characteristic of public schools. Also, the absence of teachers on the day of visit was much 
more common in public schools than in private schools. In private schools (largely staffed by female teachers), teachers were much more likely to be living in the same village as the school. Female teachers living in the same village as the school were less likely to be absent than teachers living at a greater distance, an important factor explaining these differences. However, public school teachers had better qualifications and greater experience that those in private schools.

Similarly, boys schools generally fare better than girls' schools and the larger schools are much better off than schools that just have up to primary classes. Interestingly, 51 percent of girls' schools receive subsidies or support compared to 28 percent of boys' schools, reflecting the clear policy towards supporting schools for girls.

Table 3.6 compares differences in school quality across the same sets of schools visited in the period between 1997 and 2011 in the 12 panel communities. Improvements are seen in the proportion of teachers living in the village and in infrastructure, particularly for toilets in public schools. There appears to be a narrowing in the differentials between public and private schools, except for subsidies and teachers' credentials, which remain better in public schools. 


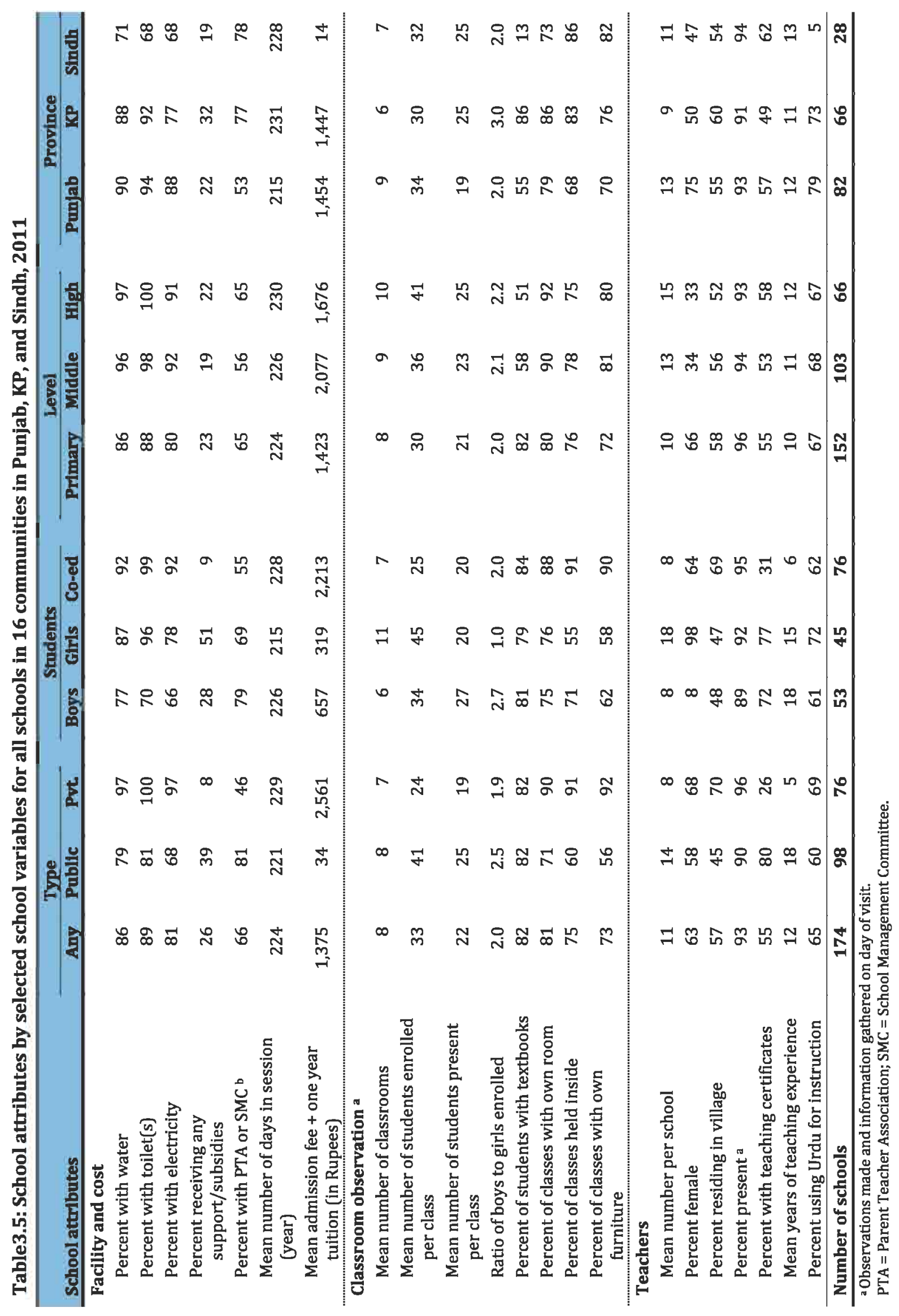




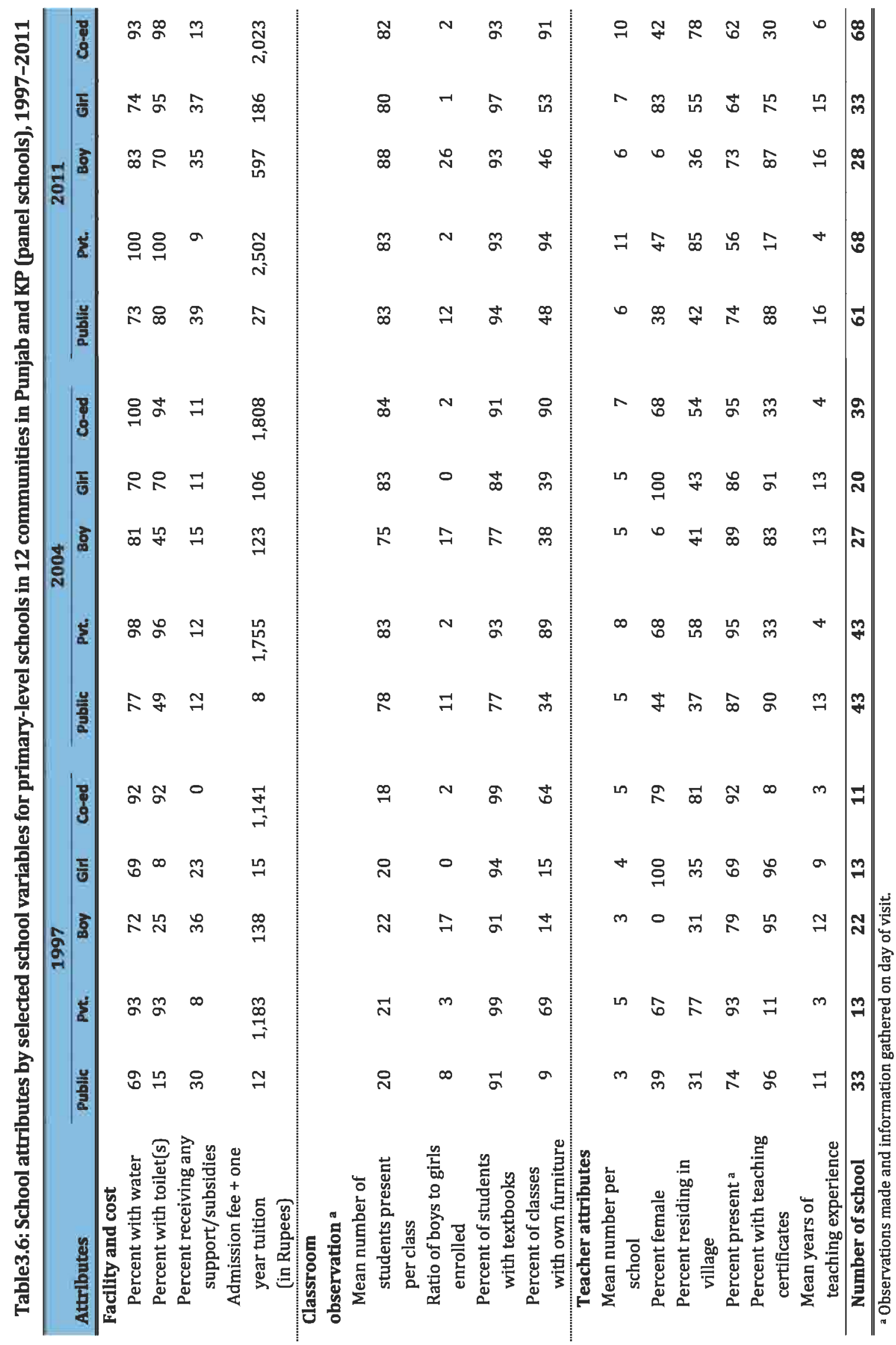




\section{School attendance and dropouts}

Girls' attendance in school by type of school currently or last attended presents a very interesting pattern. Table 3.7 shows that private schooling is a dominant choice for 5-9 year old girls; only 14.5 percent of girls in the 10-14 age group and 5.7 percent of 15-19 year olds had ever attended a private school compared to 25.7 percent of 5-9 year old girls. Clearly there are fewer choices for older girls in post-primary education in the private sector. There is also the largest proportion of dropouts in the oldest age group, concentrated mainly among those girls who had attended a public school. Those who had attended or were attending a private school were hardly likely to drop out.

The highest ever schooling was for 10-14 year olds as in fact this represents the full chance of having attended a primary school and also of continuing to middle-school. Almost 60 percent of 10-14 year olds were also currently attending school, just shy of the proportion of 5-9 year olds who are currently attending, and much higher than the 15-19 age group. This represents a real improvement in enrollment rates trend for girls.

Table 3.7: Girls school attendance by age group and type of school, in 16 communities in Punjab, KP, and Sindh

\begin{tabular}{lrrr}
\hline & \multicolumn{3}{c}{ Age group } \\
\cline { 2 - 4 } Enrollment & $\mathbf{5 - 9}$ years & 10-14 years & 15-19 years \\
\hline Ever (current + dropout) & $\mathbf{6 5 . 1}$ & $\mathbf{7 5 . 2}$ & $\mathbf{6 2 . 5}$ \\
Public & 38.8 & 60 & 56.6 \\
Private & 25.7 & 14.5 & 5.7 \\
Religious & 0 & 0.2 & 0 \\
Other & 0.6 & 0.7 & 0.2 \\
\hline Current & 63.2 & 59.5 & $\mathbf{2 3 . 6}$ \\
$\quad$ Public & 37.2 & 45.2 & 19.6 \\
Private & 25.5 & 13.8 & 4 \\
Religious & 0 & 0.2 & 0 \\
Other & 0.6 & 0.3 & 0 \\
\hline Never & $\mathbf{3 4 . 9}$ & $\mathbf{2 4 . 8}$ & $\mathbf{3 7 . 5}$ \\
\hline Total N & $\mathbf{4 9 5}$ & 602 & $\mathbf{6 3 2}$ \\
\hline
\end{tabular}

In Table 3.8, we compare the panel of communities to look for similar trends given the changes seen in the availability of schools. There is a dramatic rise in ever and current schooling of 5-9 and 10-14 year old girls, but hardly any change in the schooling of 15-19 year olds. The increase in current attendance in private schools is slightly greater than in public schools for the youngest ages, but the public sector still claims the larger share of enrollments for girls, overall. Once more, the dropout rate is clearly higher from public 
schools with very little difference in current and ever-attendance in the private school category.

Table3.8 : School attendance of girls by type of school and age group, 1997-2011, in 12 panel communities in Punjab and KP

\begin{tabular}{|c|c|c|c|c|}
\hline \multirow{2}{*}{ Year } & \multirow{2}{*}{ Enrollment } & \multicolumn{3}{|c|}{ Age group } \\
\hline & & 5-9 years & 10-14 years & 15-19 years \\
\hline \multirow{12}{*}{2011} & Ever (current + dropout) & 70.3 & 80.0 & 67.5 \\
\hline & Public & 40.4 & 63.3 & 61.0 \\
\hline & Private & 29.7 & 16.4 & 6.5 \\
\hline & Religious & 0.0 & 0.2 & 0.0 \\
\hline & Other & 0.3 & 0.0 & 00 \\
\hline & Current & 68.8 & 64.1 & 27.2 \\
\hline & Public & 39.1 & 48.3 & 22.6 \\
\hline & Private & 29.4 & 15.6 & 4.7 \\
\hline & Religious & 0.0 & 0.2 & 0.0 \\
\hline & Other & 0.3 & 0.0 & 0.0 \\
\hline & Never & 29.7 & 20.0 & 32.5 \\
\hline & Total N & 391 & 499 & 536 \\
\hline \multirow{12}{*}{2004} & Ever (current + dropout) & 41.3 & 68.6 & 61.5 \\
\hline & Public & 25.7 & 51.3 & 52.4 \\
\hline & Private & 15.2 & 16.3 & 9.1 \\
\hline & Religious & 0.0 & 0.0 & 0.0 \\
\hline & other & 0.4 & 1.0 & 0.0 \\
\hline & Current & 40.4 & 53.3 & 21.5 \\
\hline & Public & 25.0 & 36.9 & 13.8 \\
\hline & Private & 15.0 & 15.3 & 7.6 \\
\hline & Religious & 0.0 & 0.0 & 0.0 \\
\hline & Other & 0.4 & 1.0 & 0.0 \\
\hline & Never & 587 & 314 & 38.5 \\
\hline & Total N & 460 & 398 & 340 \\
\hline \multirow{12}{*}{1997} & Ever (current + dropout) & 54.1 & 64.3 & 56.3 \\
\hline & Public & 44.0 & 55.6 & 52.3 \\
\hline & Private & 10.1 & 8.7 & 4.1 \\
\hline & Religious & 0.0 & 0.0 & 0.0 \\
\hline & Other & 0.0 & 0.0 & 0.0 \\
\hline & Current & 51.9 & 47.5 & 18.8 \\
\hline & Public & 42.5 & 39.3 & 15.2 \\
\hline & Private & 9.4 & 8.1 & 3.6 \\
\hline & Religious & 0.0 & 0.0 & 0.0 \\
\hline & Other & 0.0 & 0.0 & 0.0 \\
\hline & Never & 45.9 & 35.7 & 43.7 \\
\hline & Total N & 414 & 356 & 197 \\
\hline
\end{tabular}

\section{E. Affordability of schooling}

Last, and perhaps the strongest consideration for households and communities is affordability. Poverty is strongly related to poor children's schooling outcomes and 
particularly for girls (Parveen 2008; Roudi-Fahimi and Moghadam 2003). At the same time, the availability of schools has increased thereby enhancing choices, and distances to schools have diminished providing some incentive for parents and girls to currently enroll in school. Given these positive changes, we do expect some changes in outcomes for girls schooling in rural Pakistan. We will examine household economic standing through the standard of living (SLI) index and assess the constraints of the poorest of households.

In Figure 3.3, we see that there is strong relationship between the SLI index and girls' attendance in public school. In particular, girls aged 15-19 whose enrollments are lowest, suffer the most with only those from the richest households reaching a 37 percent attendance in public schools. Clearly, these low enrollments are due to the combined effect of poverty and lack of access to schools.

The tradeoff with increased private schooling attendance is much more apparent. Fiftythree percent of 5-9 year olds in the richest households are going to private school as compared to 36 percent attending public school. In the case of 10-14 year old girls, there is a sharp positive association between income levels and attendance in school, and the majority always attends public school. Even girls who belong to the richest households have a 51 percent attendance in public school and 32 percent attendance in private school. There is a clear positive association between school attendance of 15-19 year olds and household income levels. The tradeoff for 15-19 year olds between public and private schools is even more constrained; hardly any girls of that age attend private schools and even in the richest households, only nine percent attend private school.

Figure 3.3: Percent of girls currently attending school by type of school and standard of living (SLI) index
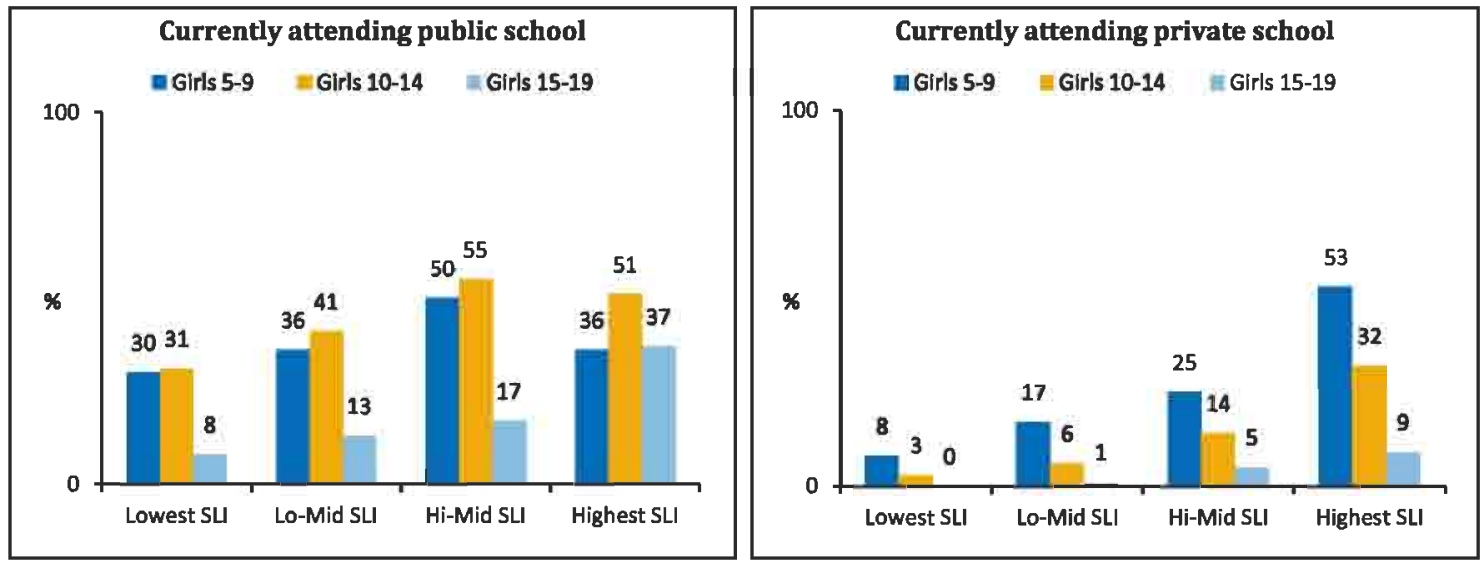


\section{F. Influences in combination}

Finally, we turn to look at the combined influence of some of the major factors affecting girls' schooling on outcomes. We consider household economic standing as the most important factor influencing girls schooling choices. We use this as a factor in the following logistic regressions, but add in turn each of the other three sets of factors (choice, distance, and quality) to see if their influences still weigh in.

Starting in Figure 3.4, we look at predicted levels of schooling if girls have increasing school choices. The results predict that with a choice of three schools (with a primary section), enrollments for girls aged 5-9 increase to 50 percent; and for older girls aged 10-14 with even just two schools (with middle section), enrollments rise to 50 percent. The predicted probability for 15-19 year olds attending school remains quite low with the addition of middle-plus schools. Even with five or more schools, their enrollment probabilities remain at the low level of 20 percent.

Figure 3.4: Predicted probabilities of school attendance by numbers of girls' schools (controlling for SLI)
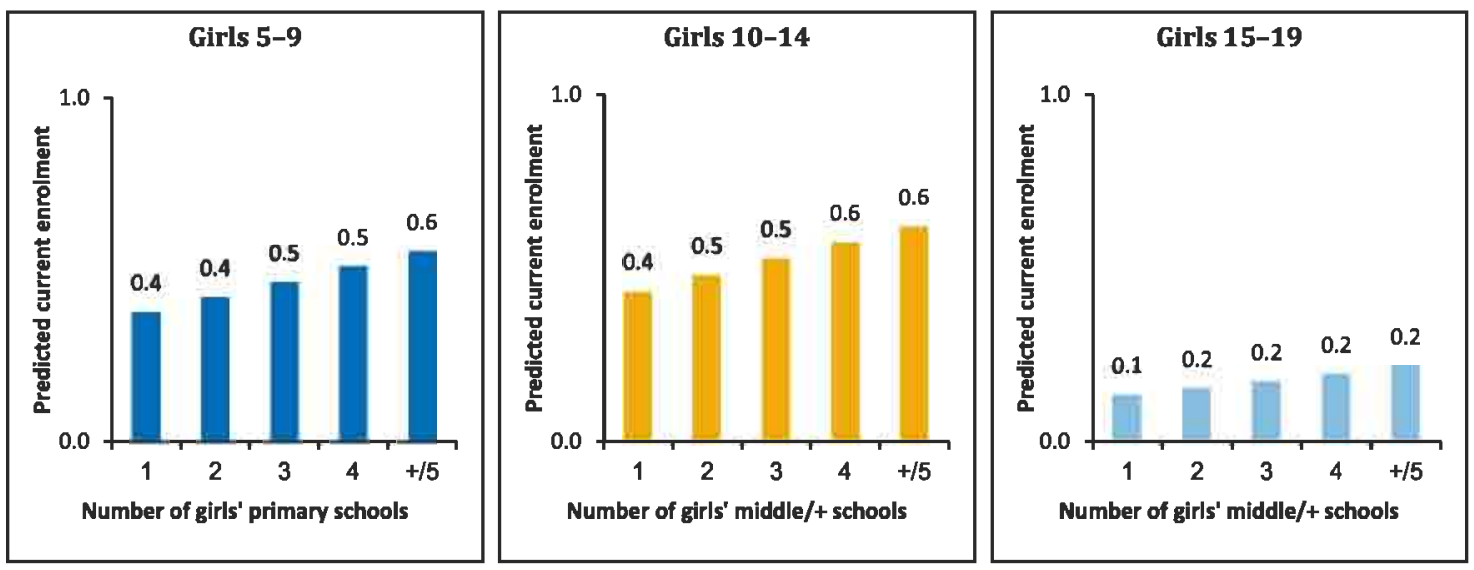

Next, we examine the influence of distances on school enrollments (Figure 3.5). We find, once again, after controlling for SLI, that girls are much more likely to be in school if it is located nearby. A school with a primary section within one kilometer raises predicted school attendance to 73 percent for 5-9 year olds and to 65 percent if a middle-school or higher is nearby for 10-14 year olds. If the primary school is more than four kilometers away, the probability of attendance falls to three percent, and to 54 percent in the case of middle-school. The distance to middle-plus schools does not retain strong explanatory power in the case of 15-19 year olds. Factors other than choice and distance are more important in determining school attendance for older girls. 
Figure 3.5: Predicted probability of current attendance in school by nearest distance to primary and middle/+ girls' schools (controlling for SLI)
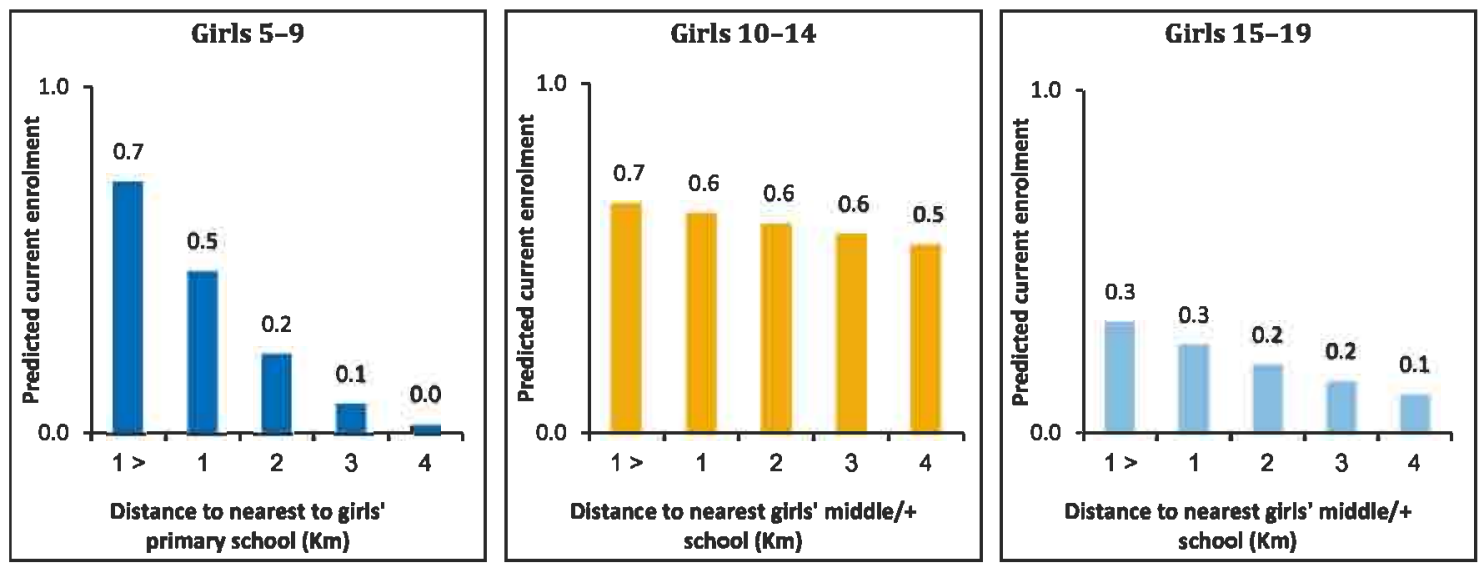

As with choice and distance, we assess whether or not there is any association between quality of schools and girls' school attendance. Rather than focusing on whether the school is private or public, we present logistic regressions of $5-9,10-14$, and $15-19$ year old girls' school attendance by some of the more prominent schooling characteristics (Figure 3.6). Attendance in school of 15-19 year old girls is more highly associated with school quality characteristics as compared to younger girls. This presents an interesting insight into why access appeared to be more mutely associated with school attendance for older girls.

In the set of quality factors, the one that is most strongly associated with school attendance is the presence of the teacher, which is important for girls of all ages. Predicted probability of girls' attendance if all schools have a teacher present goes up to 80 percent for 5-9 year old girls, 70 percent for 10-14 year old girls, and 60 percent for 15-19 year old girls. Having toilet facilities is also important for all ages, though not as important as teacher presence. When all schools have a toilet, attendance goes up to 70 percent for 5-9 and 10-14 year old girls and to 40 percent for 15-19 year old girls. This is quite striking, given that predicted probabilities of school attendance for the 15-19 year olds peaked at just 30 percent even if a middle or higher school was within a one kilometer radius, or to just 20 percent if there are more than five schools available in the community. Quality trumps access in the case of 15-19 year olds. 
Figure 3.6: Predicted probabilities of girls' school attendance based on quality of school indicators (controlling for SLI)
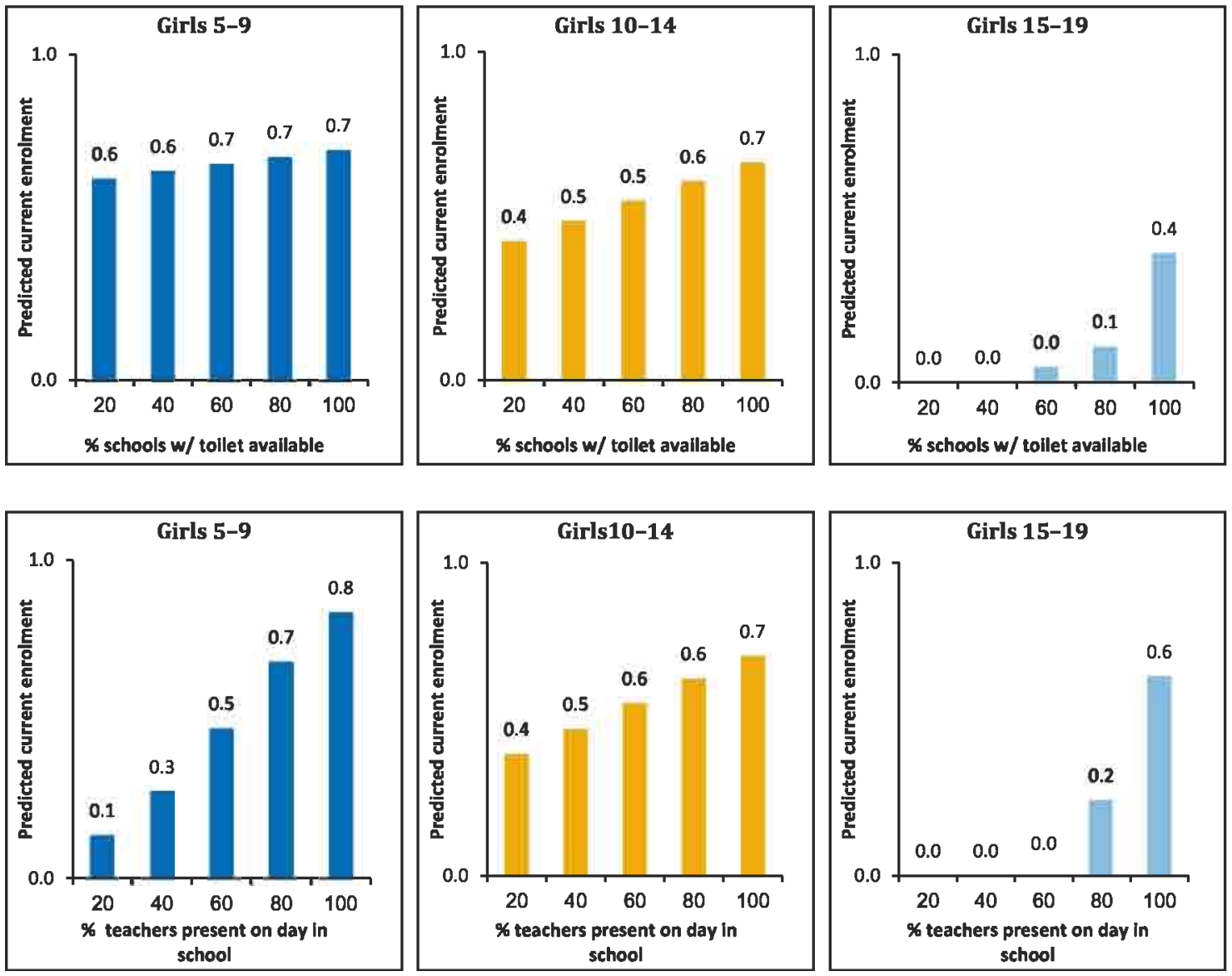

\section{G. Conclusion}

In conclusion, there is much to be hopeful about in terms of girls schooling. The access to school for rural girls has clearly improved not just for primary, but for middle-level schooling as well. Because the numbers of schools accessible to girls has increased, the distance they have to travel has also diminished. Recent changes do appear to favor girls more than was the case about 15 years ago.

The quality of schools has improved, but not dramatically. Public versus private quality differentials have narrowed to some extent. Private schools still fare better on quality indicators with a few exceptions, such as subsidies and teacher qualifications.

While school attendance has seen clear improvements, especially for younger girls, the room for improving enrollments for older girls is huge. Those girls who do attend school drop out sharply after the age of 14 , and even the dropout rates are high especially for public schools. Distance to school is negatively associated with school attendance, and the 
increased number of schooling choices is a positive impetus for attendance. Clearly, more schools increase enrollments, but ultimately, the quality of schools is very important. A minimal number of 3-4 primary and middle-plus schools are probably sufficient for a community to increase girl's enrollments to 70 percent. There is a clear indication that choice and access to schools influence school attendance by younger girls. For older girls, the quality of education is more important.

A note of caution, however, is that schooling choice has to be seen through the lens of community development and household income levels. While the number of private schools has expanded, they tend to be located in more developed communities and are only affordable in reality to girls belonging to richer households. Income levels and affordability will remain an issue, and for this, subsidies, scholarship, and conditional cash transfers may be very effective in minimizing enrollment differentials by income. 


\section{AVENUES OF CHANGE IN YOUNG WOMEN'S LIVES: ROLE OF GIRLS' SCHOOLING*}

The previous chapters presented findings from the community, school, and household questionnaires and observations, looking at supply-side factors that influence the enrollment of girls. In this chapter, the focus is on what makes education valuable to parents, society, and girls themselves. We investigate avenues that make schooling relevant, such as contribution to household income, better marriage prospects, or a better life for the next generation. We use the young women's data to answer these questions. The appendix of this report includes an overview of the field survey of which the women's survey was one part.

Detailed information on schooling, employment, marriage, and childbearing of both married and unmarried women aged 18 to 35 allows us to unpack how the role of schooling plays out in these three important transitions in a girl's life. Assessing the strength of education's impact on these transitions will shed light on the degree to which these relationships offer incentives for schooling for both parents and girls.

\begin{tabular}{|c|c|c|}
\hline Characteristic & Percent & Number \\
\hline \multicolumn{3}{|l|}{ Age } \\
\hline $18-22$ yrs & 41.5 & 561 \\
\hline $23-28$ yrs & 30.4 & 411 \\
\hline $29-35$ yrs & 28.1 & 380 \\
\hline \multicolumn{3}{|l|}{ Marital status } \\
\hline Never married & 34.6 & 468 \\
\hline Ever-married & 65.4 & 884 \\
\hline \multicolumn{3}{|l|}{ Number of live births } \\
\hline Never been pregnant & 11.0 & 97 \\
\hline Currently pregnant & 4.5 & 40 \\
\hline Had live birth & 84.5 & 747 \\
\hline \multicolumn{3}{|l|}{ Birthplace } \\
\hline This village & 71.0 & 965 \\
\hline Other village & 19.0 & 256 \\
\hline Other town/city & 10.0 & 131 \\
\hline \multicolumn{3}{|l|}{ Province } \\
\hline Punjab & 38.0 & 514 \\
\hline Sindh & 21.0 & 280 \\
\hline $\mathrm{KP}$ & 41.0 & 558 \\
\hline \multicolumn{3}{|l|}{ Language } \\
\hline Punjabi & 16.0 & 216 \\
\hline Siraiki & 30.5 & 413 \\
\hline Hindko & 11.6 & 157 \\
\hline Pashto & 29.6 & 400 \\
\hline Sindhi & 10.4 & 141 \\
\hline Other & 1.8 & 25 \\
\hline \multicolumn{3}{|l|}{ Number of siblings } \\
\hline $0-2$ & 6.4 & 86 \\
\hline $3-5$ & 36.0 & 486 \\
\hline $6-8$ & 44.1 & 596 \\
\hline $9+$ & 13.5 & 183 \\
\hline \multicolumn{3}{|l|}{ Education } \\
\hline None & 51.6 & 698 \\
\hline$<$ Primary (1-4) & 6.7 & 91 \\
\hline < Middle (5-7) & 14.1 & 191 \\
\hline$<$ Matric (8-9) & 7.8 & 106 \\
\hline Matric plus (10+) & 19.7 & 266 \\
\hline \multicolumn{3}{|l|}{ Work } \\
\hline Never & 68.6 & 926 \\
\hline Past & 7.0 & 94 \\
\hline Current & 24.4 & 330 \\
\hline Total & 100.0 & 1,352 \\
\hline
\end{tabular}

* This chapter was authored by Batool Zaidi. 


\section{A. Overview of characteristics}

Table 4.1 provides information on the characteristics of the women in our sample. Of the 1,352 women, 38 percent were from Punjab, 21 percent from Sindh, and 40 percent from KP. Siraiki (Dera Ghazi Khan, Rahim Yaar Khan, and Dadu) and Pashto (Swat, Karak, and partially, Abbottabad) were the most common languages spoken. Forty-two percent of the women were aged 17-22 years, 30 percent were 23-28, and the remaining 28 percent were 29-35. More than 70 percent of the women had been living in the same community since birth. Among those who were not born there, 97 percent had moved to the community at the time of marriage.

Around two-thirds of the women were ever-married and one-third were single; among married women, only three percent were not currently married. Of the 884 women who had been ever-married, 787 ( 89 percent) had already had children or were currently pregnant with their first child. The women from our sample came from large families themselves, with more than half of them reporting six or more siblings. There was slight evidence of a reduction in family size over time because the average number of siblings was slightly smaller for women from younger cohorts.

Half the women in our sample never attended school; this proportion is much less for the younger age group. Only six percent were currently attending school. of these, the majority ( 85 percent) were from the youngest age cohort. Twenty-one percent had less than eight years (middle-school) of schooling, and the remaining 28 percent had more than eight years of schooling. Typical to rural Pakistan, close to a third of the sample had engaged in economic activity; among these, the majority (46 percent) had been, or were engaged in agricultural activities. The second-most common form of economic activity was stitching and embroidery ( 36 percent), followed by teaching/tutoring (eight percent).

\section{B. Education}

\section{Level of education completed}

While a majority of the women in the sample never attended school, improvements in education levels can be seen across different age cohorts. Women with no education were more concentrated in the older age cohorts: two of every three women aged 29-35 had no education, compared to two of every five women aged 18-22. 
For those whose schooling was complete, the average years of schooling was just less than middle-level (7.4 years). For the 87 women in our sample currently attending school, the average years of school completed was 11.4 years. Forty-two percent of all women had completed primary school. This proportion varied across our communities; the variation in the proportion completing primary school reflected the variation in the number of schools available in the community. Utilizing the schooling data, we find that the association between the proportion with at least five years of schooling and the number of schools accessible to girls at the time these women were finishing primary school, is very strong (large R-squares) (Figure 4.1). Interestingly, this correlation is stronger for older women, possibly indicating that the availability of schools was a bigger issue for older women.

Figure 4.1: Proportion of women who finished primary school, by age cohort and number of schools in community

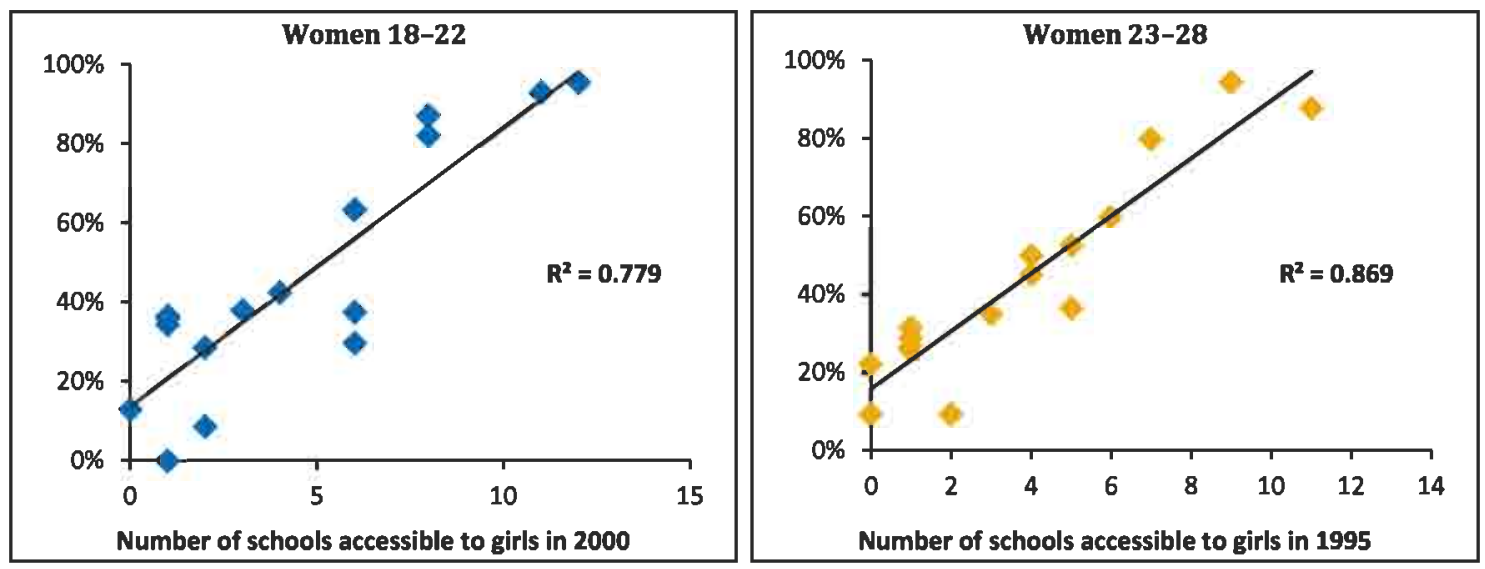

Note: Number of schools available are shown for two points in time when our two cohorts of women were finishing primary school. Data on number of schools is from the schooling survey.

\section{Type of school attended}

Among all of the women that had ever attended school, 16 percent had attended a private primary school and 15 percent were last in a private school (irrespective of level). However, the proportion that attended a private school varied by age, household wealth, and community. Of those in the poorest 25 percent (quartile) for household wealth, none attended a private primary school; in the second poorest quartile, eight percent did, as did ten percent in the second wealthiest quartile. Among the wealthiest 25 percent, 26 percent attended a private primary school. 


\section{Dropouts}

Looking at dropout rates among women that ever attended school, we find that, as expected, women from the youngest age cohorts are more likely to still be in school: almost 80 percent of these young women are no longer in school compared to almost a 100 percent of women from the oldest age group. The real difference in dropouts between the cohorts is at the matric level (Figure 4.2). The dropout rate for the oldest women (aged $29-35$ ) increased from 63 to 88 percent ( 25 percentage points) after completing the $10^{\text {th }}$ grade, whereas for girls from the youngest cohort, this increase is from 57 to 72 percent (15 percentage points).

The difference in dropouts is even more pronounced when comparing women who attended private versus public primary school: 17 percent in public schools dropped out before completing primary school, compared to only three percent in private school. Dropout rates after completing primary school are again higher for public school with 26 percent dropping out after the fifth grade. Not only do fewer women (ten percent) in a private primary school drop out after the fifth grade, but more of them stay in secondary school until completion (77 percent). Dropout rates for women who attended public primary are lower post-matric degree - with only ten percent

between 11 and 16 years of school. The patterns for dropouts by public versus private primary schooling remain the same, even when controlling for age. These findings are also in line with dropout patterns seen in the previous chapter.

Figure 4.2: Dropout rates by grade completed, by age cohort and type of primary school attended
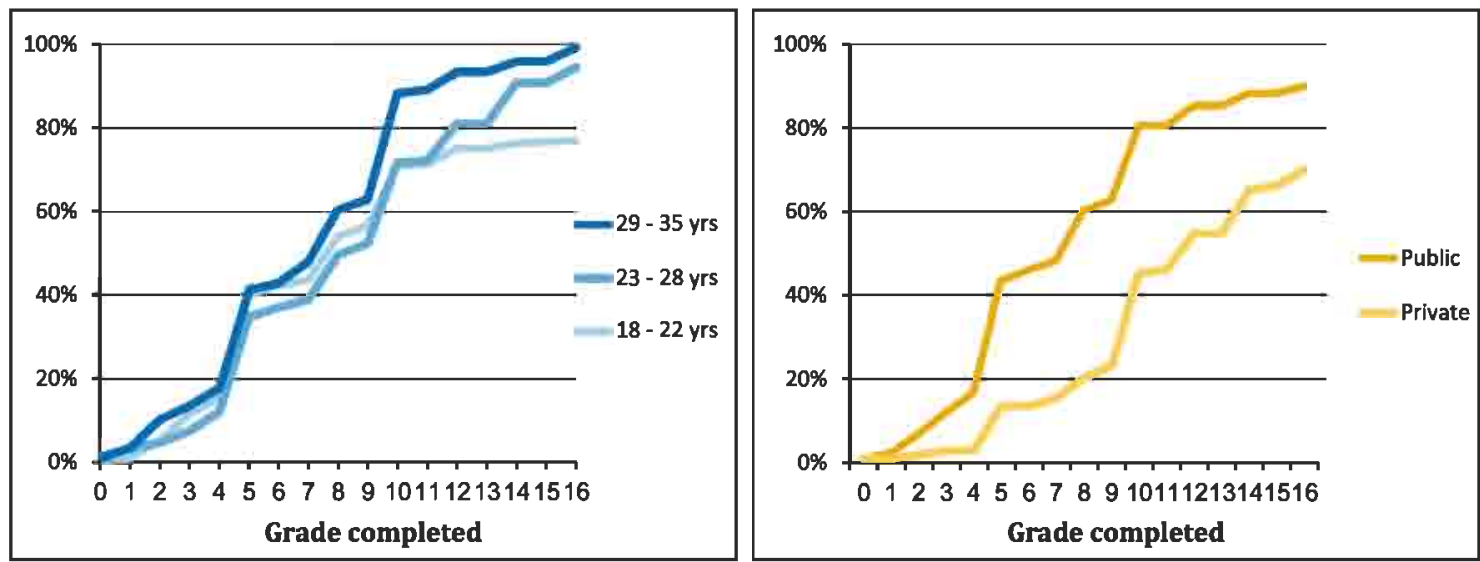


\section{Reasons for not attending school}

Reasons for never attending school differ in their relative strength across age groups. The lack of school availability is one of the topmost common reasons for never going to school reported by women from the older cohorts. However, for the youngest cohort, family disapproval and lack of interest (both demand-side factors) are the most common reasons.

For women who drop out of school, the reasons differ by the level at which they left school (Figure 4.3). For those women who left school before completing middle-school, the lack of availability of schools is the most common reason, while the two most common reasons for women who drop out after middle-school are marriage and domestic responsibilities.

\section{Figure 4.3: Proportion of past attendees, by reason and level completed}
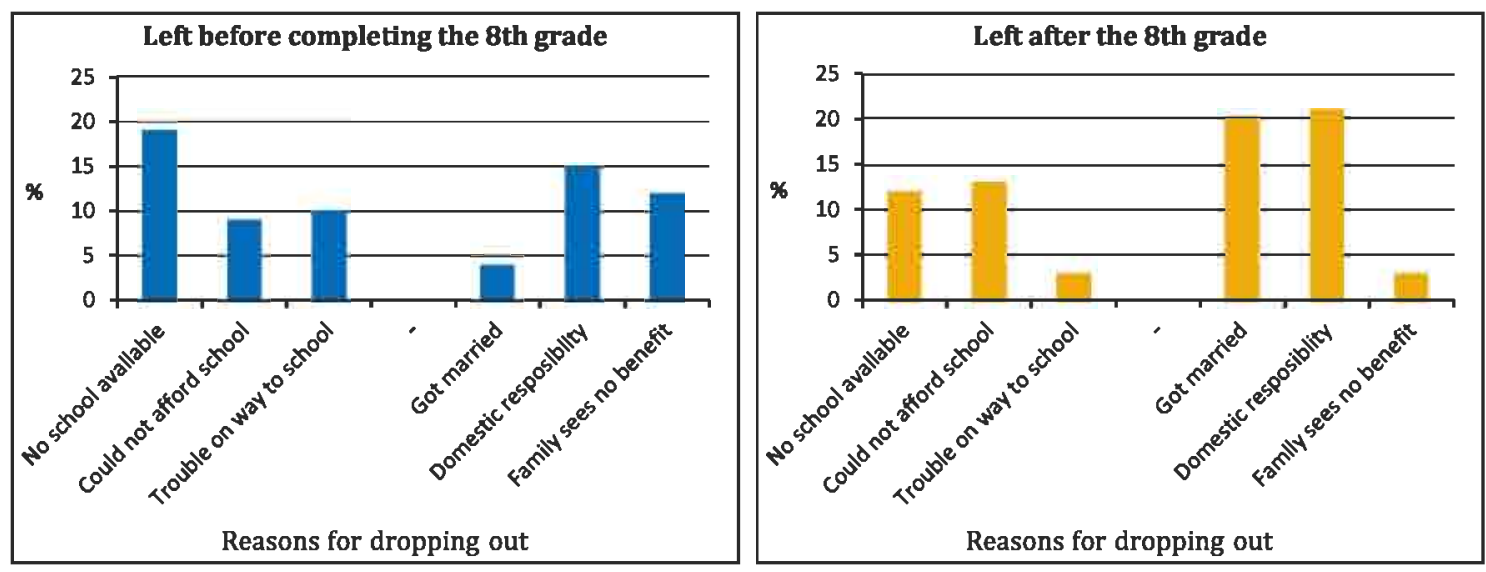

\section{Marriage}

Marriage for young women involves dramatic changes in responsibility and residence. It can be seen as the main marker of the transition to adulthood for young women. Later events in life, age at first pregnancy, care during pregnancy, infant and child mortality outcomes, and contraceptive and abortion choices are also closely related to marriage age, marriage partner, and the social and other capital a young woman brings to her marital home.

\section{Timing of marriage}

Schooling has a great impact on age at marriage. Nationally, age at marriage in Pakistan is delayed by more than six years for women with higher education as compared to women with no education (National Institute of Population Studies 2008). Our sample, even though primarily rural, shows stark differences in timing of marriage by education as well. 
Overall, 41 percent of all women in our sample were married by the age of 18 . This proportion falls significantly with educational attainment (Figure 4.4). More than half of the women with no education were married by age 18 compared to slightly more than a third of women with primary education, and only one in every five women who had ten years (matric level) of schooling.

\section{Figure 4.4: Proportion of women married by age 18, by education}

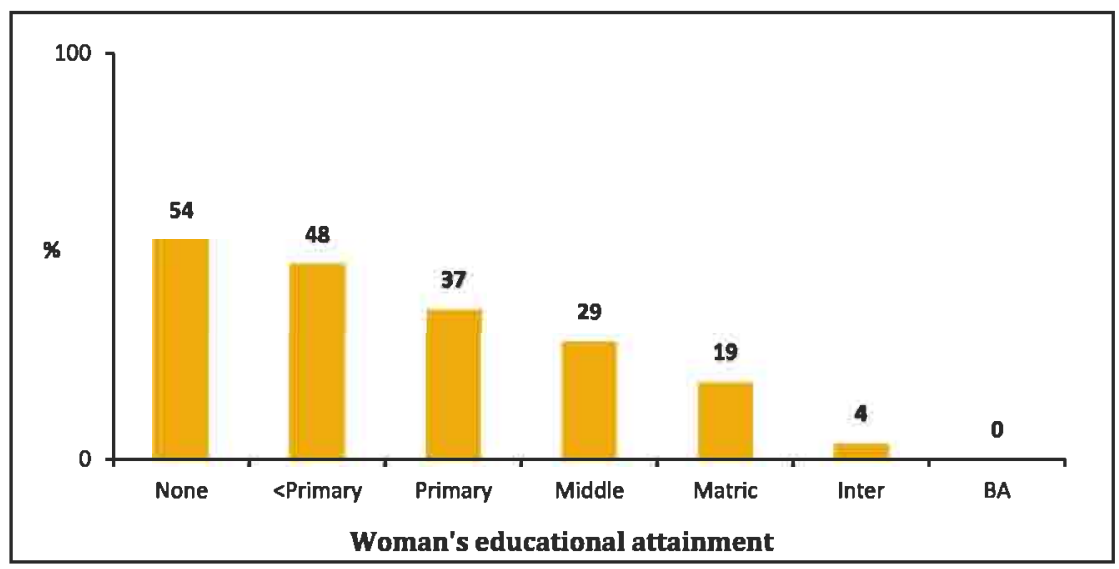

We find a clear cohort effect on early marriage (as defined by those married by the age of 18) with 60 percent of women from the 29-35 cohort compared to 30 percent from the 18-22 cohort marrying early, indicating that early marriage practices are lessening over time (Figure 4.5). Of course, most highly educated girls are from the youngest cohort, but even when controlling for age (Figure 4.5), education's negative correlation with early marriage persists.

The differentials in timing of marriage are not limited to the level of schooling; these differentials are seen when looking at the type of school women last attended. Women who last attended a public school have a higher proportion marrying early compared to women who attended a private school. However, we also find that this differential is decreasing over time with very little difference in the prevalence of early marriage among the youngest cohort of women who attended a school, whether public or private school (figure 4.5 right). 
Figure 4.5: Proportion of women married by age 18, by age cohort and education characteristics
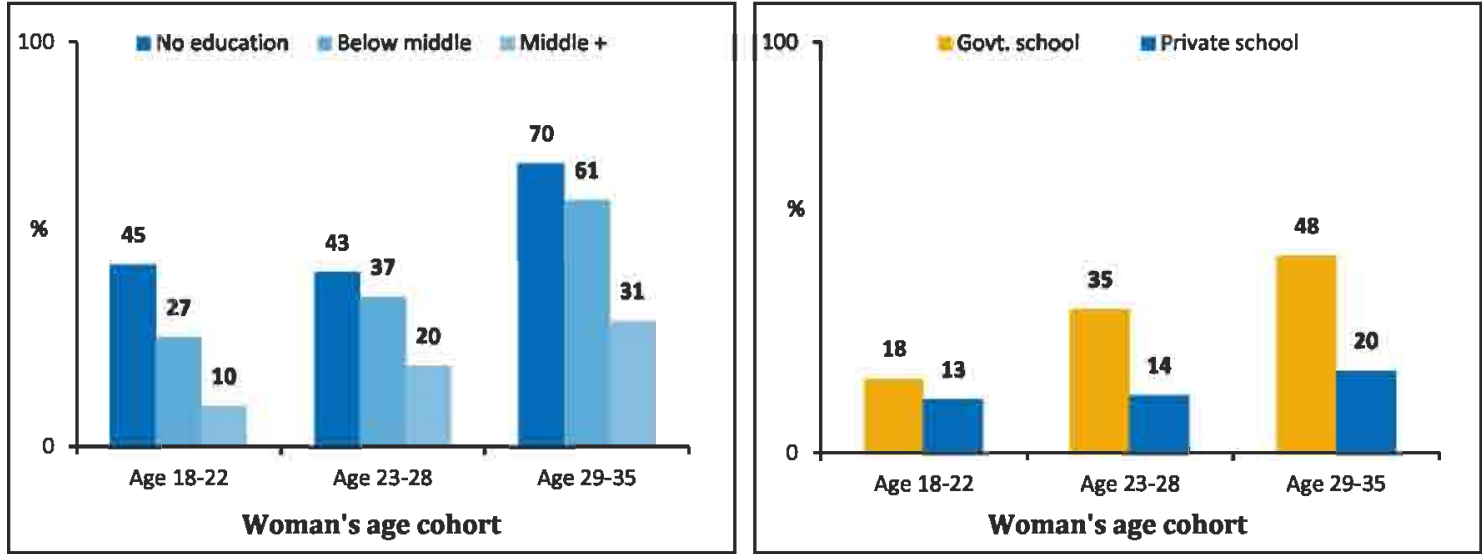

Previous studies have shown that marriage patterns are strongly influenced by the cultural norms of society, and studying variation in marriage practices across cultural groups often provides more insight than the typical regional/provincial analysis (Sathar et al. 2008; Zaidi and Reichenbach 2009). Our sample of communities allows us to look at marriage practices across almost all major cultures/ethnicities across three provinces of Pakistan. Differentials in timing of marriage across ethnic groups (as identified by language) in our rural sample reflect the national picture.

While ethnicity plays a big role in marriage timing, regression analysis shows that educational attainment, even completion of primary school, is strongly correlated with timing of marriage after controlling for ethnicity, cohort differences, and household wealth.

\section{Spouse selection}

It is not just the age at which women marry that determines their future life experiences, but also who they marry. Our survey allows us to study how a woman's educational attainment influences or is related to who she marries, by looking at her role in the decision-making around marriage, the characteristics of her husband (kin status, education, age difference) as well as her perceptions about education's influence on choice of partner.

Around a third of unmarried women and half of married women reported that the discussion on who they marry had taken place in their household. While women's educational attainment did not have any impact on the discussion taking place, it did have 
a positive correlation with whether the woman was able to voice her opinion on the matter when discussed (Figure 4.6).

Figure 4.6: Proportion reporting discussion on choice of partner and participation in discussion, by education
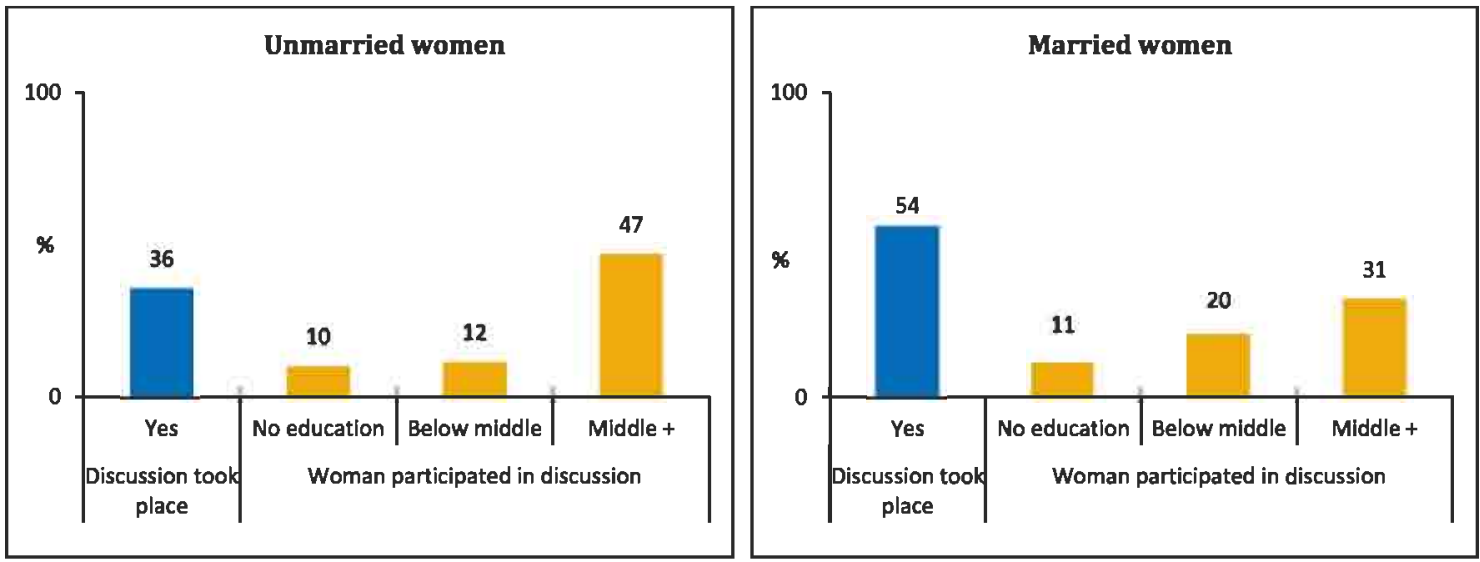

However, decisions regarding who women marry lie largely with parents - of the 54 percent of married women (480 out of 882 ) who reported discussion on the topic, only 17 percent ( 82 women) participated in the discussion, of which only a quarter (21 women) had a say in who was selected to be their husband. Educational attainment did not impact the likelihood of having a say in the selection of a husband.

Figure 4.7: Proportion of women married to kin, by education and ethnicity

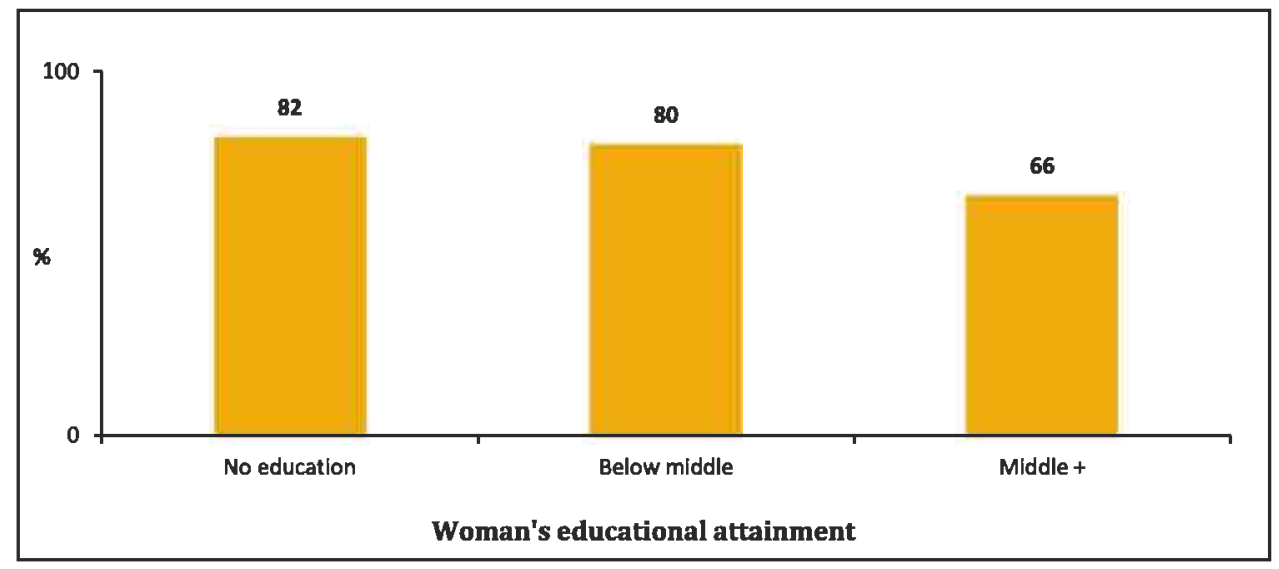

Part of the reason that women (irrespective of their education) have such a small role in choosing their life partner is the high prevalence of kin marriages in rural Pakistan. In our sample, 59 percent of the women were married to a first cousin and another 20 percent to a second cousin. The prevalence of kin marriage is negatively correlated with education, but this relationship becomes insignificant when controlling for community/ethnicity effects (Figure 4.7). 
Similarly, spousal age difference does not have a significant relationship with the woman's level of education. The average difference between a husband and wife's age in our sample is 4.6 years (husband older). This difference does not change much across women's educational attainment. Age at marriage does have a significant impact on spousal age difference - the later the age at marriage, the lower the spousal age difference. Schooling therefore affects spousal age difference indirectly through its effect on age at marriage.

Women's educational attainment does, however, have a significant and negative correlation with the difference between a woman's own education and her husband's education. The average difference in years of schooling between a husband and wife in our sample is just above three years. But women with higher education are married to men who have, on average, fewer years of schooling than they have. (Table 4.2). In a society where educational hypergamy for women is the traditional norm, women with high levels of education find it difficult to marry upward (educationally). This phenomenon, referred to as the 'success penalty' of high educational attainment, is also seen at the national level by previous studies as well (Nayab 2009).

Table 4.2: Mean difference between husbands' and wives' years of schooling by wives' level of education

\begin{tabular}{lrrr}
\hline Wives' educational attainment & Number & Mean & Standard deviation \\
\hline \hline No education & 536 & 4.9 & 4.67 \\
Below matric & 223 & 1.7 & 4.63 \\
Matric+ & 120 & -1.4 & 3.74 \\
\hline Total & $\mathbf{8 7 9}$ & $\mathbf{3 . 2}$ & $\mathbf{5 . 1 0}$ \\
\hline \hline
\end{tabular}

Household wealth and the schooling environment of the community also have a significant effect on the difference in educational attainment of spouses. Belonging to a wealthier household reduces the success penalty, most probably because a woman from a wealthy household has more demand and, therefore, more choice in the marriage market; she is also more likely to find men with high levels of education in her socio-economic circle.

Additionally, communities with rich schooling environments (a large number of private or primary-plus schools) have lower spousal differences in education; the average difference between husband's and wife's education is five years for women from communities with less than six primary-plus schools, compared to only two years for those from communities with six or more primary-plus schools. The community's schooling environment reduces the success penalty educated women face in finding a spouse because these communities are likely to have more educated male residents. In such 
communities the equality in educational attainment among spouses is likely to translate to broader gender equality and improved status of women.

\section{Marital transactions}

Martial transactions vary across all 16 communities. More than 80 percent of married women from all communities reported bringing some dowry with them as well as receiving some haqmehr and bari from the groom's family at the time of marriage. The prevalence of these transactions is higher among women with more schooling and those from wealthier households. More importantly, women's level of schooling has a strong positive correlation with control over these marital transactions. The proportion of women who alone decide how to spend the gifts received at the time of marriage is less than 30 percent among those with no education, or even those with less than eight years of schooling. Among women with eight or more years of schooling, almost half have complete control over how their wedding gifts are utilized (Figure 4.8).

Figure 4.8: Proportion of married women who alone decide how their wedding gifts are spent, by education

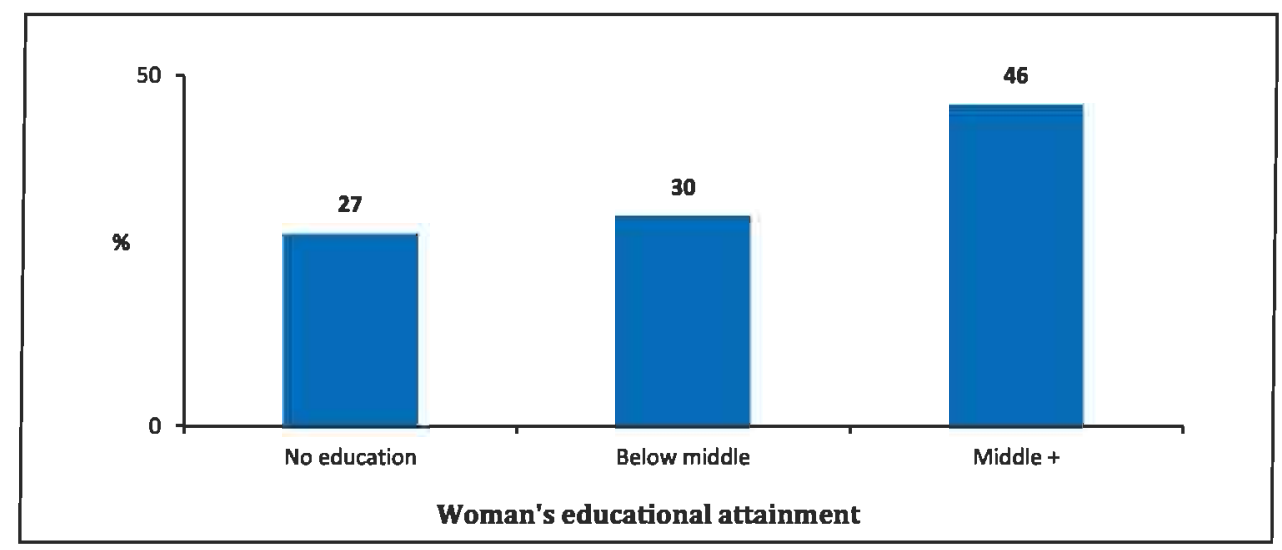

\section{Autonomy within marriage}

Data from the nationally representative Status of Women, Reproductive Health, and Family Planning Survey (SWRHFPS) 2003 show that female education also has a direct link with women's level of autonomy within their marital household. Analysis of the same survey found that women with higher education have greater mobility and decisionmaking power within the household compared to their uneducated counterparts. These effects might very well be confounded by various other factors on the initiation of marriage, such as its timing, choice of partners, age differences between spouses, and cash transfers in marriage. We utilize the data from our survey to better understand the level of 
women's autonomy within marriage with respect to differences in education and the factors around the initiation of marriage.

Women with higher education from our sample also have more decision-making power in the households, but the increase in decision-making power is significantly higher only when women achieve eight or more years of schooling (Figure 4.9). Higher age at marriage, marrying outside kin, and same-or-more schooling than husband all increase the likelihood of a woman having a larger role in making decisions regarding the household. But the strongest predictor of high levels of decision-making is age: women from the oldest age group are thrice as likely to have a high decision-making role as women from the youngest group.

Figure 4.9: Proportion with some role in decision-making, by age and education (married women) a
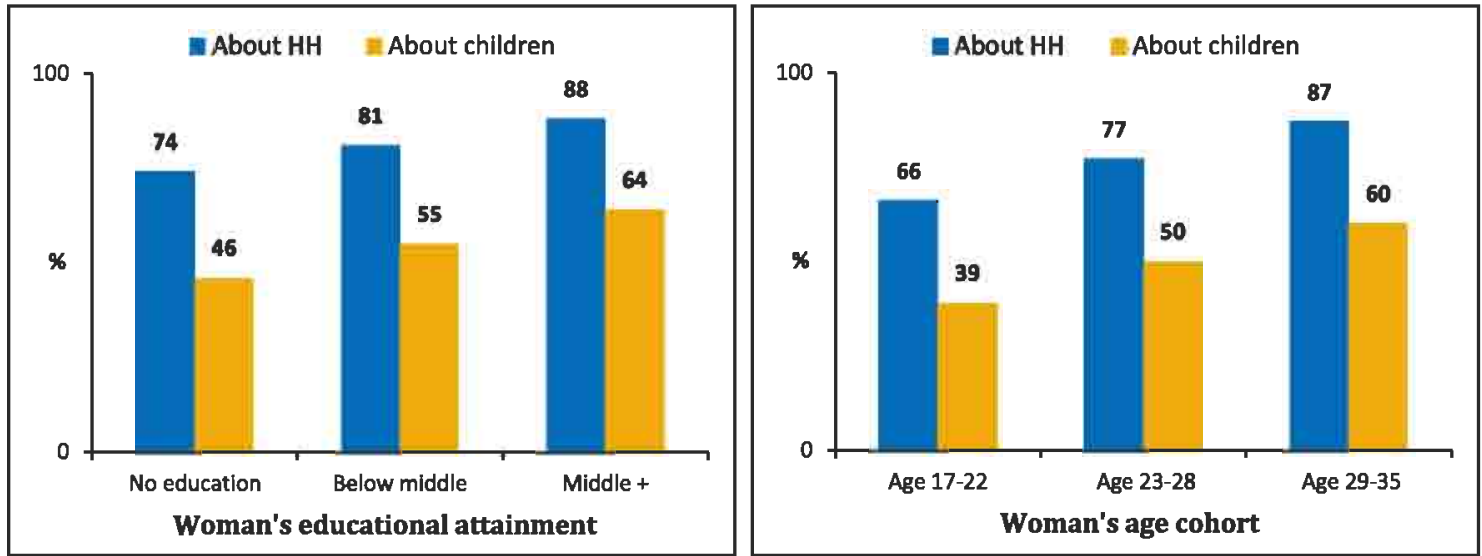

a For household decision-making, there were eight questions regarding cooking, guests, etc. Decision-making about children included four questions on health, schooling, and marriage.

Surprisingly, even when controlling for all the above-mentioned factors, the schooling environment of the community the woman resides in has a significant impact on her decision-making power inside her marital home. This once again indicates that perhaps communities with high levels of education attach a greater value to women and award them higher status.

\section{Children and contraception}

\section{Timing of first birth}

Young uneducated girls that marry early also start childbearing early. Since fertility control is low in rural Pakistan, marriage becomes a major marker for all related outcomes such as the timing and spacing of reproduction, numbers of unwanted pregnancies, and 
ultimately, contraceptive uptake. According to national statistics, education differentials in the median age at first birth closely correspond to the age at which women marry. Findings from our survey support this pattern, with the proportion of women giving birth by the age of 19 decreasing by educational attainment at the same rate as timing of marriage. The proportion of women with a birth before the age of 19 is more than half for women with no education (58 percent), or even those with less than eight years of schooling ( 56 percent), but falls to less than a quarter ( 24 percent) for women who have eight or more years of schooling.

Results from our analysis also point to little variation in the marriage-to-first birth interval, and the correlation with education is insignificant. Interestingly, the effect of the community variable (development score) on timing of first birth remains significant and positive even when controlling for age at marriage, spousal age difference, respondent's age cohort, and education.

\section{Pregnancy and delivery care}

When it comes to health behavior during pregnancy, our survey findings once again mirror national patterns. Women's educational attainment has a strong positive correlation with the proportion of women not only seeking antenatal care, but also having a skilled birth attendant (SBA) present at the time of delivery. The effect of education remains strong, almost doubling attendance by SBA from 35 percent to 67 percent among uneducated and middle-plus educated women, even when controlling for household wealth status (Figure 4.10 left).

A woman's health-seeking behavior is not just determined by her educational background, but also by the kind of community she lives in. We find that in our sample, development levels of the community women belong to have a significant effect on delivery care indicators. The proportion of women that had an SBA present at the time of their first delivery increases from 27 percent for those in less-developed communities to 60 percent for those residing in relatively high-developed communities (Figure 4.10 right). This indicates that safe delivery practices are contingent upon the level of development in the community, including the availability of medical facilities, roads, etc., as well as personal educational characteristics. 
Figure 4.10: Proportion of women with first birth delivered by skilled birth attendant (SBA), by education and community development score
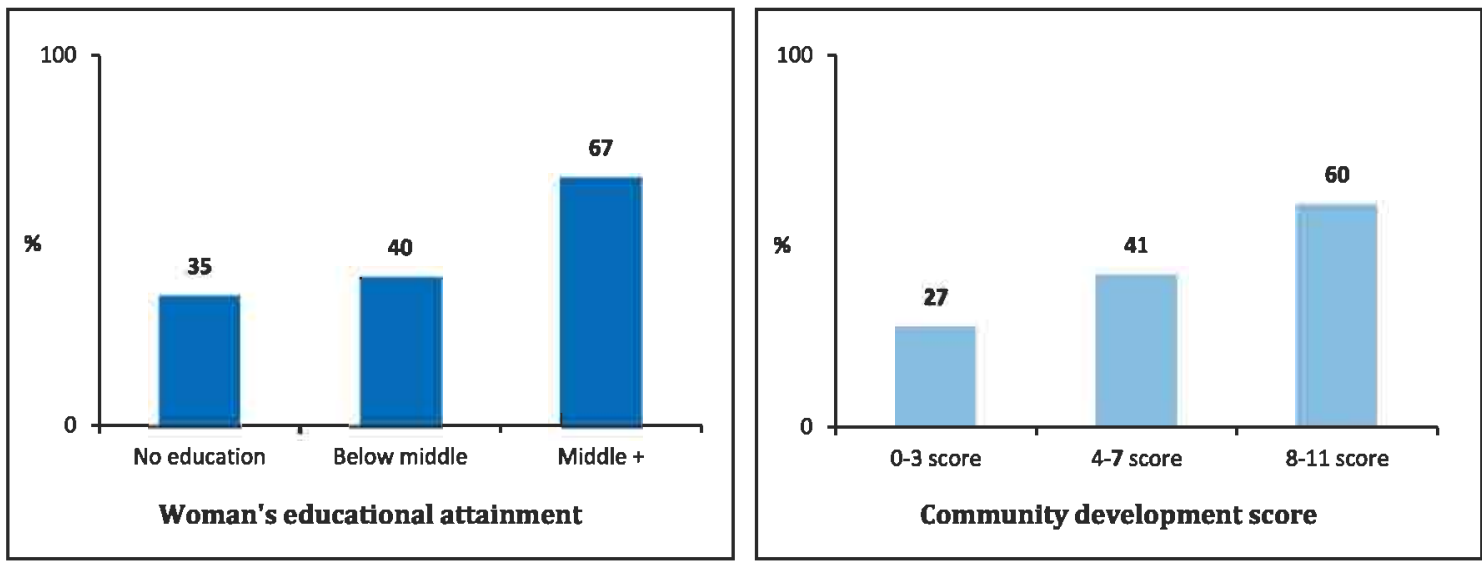

\section{Ideal family size}

Education influences not just fertility behavior, but intentions as well; it is a critical prerequisite for bringing about the ideational change required for smaller family size. In our rural sample, women's educational attainment is negatively correlated with the ideal number of children they report. For women with eight or more years of schooling, 36 percent report the ideal number of children to be three or less, only 15 percent of uneducated women report the same number. For uneducated women, 50 percent report five or more children as the ideal number or that the number of children is up to God.

Figure 4.11: Proportion of women who report three or fewer children as the ideal number
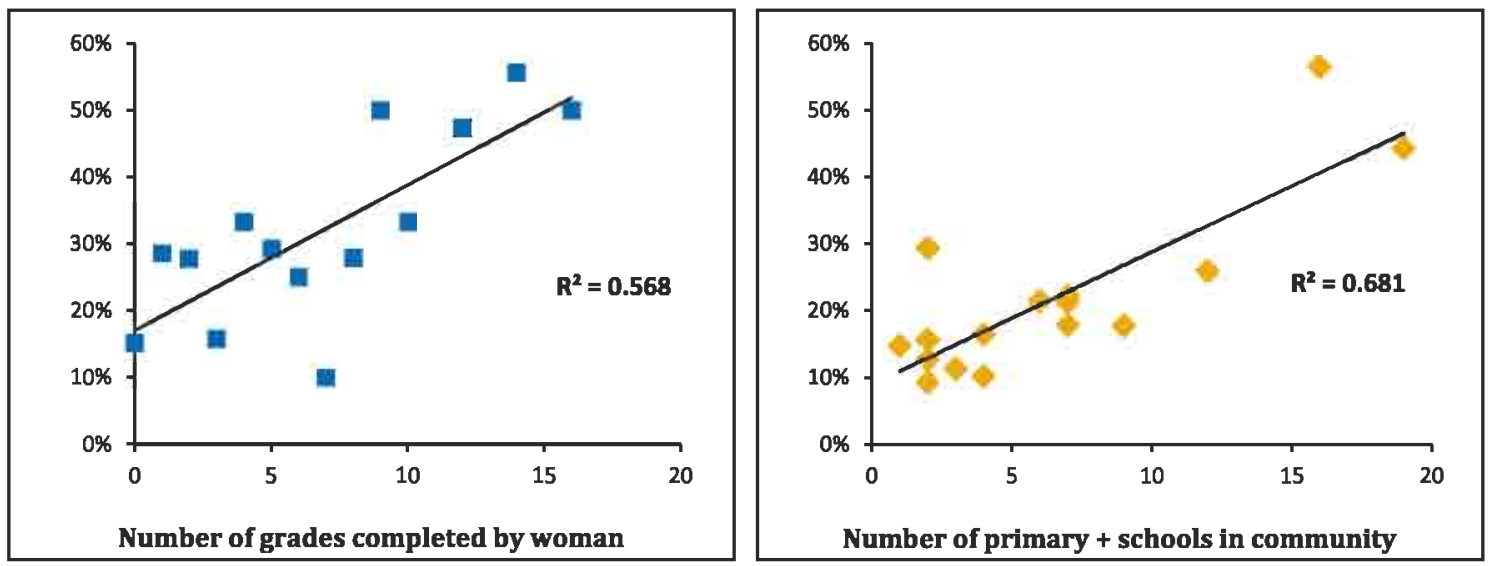

The effect of women's education can be seen in Figure 4.11 (left), which shows years of schooling to be positively correlated with the proportion of women wanting a small family size (three or fewer children). The effect of education on ideal family size is not limited to women's attainment, but also to the overall level in the community they reside in. The right side of Figure 4.11 indicates that the number of schools in the community (a proxy 
for the demand, value, and level of education) is significant and positively associated with ideals of fewer children. Women residing in communities with a richer schooling environment (more schools) want to have fewer children. In fact, the level of education in a community has better explanatory power (greater R-square) for women's ideal family size than their own educational attainment. This hints at young mothers beginning to invest more in fewer, but more educated children in areas where they see visible opportunities for children.

\section{Decision-making regarding family size}

Although women have a disproportionately high share of the childbearing and rearing burden, they have limited control over their fertility. Our rural sample shows that among married women, only 12 percent have the final say and 42 percent have some say in deciding how many children to have. Education increases a woman's role in decisions regarding her fertility. While only eight percent of uneducated women are the main decision-makers regarding number of children, this proportion triples to 26 percent among women with eight or more years of schooling (Figure 4.12). Similarly, fewer women with no education have any say in this decision. Even a primary education increases women's participation in this important decision.

Figure 4.12: Proportion of women who decide how many children to have, by education

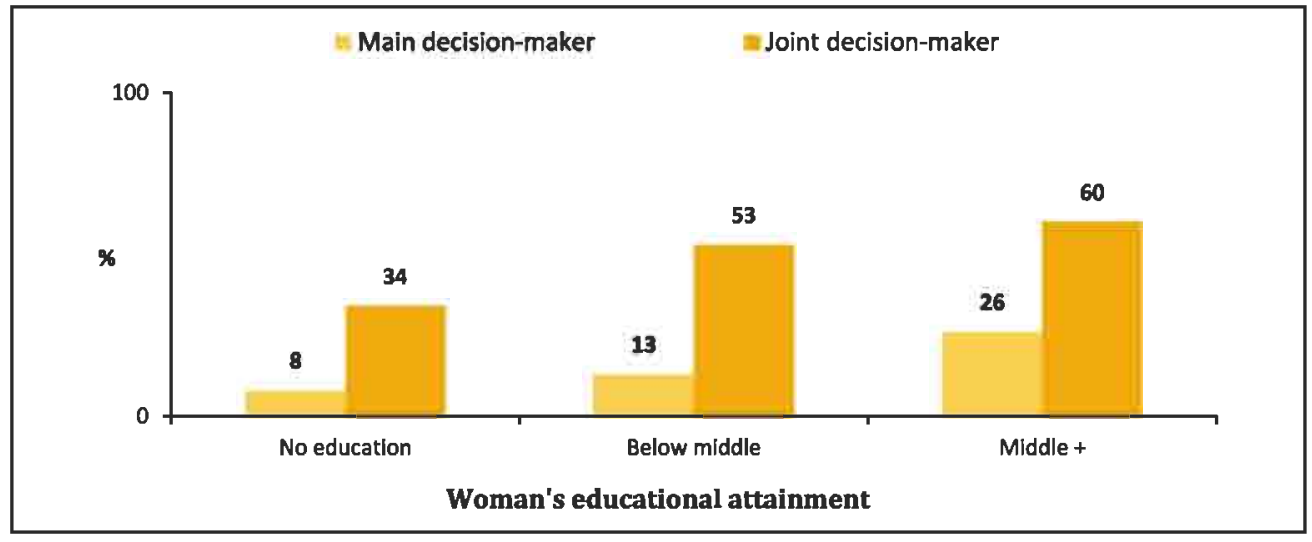

\section{Contraceptive use}

Slightly more than a third of currently married women in our sample had used a family planning method, and 20 percent were using contraception at the time of the survey. Looking across cohorts, contraceptive prevalence increased from ten percent among 2024 year olds, to 23 percent for women aged 25-29 and, finally, to 30 percent for women aged 30-34. 
The positive association between women's educational attainment and contraceptive behavior has been long established. Our rural sample gives similar findings: past, current, and future contraceptive use increases by women's education levels. Looking at the relationship across cohorts, for the older cohort of women (aged 30-34), middle and higher-level schooling had a stronger impact on contraceptive behavior (Figure 4.13). For the younger cohort (25-29), even primary-level education is sufficient in making as much impact as higher education.

Figure 4.13: Contraceptive behavior across two age cohorts, by education
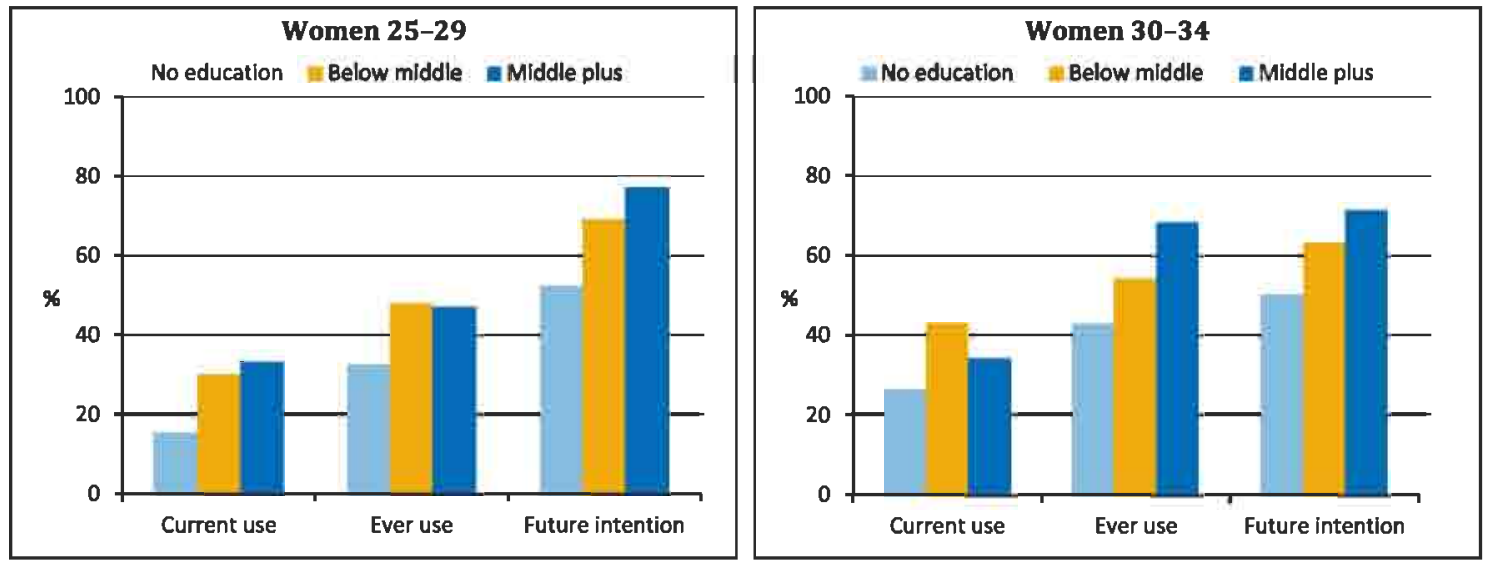

The schooling environment also influences contraceptive use uptake. Analysis of data from previous rounds of the survey found that for women of reproductive age (20-45) residing in our sample communities, schooling environment factors such as the availability of secondary schools and the ratio of girl to boy primary schools in the community had a significant positive effect on the odds of contraceptive uptake (Sathar et al. 2003).

\section{E. Work}

Perhaps one of the most important benefits of education is that it creates opportunities for economic work. National datasets show that educational attainment has a U-shaped relationship with labor force participation rates, with the proportions of women engaged in economic activity high at the no-schooling level, falling for the middle-school level, and then again high beyond matric.

Previous studies in Pakistan have found that education has a convex relationship with earnings, and that for women in particular, additional years of schooling improve both employment type and earning levels. We use our sample to see how the relationship 
between education and employment holds for rural women in Pakistan. In particular, we look at how education impacts the likelihood of women engaging in the labor market, what type of occupation they can hold, and decision-making about whether to work and keep salary.

\section{Level and type of work}

The correlation between education and economic activity takes the same U-shape in our sample as national datasets, with the proportion of women engaged in any such activity falling until a matric degree, and then rising again for those with higher education. Engagement in economic activity is more strongly linked with economic status than education. Household wealth status has a sharp negative association with women's economic activity: 55 percent of women from the poorest quartile of households work, but this proportion falls sharply to only 16 percent among women from the wealthiest quartile (Figure 4.14 right). In a regression analysis (not shown) controlling for background variables, we find that education is not significantly associated with work and that household wealth status is the strongest predictor of whether a woman is engaged in economic activity. This implies that the overarching determinant of employment in these rural communities is economic status; poverty is one of the driving reasons behind women engaging in economic activity.

Figure 4.14: Proportion of women engaged in economic activity, by education a and HH wealth

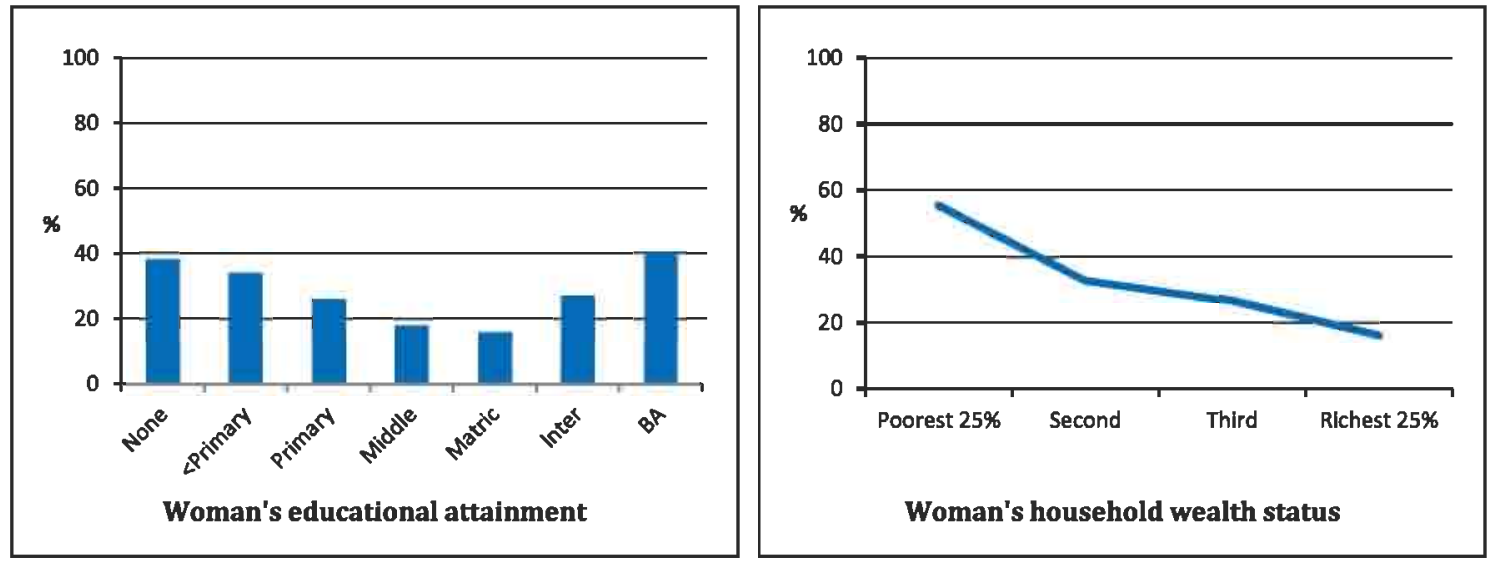

a Inter degree $=12$ years of schooling; BA degree $=14$ years of schooling.

This picture changes when we control for the type of economic activity women are engaged in. Among those who reported working, 46 percent were engaged in agricultural work, which is typically unpaid and does not require much education. If we look at just the proportions engaged in non-agricultural economic activity, we find that the relationship 
between education and work changes. Overall, 17 percent of our sample is engaged in non-agricultural economic work (Figure 4.15 left). Women with no education have the lowest rates of non-agricultural employment (13 percent), while the rate is highest for women with higher education (23 percent for inter degree holders and 40 percent for BA degree holders). The rise in off-farm work rates at the less-than-primary and primary levels is because most of the women who do stitching/embroidery work are from these educational backgrounds.

Figure 4.15: Proportion of women engaged in non-agricultural work and type of work, by education
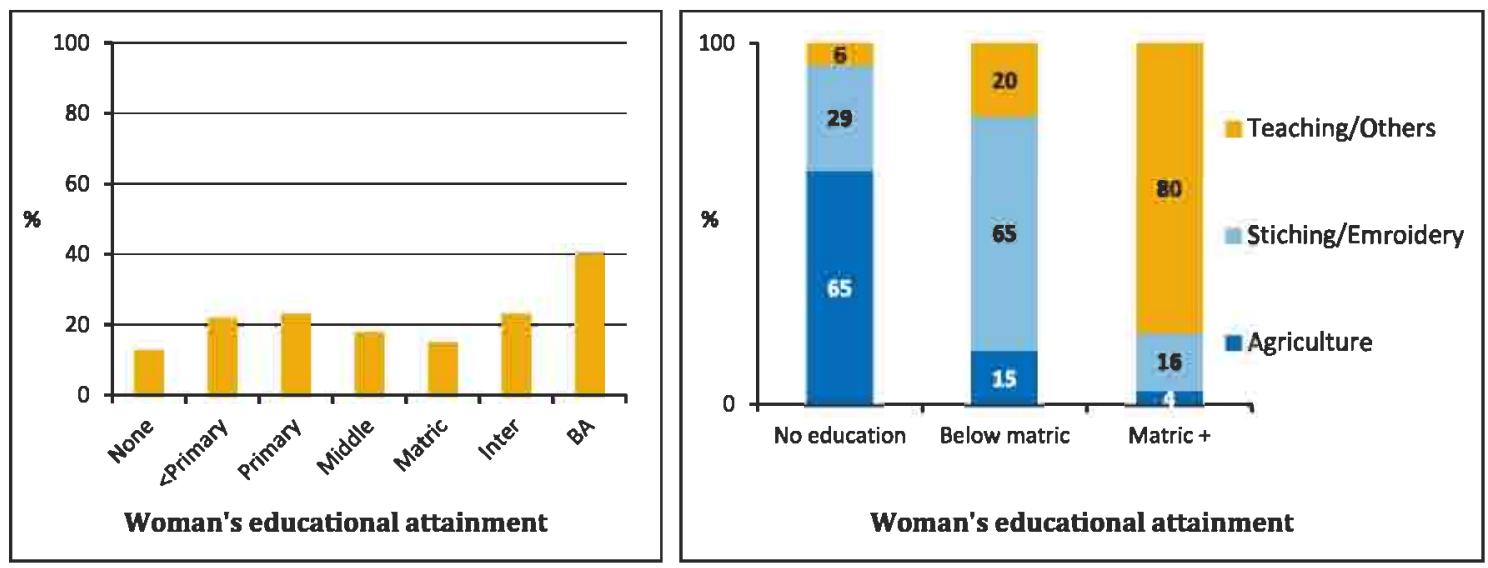

Results of regression analysis show that for non-agricultural work, wealth does not have a significant negative effect, except for the wealthiest quartile. Moreover, education has a strong positive correlation with the probability of being engaged in off-farm work - a middle or higher level education increased the odds of off-farm work by 70 percent, and a matric or higher degree increases it twofold.

There are other factors that are strongly associated with women's work: whether women have previously received vocational training and the overall employment opportunity structure of the community they belong to. In our sample, around 15 percent of all women had received vocational training. The majority of these women had received vocational training for stitching, embroidery, dressmaking, or knitting. Given that a large proportion of women in non-agricultural work (66 percent) in our sample are engaged in stitching/embroidery, it is not surprising that having received vocational training (which was mostly for stitching and embroidery) has such a strong association with nonagricultural work (Table 4.3). 
Whether a woman engages in off-farm work or not depends largely on whether there are off-farm opportunities available for her to avail. The potential avenues of employment in our rural setting include the lady health worker (LHW) program, teaching, working at a home-based factory, or being self-employed (typically stitching/embroidery work). In fact, the importance of LHWs and teachers residing in the community can be seen by differentials in non-agricultural work. The proportion engaged in off-farm work increased from ten percent in communities with no LHW, to 18 percent for communities that had a local LHW. Similarly, the proportion in off-farm work doubled from 12 percent in communities with 0-2 female teachers, to 24 percent for those communities with more than ten teachers.

Table 4.3: Proportion of women working in non-agricultural jobs, by personal and community characteristics

\begin{tabular}{|c|c|c|c|c|c|c|c|}
\hline & \multirow{2}{*}{\multicolumn{2}{|c|}{$\begin{array}{c}\text { Personal } \\
\text { characteristic } \\
\text { Vocational training }\end{array}$}} & \multicolumn{5}{|c|}{ Community characteristic } \\
\hline & & & \multicolumn{2}{|c|}{ Opportunity ranking } & \multicolumn{3}{|c|}{ Community development score } \\
\hline & No & Yes & $\begin{array}{c}\text { Low } \\
(0-4)\end{array}$ & $\begin{array}{l}\text { High } \\
(5-8)\end{array}$ & $\begin{array}{l}\text { Low } \\
(0-3)\end{array}$ & $\begin{array}{c}\text { Medium } \\
(4-7)\end{array}$ & $\begin{array}{c}\text { High } \\
\text { (8-11) }\end{array}$ \\
\hline Percent & 13 & 42 & 11 & 23 & 14 & 14 & 22 \\
\hline
\end{tabular}

Note: Community opportunity ranking is an index created as a proxy measure for female work opportunities. It is based on the following five questions (given equal weight) from the community questionnaire: 1. Presence of LHW; 2. Presence of vocational training center for young girls; 3. Presence of a home-based factory; 4. Female employment opportunities; 5. Resident female teachers.

To measure the opportunity structure of a community, we built an index that included whether there was an LHW presently residing in the community, whether there were female teachers residing in the community, whether there was a vocational training institute or a home-based factory inside the community, and whether the community members themselves perceived the existence of any opportunities. The importance of these factors can be seen in the differentials in proportions of women engaged in off-farm work by the opportunity structure of the community they belong to (Table 4.3); the proportions engaged in non-agricultural work double for women residing in communities with high opportunity structure than women in communities with poor opportunities.

Other characteristics such as the presence of a road network, electricity, etc., facilitate work. We saw these relationships play out in our sample with a higher proportion of women from communities with a high development score engaged in non-agricultural work than those from less developed communities. Regression analysis shows that of all the explanatory variables discussed above, vocational training has the strongest 
correlation with off-farm work, followed by the opportunity structure of the community the woman belongs to, followed by her educational attainment.

\section{Desire to work}

Education's association with employment may be weak in rural areas because of a lack of opportunities, but that is not the case with the desire to work (Figure 4.16). As the level of educational attainment increases, so does the proportion of women stating a desire to engage in economic activity. Thirty percent of women with no education express a desire to work, compared to almost 50 percent of those with ten or more years of schooling. Moreover, almost all women with higher education express the desire to take up employment outside the home.

Figure 4.16: Desire to work and desire to work outside home, by education and HH wealth

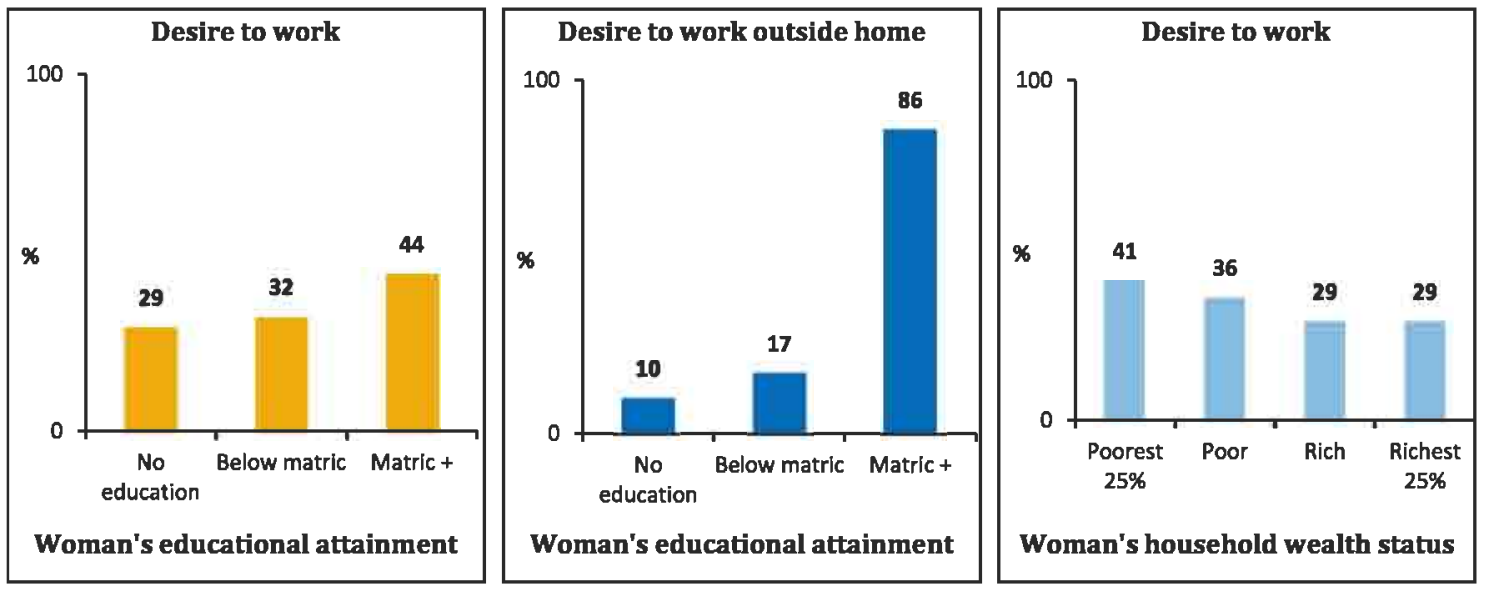

The correlation of income with desire to work is negative (even when controlling for other factors), indicating, once again, that employment-seeking behavior also remains povertydriven in these rural areas. Younger women have a higher desire to work as do those women who have received vocational training. Community-level variables such as the opportunity structure for female employment or the level of development in the community have no significant effect on desire to work.

\section{Decision to work and control over earnings}

The positive association of schooling with economic activity extends beyond desire and opportunity to work, to other factors (for example, who makes the decision to work and who controls the earnings]. Our sample shows that years of schooling is positively correlated with both factors (Figure 4.17). Women with ten or more years of schooling have greater control over both the decision to work and their earnings than their uneducated counterparts. 
Figure 4.17: Proportion of women who made decisions to work and those who can keep salary, by education
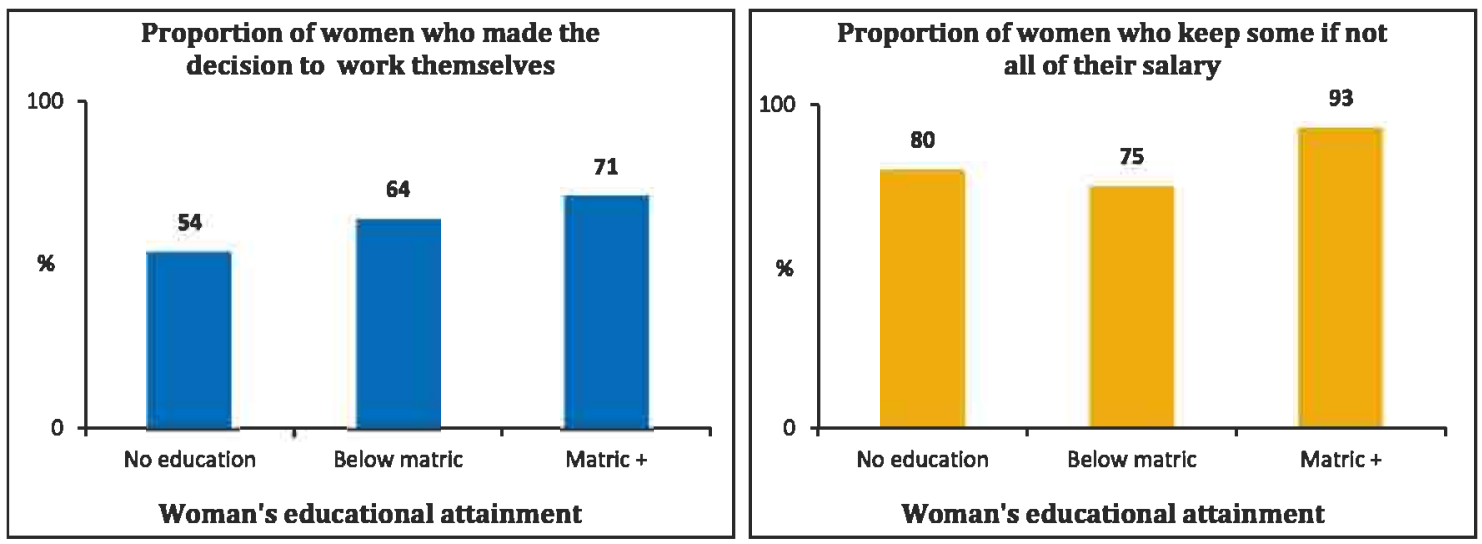

\section{F. Conclusion}

Similar to national results, we found that a girl's level of schooling is one of the strongest predictors of the age at which she will marry and of how much autonomy she will have within her new home. For timing of marriage, we find that in our rural sample, even primary schooling delays marriage by a significant amount of time. For greater autonomy within marriage, the real change is seen beyond middle-level schooling (eight years). However, education has limited association with choice of partner, which remains largely outside the control of women due to the high prevalence of cousin/consanguineous marriages in rural Pakistan.

Since childbearing in Pakistan takes place within marriage and first birth intervals remain short, education impacts age of childbearing through its effect on timing of marriage. Additionally, women's years of schooling have direct and positive associations with pregnancy care, smaller family size, fertility control practices, and greater decisionmaking regarding childbearing. For most aspects of childbearing, eight or more years of schooling make the real difference, although change can be seen at the primary level for contraceptive behavior and decision-making as well.

The relationship between economic work and education seen in national surveys also holds true for our rural sample. Women's work in these rural communities is primarily concentrated in the agricultural sector and driven by poverty. Education's association with economic work only emerges when looking at off-farm work; there is a positive correlation between years of schooling and being engaged in non-agricultural work, particularly at high levels of education. Moreover, women's education increases the desire to work even among women from wealthier households. 
The real change in employment opportunities and desires is seen with more than ten years of schooling. Not only does significant improvement in off-farm employment only kick in at this point, but there also need to be off-farm employment opportunities for women to convert desire and ability into actual work. We found the female employment opportunity structure of the community to be a stronger predictor of female engagement in non-agricultural work than educational attainment of women.

The strong influence of community-level variables is not just limited to economic work outcomes. The results of our analysis show that the schooling environment of the community in which young women reside also impacts their other life outcomes. Women who live in communities with a larger number of primary-plus schools or a higher proportion of girls attending school, have higher decision-making roles in their natal ffor unmarried women] and marital homes. This positive correlation exists beyond women's own educational attainment.

The effect of schooling environment is perhaps the strongest for outcomes related to childbearing. Women's ideal family size is strongly correlated with the schooling environment of their community, with women residing in communities with richer schooling environments (more schools) wanting to have fewer children than those residing in communities with poor schooling environments. This influence extends from ideals to practices as well. Women residing in areas with relatively high schooling levels, particularly for girls, are much more likely to be practicing contraception as well. Thus, we find that girls' schooling not only impacts the life outcomes of girls themselves, but also of women and families in the community.

Our findings show that education impacts young women's lives through both direct and indirect channels. We are able to see some of the avenues of influence of women's own educational attainment as well as of the level of education and development in the community they reside in on achieving important life outcomes. For certain markers of transitions to adulthood, such as the timing of marriage, contraceptive adoption and the desire to work, it is the young women's own educational attainment that has the strongest influence. For other outcomes such as autonomy within marriage and desired family size, the schooling environment plays just as important, if not more, a role. Yet some aspects of a young rural woman's life still remain largely outside the influence of her own or her community's schooling level. Whom she marries and the transactions around her 
marriage are largely determined by factors more to do with cultural practices than education. And while her own education open new avenues of work, whether she actually participates in economic activity outside her home depends on the opportunities in the community.

Finally, what do these findings tell us about incentives to school girls? Economic support, as an incentive to educate girls, both for the parents and the girls themselves, is dependent largely on the availability of employment opportunities. Where these opportunities exist, the economic benefits of schooling (via paid work) are greater than where they do not exist. Greater status in marriage, better reproductive health outcomes, and better prospects for future generations as incentives for schooling girls, all hold true for rural households. But girls need to remain in school beyond the primary level to truly realize these incentives.

When it comes to addressing the low school attendance of girls, our findings have obvious policy and programmatic implications. Addressing demand-side issues (lack of incentives to school girls) alongside efforts to improve the supply of education, is imperative. In communities with weak demand for girls' schooling, special efforts need to be made to enhance economic opportunities for young women. Additionally, ensuring that girls progress from primary to secondary school through provision of easily accessible and quality secondary schools, is also critical for translating the benefits of schooling into reality; non-economic incentives for educating girls really come to play with a secondary education.

Our survey demonstrates ideational change in family size taking place in communities with better schooling environments. Investing in the schooling environment of communities will not only impact reproductive health outcomes for young girls' transitioning to adulthood, but will also impact reproductive experiences of older women as well. The strong impact that women's education has on their own health outcomes is hard to translate into immediate policy and intervention since most of these women are now too old to increase their educational attainment. But the strong impact of the communities' children's education on these women's outcomes can be. Investing in education outcomes of the community, particularly by focusing on retention in secondary school, has immediate and long-term impact on women's reproductive health. 


\section{EVALUATING PROGRAMS: WHAT WORKED AND WHY IN GIRLS' EDUCATION IN PAKISTAN*}

From time to time, there have been a number of schemes to increase access, equity, and retention of students, particularly girls, to overcome inadequacy of resources, and to overcome socio-cultural barriers towards girl's education. Initiatives by the government, donors, and/or civil society have been undertaken both on the supply-side (free schooling, school construction) and demand-side (feeding programs, scholarships, physical facilities, female teachers, flexible timings). The primary goal of most of these initiatives has been to increase girl's enrollment in formal schooling, typically by reducing costs on the demandside and increasing access on the supply-side. Yet the gap remains substantial in terms of the unmet educational needs of adolescent girls and of program effectiveness.

The reasons for these shortfalls have been examined in studies which point to unrealistic targets; ineffective and inconsistent strategies; failure to allocate adequate resources to meet targets and to use funds effectively; expectations of the private sector and communities to establish schools in disadvantaged communities where cost-sharing is beyond the resources of families; non-availability of comprehensive and reliable statistics for planning; and lack of political will (Khalid and Mukhtar 2002). It is imperative to review what programs have actually worked and why and what the lessons learnt, are. Some lessons from experiences with programs to support girls' schooling can be gleaned from commissioned program reviews and other third-party/external evaluations. Some of the projects have been successful and have emerged as regular programs. Others have been successful, but phased out with project closure, and yet there are some that could not make any impact even during the project period.

The high social and private returns of female education (better family health care, slower population growth, boost in economic productivity, earning capacity, decision-making, etc.) put a responsibility on program designers and implementers to overcome the handicaps of illiteracy and lack of education.

This chapter is based on the findings from an extensive review of the literature available on the different programs on girls' education. The objective of this review was to analyze the success of the key initiatives undertaken by policymakers, development practitioners,

\footnotetext{
" The program evaluation (this chapter) was commissioned to the Society for the Advancement of Education (SAHE). Authors include Fareeha Zafar, Hina Shaikh, and Salaeya Butt.
} 
governments, and donors and civil society organizations to develop sustainable future strategies to overcome barriers to girls' education in Pakistan.

\section{A. Barriers to girls' education}

It is important to look at the barriers to girls' schooling before delving into reviewing what strategies have worked. A list of the factors that affect girls' schooling in Pakistan are given below:

Table 3.1: Factors affecting girls' education

\begin{tabular}{|c|c|}
\hline In-school factors & Out of school factors \\
\hline Low starting base of female enrollment & Widespread poverty \\
\hline Poor physical facilities & High population growth rate \\
\hline Lack of qualified female teachers & $\begin{array}{l}\text { Socio-cultural barriers, bias against female } \\
\text { education }\end{array}$ \\
\hline $\begin{array}{l}\text { Unattractive service conditions in rural } \\
\text { areas for female teachers }\end{array}$ & $\begin{array}{l}\text { Lack of parental interest to educate girls, } \\
\text { particularly in rural areas }\end{array}$ \\
\hline Absenteeism amongst teachers & Difficulty in recruiting female teachers \\
\hline Inadequate learning materials & Inadequate school-community interaction \\
\hline Irrelevant and overloaded curricula & Lack of incentives for parents to send girls to school \\
\hline Rigid timetables/school schedules & Lack of incentives for teachers \\
\hline
\end{tabular}

Limited availability of schools for girls

Source: (UNESCO 2000) ${ }^{10}$

Generally, these barriers can be divided into two categories. On the supply-side, a lack of schools, inadequate infrastructure, a lack or absence of female teachers, and poor quality of teaching. On the demand side, poverty, parents' education, and a variety of sociocultural factors are the major barriers to girls' enrollment, attendance, and retention in schools.

School supply barrier: According to the Pakistan Ministry of Education, 43.8 percent of schools are for boys, 31.5 percent are for girls, and the remaining 24.7 percentage have mixed enrollment. Hence, Pakistan has fewer schools for girls than for boys. In addition, a majority of Pakistani villages do not have middle/high schools for boys or girls.

${ }^{10}$ Adapted from a number of national and provincial studies 
Proximity to schools and infrastructure in rural areas: Following from this, one of the main constraints to expanding girls' schooling in Pakistan is a lack of proximity to schools (World Bank 2005).

Lack of trained female teachers: Even where feasible, the construction of new schools is likely to face another important constraint: few educated women. Government schools for girls require female teachers, but mobility prevents educated women from relocating or commuting to where the jobs are.

Social and cultural constraints: Social and cultural constraints such as those on female mobility are not likely to yield to short-run policy levers. The creation of a group of educated women in every village may be a viable policy intervention. Marriage, residence, and migration patterns have suggested that educated girls frequently remain in the villages they come from; this constitutes a potential pool of future teachers for the next generation (World Bank 2005).

\section{B. Government priorities: delayed agenda for girls?}

The above stated barriers still persist despite the fact that the GoP has launched a number of initiatives since 1990 to improve access to, and provision of girls' education. A timeline for the last 40 years has been developed below to consider policy shifts: 
Table 5.2: Policy shifts in education over the last four decades

\begin{tabular}{ll}
\hline Timeline & Policy shifts: national and international \\
\hline \hline 1970s & Nationalization for equity, focus on basic education for rural girls \\
& Shift in thinking and lending for education (1975) \\
& UNESCO non-formal education alternatives \\
& 1979 National Education Policy: Islamization of education (SAP) \\
& Denationalization \\
& Privatization of education and non-formal education, especially for girls \\
\hline 1980s & Increased access with community participation \\
& Privatization of education \\
& EFA with gender focus \\
& Basic learning needs linked to Universal Declaration of Human Rights \\
& Provision of female teachers and infrastructure in rural areas \\
& Access for girls: education in disadvantaged areas \\
& Fourth UN Conference on Women (Beijing, September 1995) \\
& Opportunities for female vocational and technical education \\
& Availability of gender disaggregated data \\
Gender focus and middle-schools for girls \\
World Food Program to increase girls enrollment and retention \\
Access and quality of education, community ownership \\
EFA - Dakar Framework \\
MDGs \\
Access, equity, and quality issues addressed through financial support in \\
form of stipends, voucher schemes, provision of more female teachers, etc. \\
Privatization in education pushed by WB \\
Gender parity and meeting MDGs (2007) \\
Public-private partnerships in education (2009) \\
\\
\hline \hline 2000s
\end{tabular}

\section{Programs in girls' schooling in Pakistan}

Based on a review of available documentation of key program strategies that have been used, we have compiled a list of past intervention/programs, the years they were in operation, and the central theme(s) of their efforts, to change girls' schooling in Pakistan (Table 5.3). 
Table 5.3: Past interventions in girls' education

\begin{tabular}{|c|c|c|}
\hline Program/intervention & Year(s) & Theme \\
\hline $\begin{array}{l}\text { Allama Iqbal Open University (AIOU) Non-formal } \\
\text { education programs }\end{array}$ & 1974 to date & - Access \\
\hline $\begin{array}{l}\text { Asian Development Bank's (ADB) Primary Education } \\
\text { Girls' Sector Project }\end{array}$ & 1989-1996 & - Access • Quality \\
\hline Baluchistan Primary Education Project (BPEP) & 1993-1997 & - Access \\
\hline Bunyad Literacy Community Council & 1994 & - Access \\
\hline $\begin{array}{l}\text { Cooperation for Advancement, Rehabilitation, and } \\
\text { Education }\end{array}$ & 1991 to date & - Access \\
\hline Developments in Literacy in Pakistan & 1997 to date & - Access \\
\hline Fellowship program (Baluchistan, then Sindh) & 1994-1998 & - Access \\
\hline Girls Primary Education Development Project & $1998-2005$ & - Access • Quality \\
\hline Indus Resource Center & 1999-present & - Access • Quality • Advocacy \\
\hline Khuwendo Kor & 1993-present & - Access \\
\hline Northern Areas Education Project & 1998-2003 & $\begin{array}{l}\text { - Access - Quality } \\
\text { - Institutional strengthening }\end{array}$ \\
\hline NWFP Teacher Training Program & 1996 & - Access • Quality \\
\hline Oxfam's Girls' Education Program & 2009-2014 & - Access • Quality • Advocacy \\
\hline Pakistan Literacy Commission & 1995 & - Access \\
\hline Punjab Middle-School Project (PMSP) & 1994-2000 & $\begin{array}{l}\text { - Access • Quality } \\
\text { - Institutional strengthening }\end{array}$ \\
\hline SAHE's Community-Based School Program (CBSP) & 1996-2012 & - Access • Quality \\
\hline Social Action Program (SAP I and II) & 1993-2002 & - Access • Quality \\
\hline Tawana Pakistan & 2002-2006 & - Access $\bullet$ Health \\
\hline The Citizen's Foundation & 1995-present & - Access \\
\hline The Punjab Education Voucher Scheme & $2006-2009$ & - Access \\
\hline USAID Primary Education Development Program & 1989 & - Access • Quality \\
\hline World Bank Stipend Program & 2004-present & - Access \\
\hline World Food Program - Food For Education Program & 1995 & - Access • Retention \\
\hline
\end{tabular}

Several organizations and practitioners have attempted to document key strategies that have worked. Based on the document review, the following section discusses some of the principal approaches, in view of recent experience, that can be successful in promoting girls' education in developing countries like Pakistan. 


\section{Key strategies that work to promote girls' education}

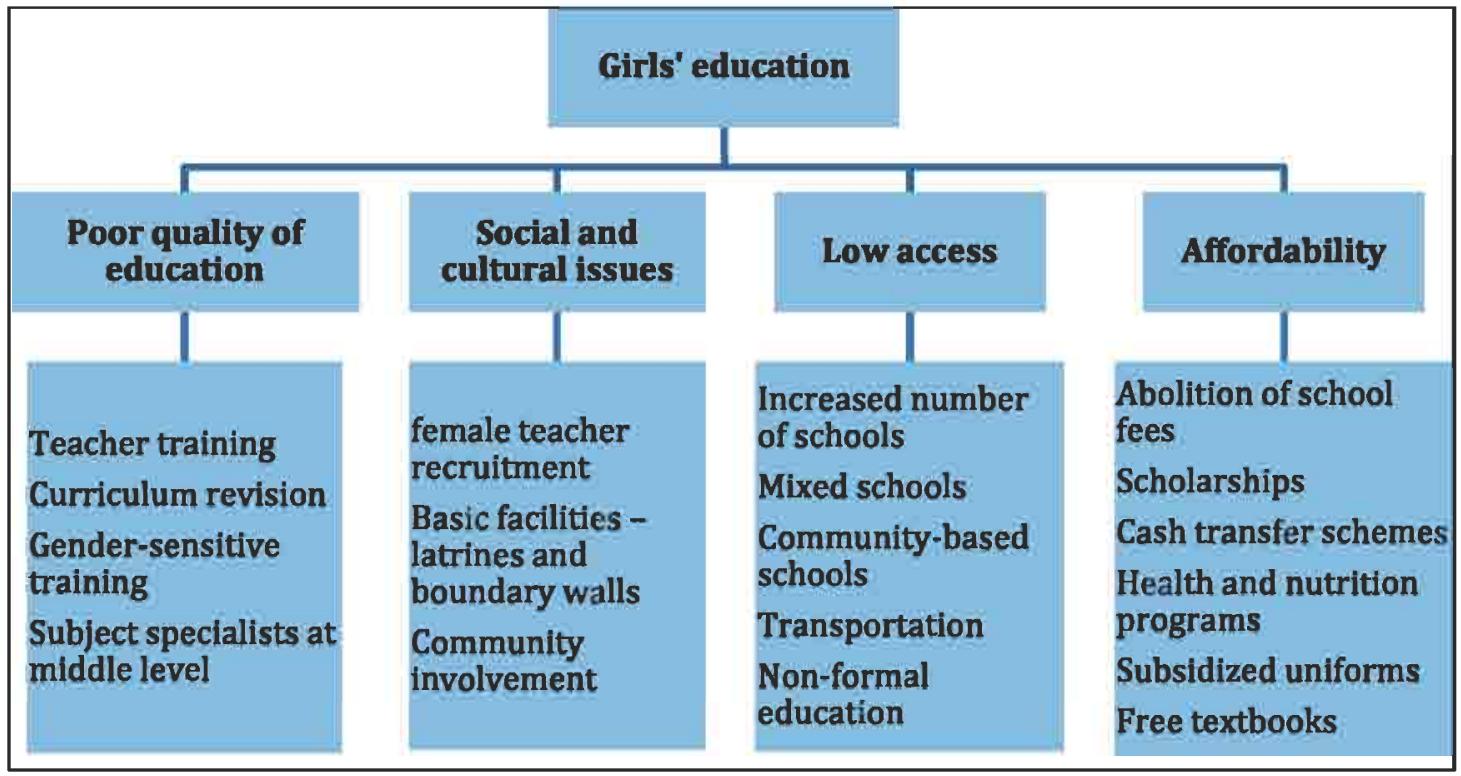

\section{Increasing access}

Increasing access to schools is the key strategy to increasing opportunities for girls' education. Research and program experience have suggested that building decent schools nearby are often enough to bring most girls into school.

Building schools close to girls' homes boosts enrollments: Research in Pakistan shows that distance matters for all children, and often especially for girls (Andrabi et al. 2007). In parts of Pakistan, girls are simply not allowed to attend distant schools.

Mixed schools at primary level: Since it is probably not practical or possible to place public primary schools and middle or high schools in every rural community, policymakers should consider cost-effective alternatives that compensate for the constraint of distance. The Social Action Program (SAP) adopted by the GoP in 1993 encouraged mixed primary schools and a 60:40 ratio has been decided in favor of girls in new school construction. Indeed, co-educational private primary schools' tendency to attract young girls shows that parents are not averse to sending girls to co-educational schools at the primary school level. Similar strategies can be used by government schools.

Middle-schools: Other than increasing access to primary schools for girls, it is important to build middle-schools as well to continue the education cycle. Middle-school projects such as the Community Model School project for girls (1994-99) which constructed schools staffed with a head teacher and five teachers for outreach by the ADB, and the Punjab 
Middle-School Project (1992), that focused on middle-schools for girls, teacher training in gender, and gender-related learning materials supported by the Department for International Development (DFID), had a substantial impact. Under the Education Support Program in Punjab, the Middle-School Stipend Initiative (2004) has been successful in increasing enrollment and retaining girls. It has consequently been scaled-up to the high school level, as well.

Addressing the mobility constraints of female teachers and girls: Another alternative to increasing access can be by providing mobility allowances or transport facilities, and by hiring local teachers and creating a pool of qualified teachers within easy reach of communities. The cluster approach for continuous teacher training can also help in reducing distance and training costs. The NWFP Teacher Training Program (1996) used this approach with regular visits by district officers.

Flexible schedules: Providing flexible schedules can also help in enrolling girls. In general, offering flexible schedules in both regular and informal schools helps boost enrollments by accommodating children's work, making it easier for children to care for younger siblings, do chores, or even work for wages while enrolled in school.

\section{Make schooling affordable}

Building schools will be of little help if children are not able to afford schooling or the various costs associated with it. The fastest and most direct way for governments to boost school enrollments is to reduce the direct, indirect, and opportunity costs to parents of educating their daughters. The Middle-School Stipend Initiative is one such initiative taken by the GoP.

Reducing direct costs: Direct costs can be reduced by cutting school fees which will, as experience has shown, automatically increase girls' enrollment. Providing subsidies leads to a guaranteed increase in enrollment. Examples such as the Punjab Education Foundation and Sindh Education Foundation's FAS initiative have been very successful and are being scaled-up, now. There is no direct evidence of the impact of other cash transfer schemes such the Benazir Income Support Fund on education, yet.

Covering direct and indirect costs and easing management procedures: Offering scholarships and stipends can be one way of achieving this. Since many parents find costs higher for girls because of practical concerns about girls' safety and lost household chore 
time, scholarships have proved particularly important for girls in varied settings including Pakistan, Bangladesh, Kenya, and Mexico (Herz and Sperling 2004). For the Sindh Primary Education Development Program (SPEDP), (1990), progress was minimal due to complicated banking procedures that made access to scholarships difficult. For similar reasons, a fellowship program (1994-1998) was successful only in urban Baluchistan and Sindh. Therefore, it is very important that sustainable methods be devised for resource constraints, specifically in rural areas.

School-based health and nutrition programs: These also cover indirect costs and may increase attendance. Research also suggests that programs that reduce the cost of schooling by providing supplies such as textbooks and uniforms or programs that offer meals or school-based health care, can have significant impacts, especially for girls. One such successful project was the Food for Education Program (1995) by the World Food Program. The National Commission for Human Development's (NCHD) set up for basic primary education and health provision in 2002 and the Tawana Pakistan (2002-06) nutrition program for girls linking school and community, have both resulted in increasing enrollment.

\section{Community support}

Providing a basic school nearby with some additional financial support through books or transportation, is an important first step to increasing girls' enrollment. Evidence particularly from South Asia and Africa, including areas where hardly any girls have attended school, shows that community-based approaches can sharply boost girls' enrollment and achievement in just a few years (Herz and Sperling 2004). Successful approaches include explicit agreements within the community to educate girls and boys, community influence over teacher selection and school operations, and genuine partnerships between communities and the federal government. Often, local NGOs help organize such community participation, and PTA-type organizations at schools may be established.

Safety policies and codes of conduct: These should be developed for each school in line with cultural requirements. In some cases however, cultural requirements for privacy must also be respected. These may entail separate schools for girls, separate hours for girls in schools shared with boys, boundary walls for girls' schools, female teachers, etc. Private latrine facilities are essential in this context. Such efforts are critical not only for 
increasing enrollments, but also for achieving gender parity in primary education. Involving communities has emerged as the best way to find out what matters most to parents and how to proceed.

Provide female teachers for girls in all subjects: In some areas, particularly where girls and women are isolated within communities, solving this problem requires hiring more women teachers. However, it can be difficult to find sufficient numbers of qualified women especially in rural areas where most women have little education. Urban women with more education (or their husbands) will often not move to rural areas to work. Therefore, intensive teacher training can be planned for rural areas with regular follow-ups. The Girls' Primary Education Project (1991-96) was aimed at providing female teachers and infrastructure to rural schools. The Education Support Program has now relaxed the condition for age and qualification requirements to maintain a stable flow of teachers, and special monetary incentives have been designed to attract and retain them. In addition, community schools that provide child-care support may be particularly successful at increasing girls' enrollment.

Advocacy for community engagement for public schooling: Although community-based approaches offer great promise, there are also risks. While the Government tries to involve communities in shouldering the main burden of schooling children, communities may lack the resources to do the job. Issues of curriculum content may arise and tensions may build between Government, NGOs, and communities. Finding ways to address these risks, increasing community participation, and strengthening the public education system are key to forging a credible compact between parents, teachers, NGOs, and the Government. The Baluchistan Primary Education Project (BPEP) (1993-1997) for girls was able to increase access and enrollment with higher promotion and completion rates at different levels because of the importance given to community involvement in schoolrelated issues during the project.

\section{Focus on the quality of education}

Focusing on what children learn at school is as important as access, affordability, and role of community. Where parents are more ambivalent about educating girls, improvements in education quality may be particularly important to tip their decisions to educate daughters as well as sons. 
Teacher absenteeism: As a first step, to function effectively, any school needs enough qualified teachers who attend school regularly.

Curriculum review: What children learn also matters. Schools are more effective at attracting girls if they teach curricula that equip children for the $21^{\text {st }}$ century and if they have the requisite books and learning materials. There is thus a need to improve teachers' education and training levels, especially in new child-friendly teaching methodologies. It is also important to bring about a change in their attitudes and behavior, with a focus on mathematics and science.

Teaching in ways that discourage gender stereotypes and encourage girls to achieve: It can be expensive to change textbooks to reduce gender stereotyping, but it is certainly important that it happen. It is also important to train teachers to discourage gender stereotyping. Although research on the impact of specific programs is scarce, such efforts are underway in a number of countries and should be explored and analyzed more intensively. Fortunately, many of these can be accomplished at relatively little cost. The Northern Areas Education Project (1996) supported by DFID had a gender component for management and teacher training, and developed new gender sensitive textbooks.

\section{E. Conclusion and the way forward}

There have been some improvements in the last 20 years, but the underlying factors still make the current education system inefficient. Actually including girls in the state educational system cannot be ensured in a context where the education system suffers from fundamental structural problems such as inadequate funding, a project-based instead of sector-wide approach to educational policy planning, the political rather than merit-based appointment of teachers, and a lack of political will. Addressing these challenges requires prioritizing education sector reforms, increasing budgetary allocations to the sector, making state schools geographically accessible, and exploring options to extend community-based primary education models.

The question that launched this study was essentially "what evidence do we have on strategies for improving girls' participation in education?" Thus, when evaluating interventions, apart from assessing the best ways to get girls to complete a basic education, it is imperative to understand the critical features of approaches that lead to sustainable outcomes. It is also important to systematically evaluate current programs for girls' education and use the lessons learnt for future planning to achieve targets. Through 
the World Bank Middle-School Stipend Program, female enrollment in Government primary and middle-schools increased, and female dropout rates decreased. It is important to focuses on sustainable outcomes; therefore conditional cash transfers are more beneficial than providing cash directly to families.

Having said this, there are now new challenges and opportunities facing girls' education that will increase the value of and need for clearer evidence on how to proceed. Educating and keeping girls in school, providing necessary conditions for learning, and relating the school experience to economic and cultural success outside the school requires holistic approaches and general support for education systems as a whole; individual girls' strategies cannot make up for weak systems and a lack of commitment. In case of the Tawana program, synergies gained by dealing with nutrition, education, and empowerment issues simultaneously, helped increased enrollment by 40 percent. Also in the case of the Punjab Education Voucher Scheme (2006-09) that provided free quality education and equal access to girls, the parents had the right to choose, and then acquired bargaining power over the school administrators which resulted in a source of competition among private schools seeking to join the program. Such approaches that involve key stakeholders are successful.

Ultimately, even with ironclad evidence of the success of various strategies, one thing is certain: there is no easy road. Project design should be made sustainable and should have the potential for scaling-up, replicability with a transition plan, and a timeline for stable funding and budgeting. Institutional arrangements for implementation with an implementation body and monitoring and evaluation systems to gauge impact against certain success factors, are key for success. Public- private partnerships and community involvement can play a significant role. Civil society initiatives have been successful due to regular school supervision and monitoring. In addition to having political will, catalyzed and sustained grass-roots demand is probably the key to sustaining investments in girls' schooling and sustaining outcomes for girls' education. 



\section{SUMMARY AND CONCLUSIONS}

This report aims to inform policymakers, donors, civil society, program/intervention professionals, evaluators, and researchers, on girls' schooling in Pakistan. In order to create a document useful for such a wide audience, we addressed a few key aspects of girls' schooling. We used a combination of secondary data analysis, primary data collection and analysis, and a desk review of programs, policies, and interventions in girls' schooling to shed more light on some important questions discussed below.

\section{A. Summary}

\section{What is the status of girls' education in Pakistan right now? How far have we come over the last two decades?}

With the MDG deadline for achieving universal primary education fast approaching, Pakistan has the increasingly challenging task of increasing primary NERs by more than 40 percentage points, over a period of four years. To put this goal into perspective, we looked at how far Pakistan has come in moving towards universal primary schooling in the last two decades.

In the 1990s, there was no improvement in primary enrollment rates. At the turn of the century, however, Pakistan finally began to make progress: primary NERs increased by 15 percentage points in the last ten years. Much of the increase in primary NERs occurred between 2001 and 2006, a time period when girls' primary enrollment increased from 38 to 48 percent. Private school enrollment accounted for most of the improvements in overall enrollment.

Unfortunately, the rise in primary enrollment (particularly in private schools) slowed down in the next five years. Between the last two rounds of the PSLMS (2008/09 and 2010/11), there has been hardly any change in enrollment statistics - only 53 percent of all girls aged five to nine are enrolled in primary school. Rural enrollment continues to lag behind urban enrollment, particularly for girls. At 48 percent, rural girls have lower primary NERs than urban girls or rural boys.

The situation does offer some hope. The multitude of education policies and plans in the 1990s that heavily prioritized girls' schooling, usually said to have been ineffectively implemented, did bear some fruit. When we look at trends over time, much of the improvement in schooling outcomes (particularly at the primary level) took place after 
these policies were put in place, and seems to have been more directed toward girls than boys. In fact, girls have caught up to boys in urban areas in both primary and secondary education.

Despite these improvements, however, universal primary education is still a long way away for all girls, and much more is needed to increase the education rates for Pakistani girls, particularly the majority who reside in rural areas, in the near future.

As expected, the status of secondary education is much worse, if not abysmal. Although secondary enrollment rates for girls have been increasing since the mid 1990s (unlike enrollment rates for boys, which declined in the 1990s) and girls are catching up with boys, this increase has been very slow, and less than a third (29 percent) of girls aged $10-$ 14 years are enrolled in secondary school in 2011. Rural areas have much lower secondary education than urban areas, and again, rural girls are the most disadvantaged with only 22 percent enrolled in secondary school.

\section{Where are the pockets that are lagging behind and need immediate attention?}

Several interesting patterns and issues emerged in the trend analysis of enrollment rates at the provincial level. Not surprisingly, Punjab fares better than the other provinces; it has the highest enrollment rates for girls and has experienced the most progress over the years. Both KP and Sindh continue to lag behind Punjab. In Sindh, the difference between urban and rural enrollments is stark, in KP, urban-rural differentials for girls are relatively small, but the gender gap in enrollments is high for both rural and urban areas. Provincial patterns for secondary education are similar to those for primary education.

There have been major increases in private schooling in urban areas, particularly in Punjab where parents have greater choices about whether to send children to private or public schools. In urban areas, the proportion of girls enrolled in a private primary school (of total enrolled) has increased from 47 to 57 percent over the last 15 years. In rural areas, although the absolute level is lower, the increase has been greater: at present, one in every four girls in primary school attends a private institution, whereas in 1995, this ratio was one in ten girls.

When it comes to choosing the type of education, availability and affordability are the strongest determinants in sending children to private schools. In both urban and rural areas, there are no gender differences in the proportion enrolled in private schools; the 
real difference is across income groups, even in urban areas with high availability of private schools: 61 percent of girls enrolled in primary school from non-poor households attend private school, compared to only 22 percent of girls from poor households. Despite hopes of low-fee private schools, a private education remains largely unaffordable for the poor and has a weaker presence in rural areas. Therefore, the GoP must continue providing education to disadvantaged population groups, namely poor girls living in remote rural areas.

Which factors are important in determining access to schooling? What aspect of the quality of schools is perceived to be important? How does poverty influence schooling outcomes for girls?

In order to understand what it will take to improve girls' schooling outcomes, one has to look at both supply and demand-side issues. We collected primary data to shed more light on both sides of the issue in the rural areas of Pakistan. Through our previous panel studies (from 1997 and 2004), we captured supply and demand for schooling in 12 communities in Punjab and KP, plus an additional four communities from Sindh because of the poor education statistics there. We looked at the current schooling environment in these 16 communities and how it has changed over time (for the 12 panel communities). We investigated the impact of community-level factors on household decisions to send girls to school in this wide variety of rural settings, both remote and near-urban. The 16 communities varied in development levels, ethnicity, and impact from the War on Terror, and the 2010 floods.

Access to schools for rural girls in the panel of 12 communities had clearly improved for primary and middle grades - expansion was dramatic between 2000 and 2005, and less so between 2005 and 2011. The mix of private and public schools varied by province and community. There was a much larger proliferation of private schools in Punjab, followed by $\mathrm{KP}$, and almost none in Sindh communities.

Except in areas disrupted by flooding or fighting, the increase in numbers of schools coincided with improved road access. Overall, distances are shorter everywhere, especially for private schools. Girls' schools used to be much further than boys' schools, but they are now comparable distances. Furthermore, middle plus-level schools are now closer than they were 15 years ago. This is expected to have a notable impact on 
enrollments as parents and communities can visibly see greater potential for their children continuing beyond the primary level with a middle-school or higher education.

The quality of schools has improved, but not dramatically. Private schools still fare better on most quality indicators. Poor infrastructure including water, toilets, and furniture, is much more characteristic of public schools. The absence of teachers is much more common in public schools, though their teachers have better qualifications and more experience.

Boys' schools generally fare better than girls' schools, and larger schools are much better off than schools that just have primary classes. Interestingly, half of the girls' schools in our sample of schools receive subsidies or support compared to less than a third of boys' schools, reflecting the clear policy towards support for girls' schooling.

The economic status of households is an overriding factor in school enrollments. The choice of a school is constrained, particularly for poorer households where private schools may not present a real choice. In fact, for girls, not going to school at all is a strong probability among the poorest families. When controlling for household economic standing, we find that access to schools (distance and numbers) has more of an influence on younger girls (aged 5-9 and 10-14) than on older girls (15-19 year olds). In contrast, 15-19 year old enrollments are much more responsive to quality of schools.

It appears that the youngest cohort of girls aged 5-9 years is benefitting from the increase in schooling more than older girls, particularly those aged 15-19 whose schooling opportunities in rural areas remain limited. While sending younger girls to school is becoming more of a norm, much more will be required to get older girls to school. Here, improving the limited opportunities for female employment can make a real difference, as can opportunities for vocational training.

Our research shows that access to numbers of schools, both in terms of numbers of schools available, and actual physical distance, are important determinants of girls' schooling at the primary level. Many new schools are likely to be private schools, and the tradeoff between private and public schooling is an emerging reality even in rural areas. The positive influences of policy are apparent in the improvement of public school access for girls. Private schooling increases are more a response to demand for more choice and 
the perception that private schooling offers higher quality, found mainly in more developed communities.

\section{What makes education relevant and valuable for parents, for society and for girls themselves as they enter adulthood?}

We also looked at the potential benefits of schooling for girls, considering the incentives for parents, societies, and girls themselves. We tested the strength of education's association with the three major transition periods in a girls' life to adulthood: transition to marriage, transition to motherhood, and transition to work.

Similar to national results, we found that a girl's level of schooling is one of the strongest predictors of the age at which she will marry and of how much autonomy she will have within her new home. For timing of marriage, we found that in our rural sample, even primary education makes a difference, delaying marriage by a significant amount of time. For greater autonomy within marriage, the real change occurs when she has beyond middle-level schooling (eight years plus). However, education has limited association with choice of partner, which remains largely outside the control of women due to the high prevalence of relative/kin marriages in rural Pakistan.

Women's education has a strong impact on the age at which women begin childbearing. The length of education impacts age of childbearing directly through its effect on timing of marriage. Additionally, women's years of schooling have direct and positive associations with pregnancy care, smaller family size, fertility control practices, and greater decisionmaking regarding childbearing. There is evidence that supports female education affecting outcomes for the next generation, which our findings support. For most aspects of childbearing, eight or more years of schooling make the real difference. However, change can be seen at the primary level for contraceptive behavior and decision-making, as well.

The relationship between economic work and education seen in national surveys also holds true for our rural sample. Women's work in these rural communities is primarily concentrated in the agricultural sector and is driven by poverty. Education's association with economic work only emerges when looking at off-farm work; there is a positive correlation between years of schooling and being engaged in non-agricultural work, particularly at high levels of education. While actual work levels are influenced by 
opportunities for employment, it is clear that women's education increases the desire to work even among women from wealthier households.

When it comes to employment opportunities and desires, the real impact was seen with more than ten years of schooling (beyond a matric degree). Not only does significant improvement in off-farm employment kick in after young women have had ten years of schooling, there also need to be off-farm employment opportunities for women to convert desire and ability to actual work. We found female employment opportunity structures of the community to be a stronger predictor of female engagement in non-agricultural work than their educational attainment. Having vocational training centers, LHWs or female teachers in the community (all indicators of opportunities and level of education in the community) also were strongly correlated with the proportion of women working in the community.

In addition to its strong effect on women's immediate work and marriage and reproductive behavior, the schooling environment-as depicted by the numbers and levels of schools available in the community-also has a strong community-level influence on prevailing attitudes. For example, women living in communities with a larger number of primary-plus schools or where a higher proportion of girls attend school, had higher decision-making roles in their natal (for unmarried women) and marital homes. This positive correlation persisted beyond women's own educational attainment.

A less expected effect was that young women's ideal family size is strongly correlated with the schooling environment of the community in which they reside. Women residing in communities with a richer schooling environment (more schools) want to have fewer children. This hints at young mothers beginning to invest more in fewer, but more educated children in areas where they see visible opportunities for children. Even more importantly, this influence extends from ideals to practices: women residing in areas with relatively high schooling levels, particularly for girls, are much more likely to be practicing contraception. Thus, we find that girls' schooling not only impacts the life outcomes of girls themselves, but also of women and families in the community.

In terms of avenues for change in the lives of young women, the foremost influence of individual schooling appears to take place in terms of timing of marriage and decisionmaking space within the home. Contraceptive use, antenatal care, and delivery care are outcomes that are influenced by individual female educational levels. Influences outside 
the home for educated girls in rural areas appear limited. But the potential to change more tenacious values, such as those linked to ideational family size and actually stepping outside the home to work, do depend on both individual schooling attainment and the community environment. This offers a new benefit of improving access and opportunities for girls' schooling beyond just raising girls' enrollments, as young women in the community also absorb values that are more supportive of future changes in fertility and other behavior.

\section{What key ingredients are most likely to make certain interventions more successful than others?}

Increasing girls' access to schools: Locating new schools close to girls' homes, having mixed schools at the primary level, addressing the mobility constraints of female teachers and girls through transport allowances or facilities, having flexible school timings or schedules so that young girls have time for other commitments, and ensuring that there is a middleschool available for girls. Successful programs include those of the Citizens Foundation (on-going) and the PMSP.

Making schools more affordable: Reducing direct costs through cuts in school fees, providing subsidies, offering scholarships and stipends, and covering indirect costs by providing supplies such as textbooks and uniforms or programs that offer meals or schoolbased health care. Successful programs include the Food for Education Program (1995) by the World Food Program and the Tawana Pakistan Nutrition Program (2002-06).

Ensuring community support: Successful community-based approaches include explicit agreements within the community to educate girls as well as boys, community influence over teacher selection and school operations, and genuine partnerships between communities and the federal Government. Successful programs include SAHE's Community-Based School Program (on-going) and the Baluchistan Primary Education Project (1993-1997).

Providing quality education: Taking measures to reduce teacher absenteeism, providing teacher training, and revising curriculum to be gender sensitive. Successful programs include the Northern Areas Education Project (1996).

\section{B. Conclusions}

When it comes to addressing the low school attendance of girls, our findings have obvious policy and programmatic implications. Some key ingredients for improving the schooling 
environment are to have a public girls' school with all levels up to the secondary level available within a short travelling distance. A minimal number of 3-4 primary and middleplus schools are probably sufficient for a community to increase girls' enrollments to 70 percent. However, income levels and affordability will remain an issue. For many poorer households, subsidies, scholarship, and conditional cash transfers may be effective in minimizing enrollment differentials by income. This will ultimately bode well for universal primary education. The presence of female teachers, textbooks, and toilets are also essential for higher enrollments.

Addressing demand-side issues (lack of incentives to school girls) alongside efforts to improve the supply of education, is imperative. In communities with weak demand for girls' schooling, special efforts need to be made to enhance economic opportunities for young women. Additionally, ensuring that girls progress from primary to secondary school through the provision of easily-accessible and quality secondary schools, is also critical for translating the benefits of schooling into reality; non-economic incentives for educating girls really come to play with a secondary education.

Our findings provide evidence that schooling affects change beyond that of the lives of children who are the immediate and direct beneficiaries of it. It changes values regarding ideal family size in communities with better schooling environments. Investing in the schooling environment of communities will not only impact reproductive health outcomes for young girls' transitioning to adulthood, but will also impact reproductive experiences of slightly older women. The strong impact that women's education has on their own health outcomes is hard to translate into immediate policy and interventions as most of these women are now too old to increase their educational attainment. But the strong impact of the community's environment on their children's schooling can influence adult women's behaviors. Investing in education outcomes of the community, particularly by focusing on retention in secondary school, has immediate and long-term impacts on women's reproductive health.

Lastly, the limited programmatic review we carried out indicates that piecemeal efforts to improve girls' schooling will probably not work as well as those combined with work opportunities, or at least technical and vocational training. Other benefits through stipends and subsidies are certainly important, but they would yield better results in combination with other measures. 
Policy prescriptions need to be nuanced, taking regional differentials in educational performance into account. Education sector reforms in Punjab need to take into account the disparate situations between north/central Punjab and southern Punjab. Rural Sindh, plagued by ghost schools and recent natural disasters, is the worst off among all regions in the three provinces. The Sindh Government needs to prioritize effective provision of education, focusing on improving the political and administrative aspects of the education system. The issues facing KP are somewhat different - girls' primary education in rural areas has made remarkable progress and KP has the smallest urban-rural differentials. However, gender disparities in the province remain high. In fact, KP is the only province among the three where the gender gap persists in urban areas. In the coming years, KP needs to place a greater emphasis on addressing the increasing cultural barriers to educating girls.

If Pakistan hopes to achieve universal primary education in the next decade, immediate attention needs to be brought to the slowdown in the improvement of education indicators over the last few years. Particularly worrying is the stagnation in the rise of private enrollment. There is an urgent need to understand why growth in the education sector is slowing down - is it because of constraints faced by providers (both public and private) or by families themselves? 



\section{REFERENCES}

AEPAM. 2009. Pakistan Education Statistics 2008-2009. Academy of Educational Planning and Management, AEPAM: Islamabad.

Alderman, H., P. Orazem, and E. Paterno. 2001. School Quality, School Cost, and the Public/Private School Choices of Low-Income Households in Pakistan. Journal of Human Resources, 36(2):304-326.

Andrabi, T., J. Das, and A. Khwaja. 2002. The Rise of Private Schooling in Pakistan: Catering to the urban elite or educating the rural poor? Harvard University, Pomona College and World Bank.

Andrabi, T., J. Das, and A. Khwaja. 2006. Students Today, Teachers Tomorrow: The rise of affordable private schooling. Harvard University, Pomona College and World Bank.

Andrabi, T., J. Das, A. Khwaja, T. Vishwanath and Tristan Zajonc. 2007. Learning and Educational Achievements in Punjab Schools (LEAPS): Insights to inform the education policy debate.

Andrabi, T., J. Das, and A. Khwaja. 2008. A Dime a Day: The Possibilities and Limits of Private Schooling in Pakistan. Comparative Education Review 52 (3): 329-55.

Arif, G.M., N. Saqib, and G.M. Zahid. 1999. Poverty, gender, and primary school enrolment in Pakistan. The Pakistan Development Review, 38(4):979-992.

Campaign for Quality Education. 2007. Education in Pakistan: What works and why? Campaign for Quality Education: Lahore.

Federal Bureau of Statistics. 1991 to 2003. Pakistan Integrated Household Survey (from 1991 to 2001-02). Government of Pakistan, Statistics Division Federal Bureau of Statistics: Islamabad.

Federal Bureau of Statistics. 2004 to 2011. Pakistan Social and Living Standards Measurement Survey (from 2003-04 to 2010-11). Government of Pakistan, Statistics Division Federal Bureau of Statistics: Islamabad.

Herz, B. and G.B. Sperling. 2004. What Works in Girls' Education - Evidence and Policies from the Developing World. Council on Foriegn Relations Press.

Kardar, S. 1998. The Economics of Education in Pervez Hoodbhoy (ed) Education and the State. Fifty Years of Pakistan. Oxford University Press: Karachi.

Khalid, H. and E.M. Mukhtar. 2002. The Future of Girls' Education in Pakistan. UNESCO: Islamabad.

Khan, R.E. and K. Ali. 1999. Determinants of Schooling in Rural Areas of Pakistan. The Lahore Journal of Economics, 8(2):99-122.

Khan, S.R., S. Kazmi, and Z. Latif. 2003. A Comparative Institutional Analysis of Government, NGO and Private Rural Primary Schooling in Pakistan. Working Paper No: 2003-11, Department Of Economics Working Paper Series: University of Utah.

Levine R., C. Lloyd, M. Greene, and C. Grown. 2008. Girls Count: A global investment and action agenda. Center for Global Development: Washington DC.

National Institute of Population Studies. 2007. Status of Women Reproductive Health and Family Planning Survey 2003. National Institute of Population Studies: Islamabad.

National Institute of Population Studies and Macro International. 2008. Pakistan Demographic and Health Survey 2006-07. National Institute of Population Studies and Macro International: Islamabad. 
Nayab, D. 2009. Who Marries Whom in Pakistan? Role of Education in Marriage Timing and Spouse Selection. Presented at the XXVI International IUSSP Conference: Morocco.

Parveen, S. 2008. Female Education and National Development: As Viewed by Women Activists and Advocates. Bulletin of Education and Research. 30(1):33-44.

Roudi-Fahimi, F. and V.M. Moghadam. 2003. Empowering Women, Developing Society: Female education in the Middle East and North Africa. Population Reference Bureau: Washington DC.

Sathar, Z. and C. Lloyd. 1994. Who gets primary schooling in Pakistan? The Pakistan Development Review 33(2):103-134.

Sathar, Z., C. Lloyd, C. Mete and M. ul Haque. 2003. Schooling Opportunities for Girls as Stimulus for Fertility Change in Rural Pakistan. Economic Development and Cultural Change 51(3):677-698.

Sathar, Z., M. ul Haque, M. Khan, C. Lloyd, and M. Grant. 2006. Fewer and Better [Educated] Children: Expanded Choices in Schooling and Fertility in Rural Pakistan. Population Council: Islamabad.

Sathar, Z., L. Reichenbach, and A. Mahmood. 2008. What's hindering fertility decline in Pakistan: Perceptions and realities. Presented at Population Association of America Meeting 2008: New Orleans.

Sawada, Y. and M. Lokshin. 2001. Household Schooling Decisions in Rural Pakistan. Policy research working papers, World Bank.

Toor, I. and R. Parveen. 2004. Factors Influencing Girls' Primary Enrolment in Pakistan. The Lahore Journal of Economics, 9(2):141-157.

UNESCO. 2000. Incentive Schemes for Promoting Girls' Participation in Primary Education in Pakistan. United Nations Educational, Scientific, and Cultural Organization: Islamabad.

UNICEF. 2004. The State of the World's Children 2004 - Girls' Education and Development. United Nations Children's Fund: New York.

World Bank. 2005. Bridging the Gender Gap: Opportunities and Challenges. World Bank: Washington DC.

World Bank. 2008. Girl's Education in the 21st Century: Gender Equality, Empowerment and Growth. World Bank: Washington DC.

Zaidi, B. and L. Reichenbach. 2009. The Role of Ethnicity and Migration in Determining Fertility Behavior in Pakistan. Presented at the XXVI International IUSSP Conference: Morocco. 


\section{APPENDIX A: FIELD STUDY*}

\section{A. Study design}

\section{Sample communities}

To answer these complex questions, we took advantage of a schooling study, 'Fewer and Better Children: expanded choices in schooling and fertility in rural Pakistan' conducted by the Population Council in 2004 (Sathar et al. 2006). This study collected information on the supply of schools as well as demands for schooling in 12 communities across Punjab and KP over two time periods (1997 and 2004). Returning to those communities offered the opportunity to assess real changes in the very same communities that we visited 14 years ago, at the community, school, and household levels.

The communities were selected from three districts from each of the two provinces - they were selected on the basis of being high, medium, or low-performing districts in terms of enrollment in relation to income levels using the PIHS 1995/96 data. The districts in Punjab were Sialkot, Dera Ghazi Khan, and Rahim Yaar Khan. In KP, they were Abbottabad, Karak, and Swat. We added two districts from Sindh to our study because of the extremely poor progress in girls' schooling in rural Sindh. The districts of Dadu and Thatta were chosen purposively to represent relatively high and low performing districts. Looking at girls' primary enrollment rates for rural areas in these eight districts from 2008/09 PSLMS data, we found that the performance levels had largely remained the same in rank since our 1995/96 analysis (Figure 1).

\footnotetext{
" Several members of our team at Population Council contributed to the tedious data collection and data editing of this survey, including Ashfa Hashmi, Muhammad Ishtiaq, Muhammad Ali, and Mazher Abbas Shah.
} 
Figure 1: Primary NER for rural girls, by province and district, 2008-09

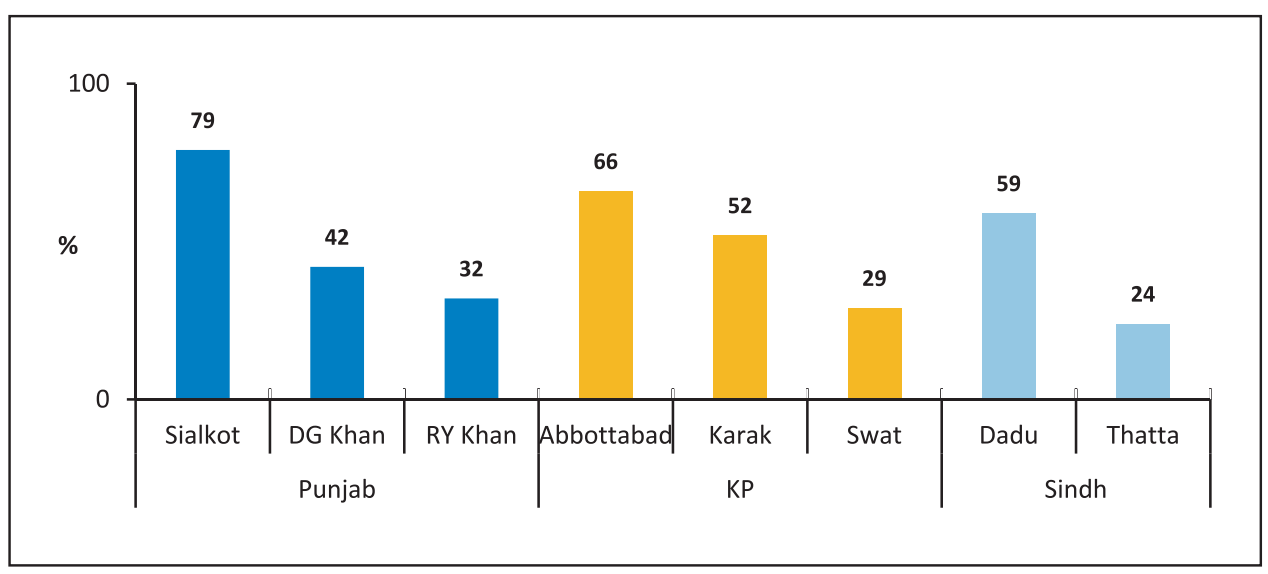

Two communities were selected in each of these districts, and households were selected systematically with a random start. Figure 2 shows the names and location of each of our 16 communities.

Figure 2: Map of 16 sample communities

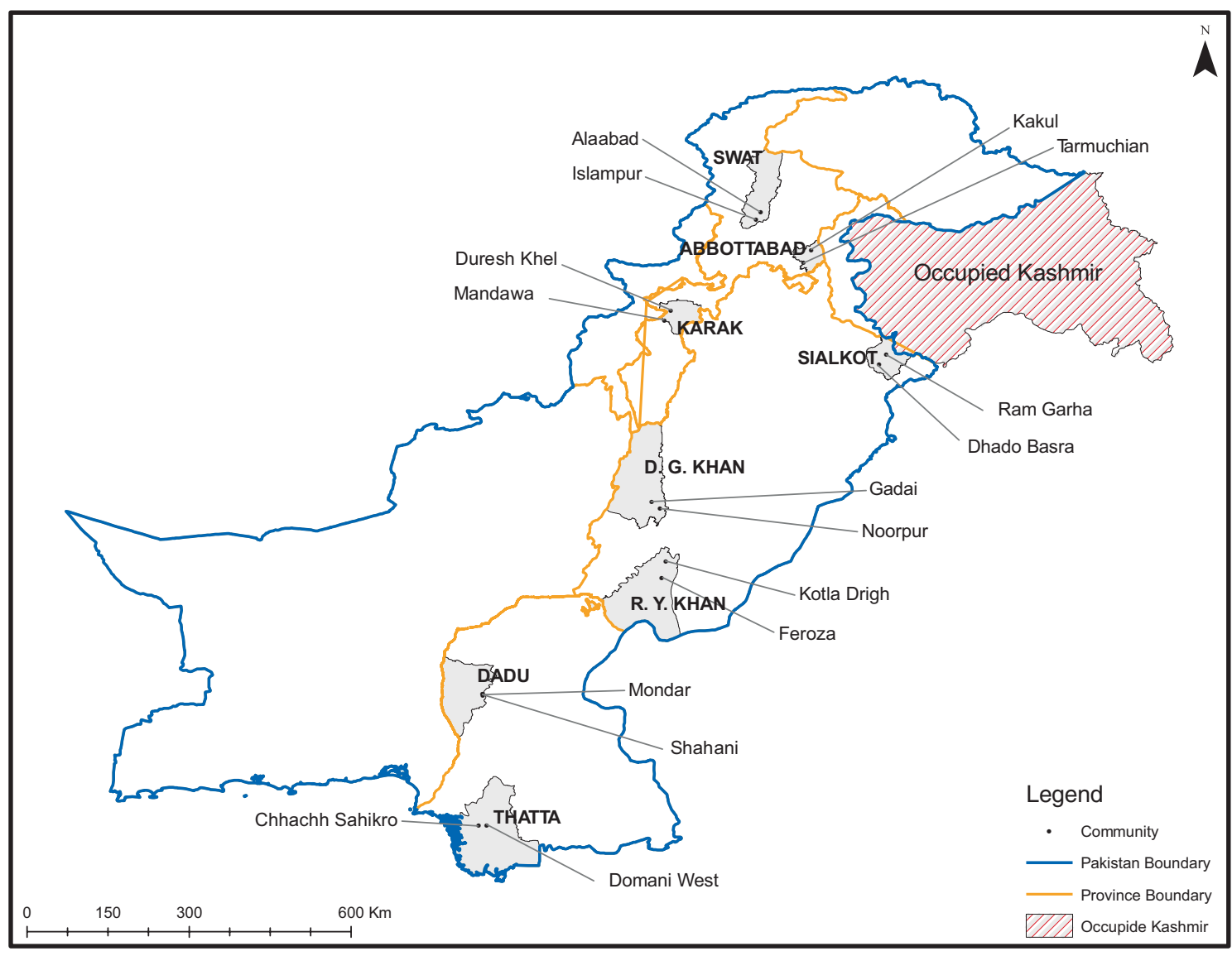




\section{Methodology}

Within each of the 12 communities, we followed the panel of the previously selected 60 plus households (selected systematically with a random start in the original study), completed a detailed household roster, and interviewed 18-35 year old women. In addition, we captured changes in the community and visited and collected data on all the schools that children aged 5-19 were attending. Details of the original sample can be found in the earlier report (Sathar et al. 2006). For the four communities in Sindh, we used the random start method to select sample households and then used the methodology followed for the other communities.

In order to truly measure access to schools, we introduced GPS technology in this round of the survey. In addition to visiting each school and updating the school inventory, we recorded the GPS coordinates of each school. Household GPS coordinates were also recorded in order to measure distances from households to school. Using GIS software, we were able to create a map of each community showing the location and road distance of each school from our sampled households. In order to measure distances to schools, a PSU centroid (geographical mean) was estimated and road distances measured from that centroid. The maps included in Figure 3 demonstrate the various ways we were able to measure access through this process. 
Figure 3: Illustration of measurement of distance from PSU centroid to schools (PSU; Ram Garha)
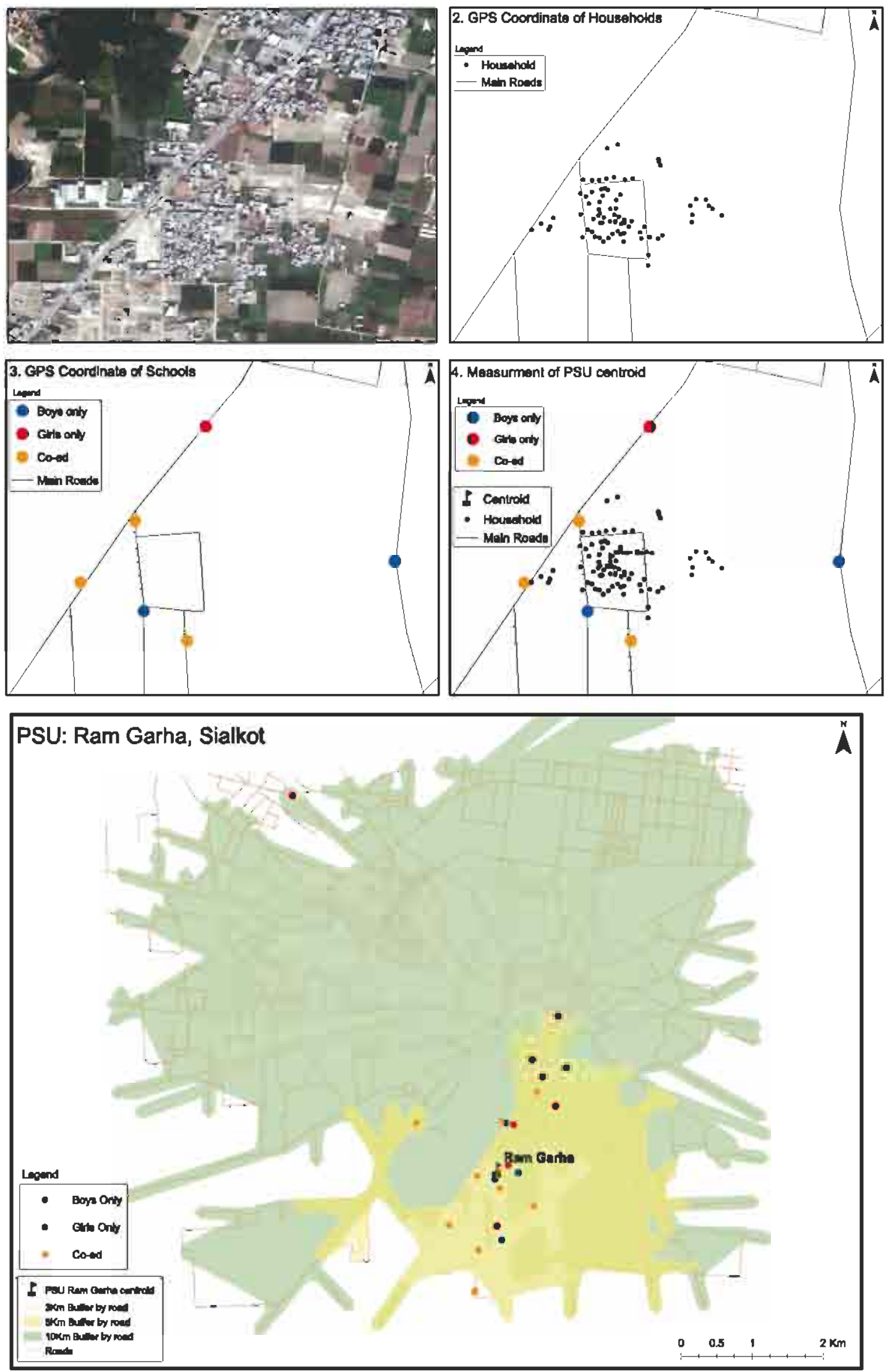

Note: Location of $\mathrm{HH}$ and schools is distorted to maintain confidentiality. 


\section{B. Questionnaires}

\section{Community questionnaire (16 communities)}

We collected information on each community's characteristics as reported by key informants. This information included:

- Availability of facilities and services, public amenities, transport and communication

- Migration

- NGOs operating in community

- Availability of schools

- Local economic activities and work opportunities

- Major events that affected the community, both natural and manmade

\section{School questionnaire (176 schools)}

All schools within the 16 communities as well as schools attended by children, particularly girls, were surveyed. Information was collected on:

- School type

- Condition of building and classrooms

- Availability of amenities

- Medium of schooling

- Availability of text books

- School fees

- Duration of daily and annual school sessions

- Total enrollment as well as attendance on day of visit

- Information on all teachers

\section{Household questionnaire $(1,191$ households)}

The household questionnaire contained information on household asset ownership and responses to economic shocks, as well as a detailed roster that obtained information on the following areas for all household members:

- Basic demographic characteristics (age, sex)

- Marital status and age at marriage

- Level and type of schooling

- Duration, type, and location of economic activity

Young women's questionnaire (1352 young women)

Our female questionnaire was designed to capture the role of education in the lives of both married and unmarried women aged 18-35. The questionnaire had detailed sections on: 
- Respondent's background

- Education, including detailed information on the various schools they attended

- Work, both actual and desired

- Mobility, decision-making within the household

- Marriage, including information on marital transactions, ideals, spouse selection and more

- Reproductive health, including information on birth history, pregnancy care, contraceptive use, and intentions

\section{Sample characteristics}

\section{Community characteristics}

Even though our survey sample consists of 16 communities only, it represents a wide variety of rural settings in Pakistan. Not only did they come from three provinces, our sample captured communities from different regions of each province; both remote, hard to access villages and those close to urban areas; large variation in development levels; five different ethnicities; and communities that had experienced the War on Terror or floods in 2010. Though much of the variation was captured at the provincial and district level, even the two communities within each district offered a different situation to analyze.

The communities in our sample differed not only in how developed they were, but also in their schooling environment. Certain communities, including those in Sialkot and Abbottabad, and Gadai in Dera Ghazi Khan, had more than 15 schools that were attended by children from the community. On the other hand, in some communities, like those in Karak and Thatta, and Kotla Drigh in Rahim Yaar Khan, had only five to seven schools attended by children from the community. Both communities in Thatta had only five schools accessed by children from the community, of which only one was accessible to girls. The variation in the choice of schools available (particularly to girls), the type of schools, and the grades taught, can be seen in Table A.1. 
Table A.1: Schooling environment of sample communities

\begin{tabular}{|c|c|c|c|c|c|c|c|c|c|}
\hline \multirow{3}{*}{\multicolumn{2}{|c|}{ Province/district }} & \multirow{3}{*}{ Community } & \multirow{3}{*}{$\begin{array}{l}\text { Community } \\
\text { development } \\
\text { score11 }\end{array}$} & \multicolumn{6}{|c|}{ Number of schools } \\
\hline & & & & \multicolumn{2}{|c|}{ Type } & \multirow{2}{*}{$\begin{array}{l}\text { Available } \\
\text { to girls } \\
\text { (girls only } \\
\text { + coed) }\end{array}$} & \multicolumn{2}{|c|}{ Grade level } & \multirow[b]{2}{*}{ Total } \\
\hline & & & & Public & Private & & Primary & Middle + & \\
\hline \multirow{7}{*}{ Punjab } & \multirow{2}{*}{ Sialkot } & Dhadho Basra & 7 & 9 & 6 & 10 & 14 & 9 & 15 \\
\hline & & Ram Garha & 8 & 7 & 16 & 17 & 20 & 19 & 23 \\
\hline & \multirow{2}{*}{ DG Khan } & Gadai & 8 & 7 & 10 & 16 & 16 & 12 & 17 \\
\hline & & Noorpur & 2 & 6 & 5 & 8 & 11 & 7 & 11 \\
\hline & \multirow{2}{*}{ RY Khan } & Feroza & 6 & 5 & 6 & 8 & 11 & 7 & 11 \\
\hline & & Kotla Drigh & 3 & 5 & 0 & 3 & 5 & 2 & 5 \\
\hline & Total & & - & 39 & 43 & 62 & 77 & 56 & 82 \\
\hline \multirow{5}{*}{ Sindh } & \multirow{2}{*}{ Dadu } & Mondar & 4 & 6 & 1 & 3 & 6 & 2 & 7 \\
\hline & & Shahani & 1 & 6 & 5 & 7 & 10 & 4 & 11 \\
\hline & \multirow[t]{2}{*}{ Thatta } & $\begin{array}{l}\text { Chhachh } \\
\text { Sahikro }\end{array}$ & 2 & 5 & 0 & 0 & 3 & 2 & 5 \\
\hline & & Domani West & 1 & 5 & 0 & 1 & 5 & 1 & 5 \\
\hline & Total & & - & 22 & 6 & 11 & 24 & 9 & 28 \\
\hline \multirow{7}{*}{$\mathbf{K P}$} & \multirow{2}{*}{ Swat } & Islampur & 10 & 5 & 4 & 8 & 7 & 6 & 9 \\
\hline & & Alaabad & 8 & 5 & 3 & 6 & 6 & 4 & 8 \\
\hline & \multirow{2}{*}{ Karak } & Duresh Khel & 6 & 5 & 1 & 3 & 5 & 2 & 6 \\
\hline & & Mandawa & 5 & 5 & 2 & 5 & 5 & 4 & 7 \\
\hline & \multirow{2}{*}{ Abbottabad } & Tarmuchian & 3 & 11 & 5 & 11 & 13 & 7 & 16 \\
\hline & & Kakul & 9 & 7 & 13 & 17 & 16 & 16 & 20 \\
\hline & Total & & - & 38 & 28 & 50 & $\mathbf{5 2}$ & 39 & 66 \\
\hline Total & & & & 99 & 77 & 123 & 153 & 104 & 176 \\
\hline
\end{tabular}

\section{Household and young women characteristics}

Our survey yielded a sample of 1,191 households across 16 communities with an average of approximately 70 households per community. Among the 12 communities of Punjab and KP, 81 percent of the households in our sample were panel households from 2004.

11 The development score of a community was constructed using the following items. In case a service was available, it was assigned 1 , otherwise zero. Thus the range of development score for a community can vary between 0 (if none available) and 11 (if all available).
1. LHW/FWC
5. Metalled road
2. Basic health unit (BHU)
3. Private doctor (MBBS)
6. Public transport
9. Electricity
4. Chemist/medical store
7. Paved streets
8. Sewerage system
10. Phone service
11. Natural gas 
Table A.2: Sample size of households and females

\begin{tabular}{|c|c|c|c|c|c|c|c|c|}
\hline & \multicolumn{4}{|c|}{ Hougeholds } & \multicolumn{4}{|c|}{ Young women } \\
\hline & Punjab & Sindb & $\mathbf{K P}$ & Total & Punjab & Sindh & $\mathbf{K P}$ & Total \\
\hline Panel & 396 & 0 & 360 & 756 & 408 & 0 & 457 & 865 \\
\hline New & 91 & 253 & 91 & 435 & 106 & 280 & 101 & 487 \\
\hline Total & 487 & 253 & 451 & 1,191 & 514 & 280 & 558 & 1,352 \\
\hline
\end{tabular}

The young women's survey was sampled on the basis of the household panel. If there was no eligible woman in the panel household or the panel household was not found, women from the next household were interviewed as replacements. Among the 12 communities of Punjab and KP, 81 percent of the women in our sample belonged to panel households while the remaining were from replacement households. The women from the four Sindhi communities were identified through a randomized sampling of households in the selected PSUs. More details about these women can be found in chapter four on the findings from the women's questionnaire. 


\section{APPENDIX B: MAPS OF SAMPLE COMMUNITIES}

\footnotetext{
* The GIS maps were produced by the hard work of Muhammad Usman Ghani, Touqeer Izhar and Saquib Ilyas.
} 


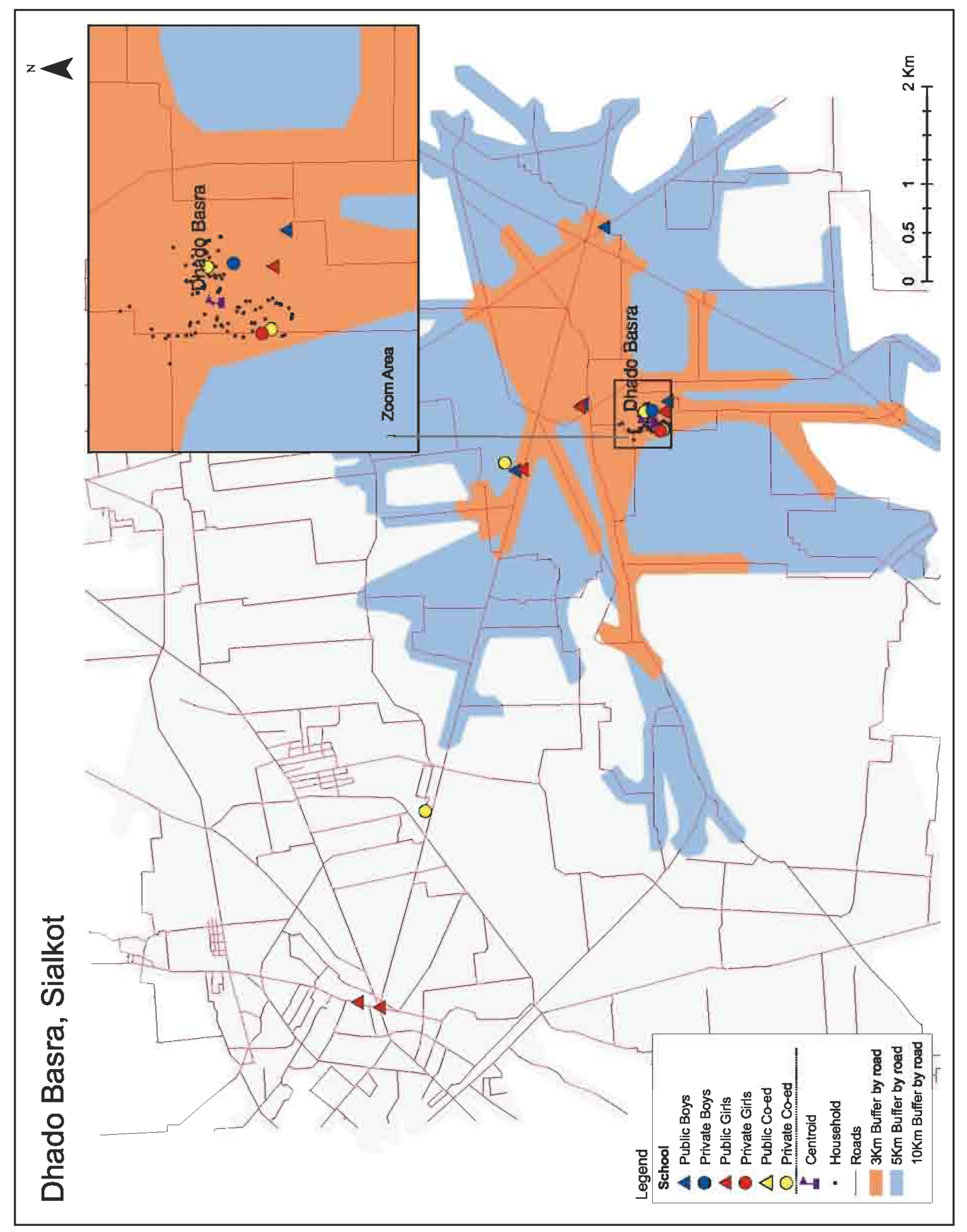




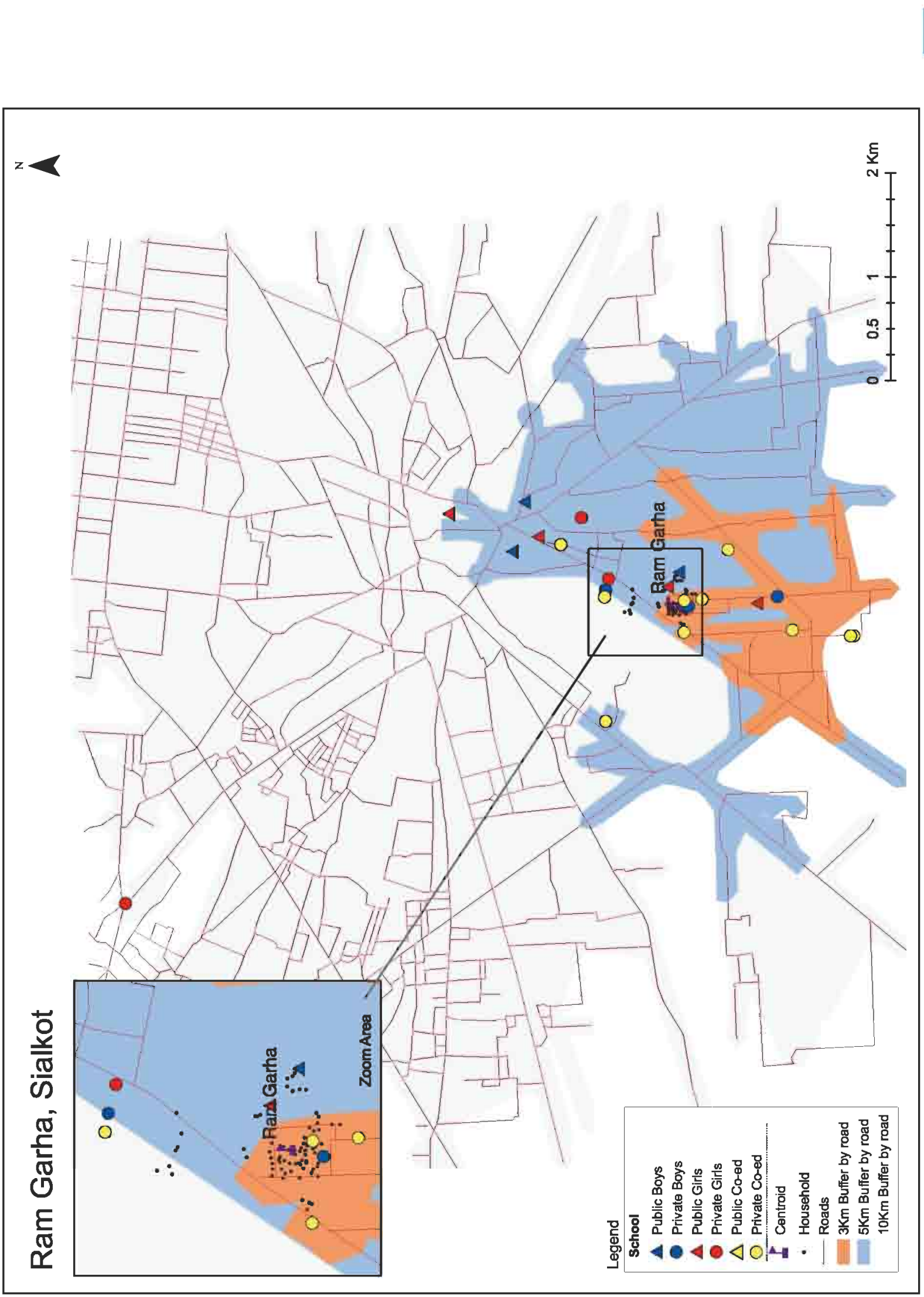




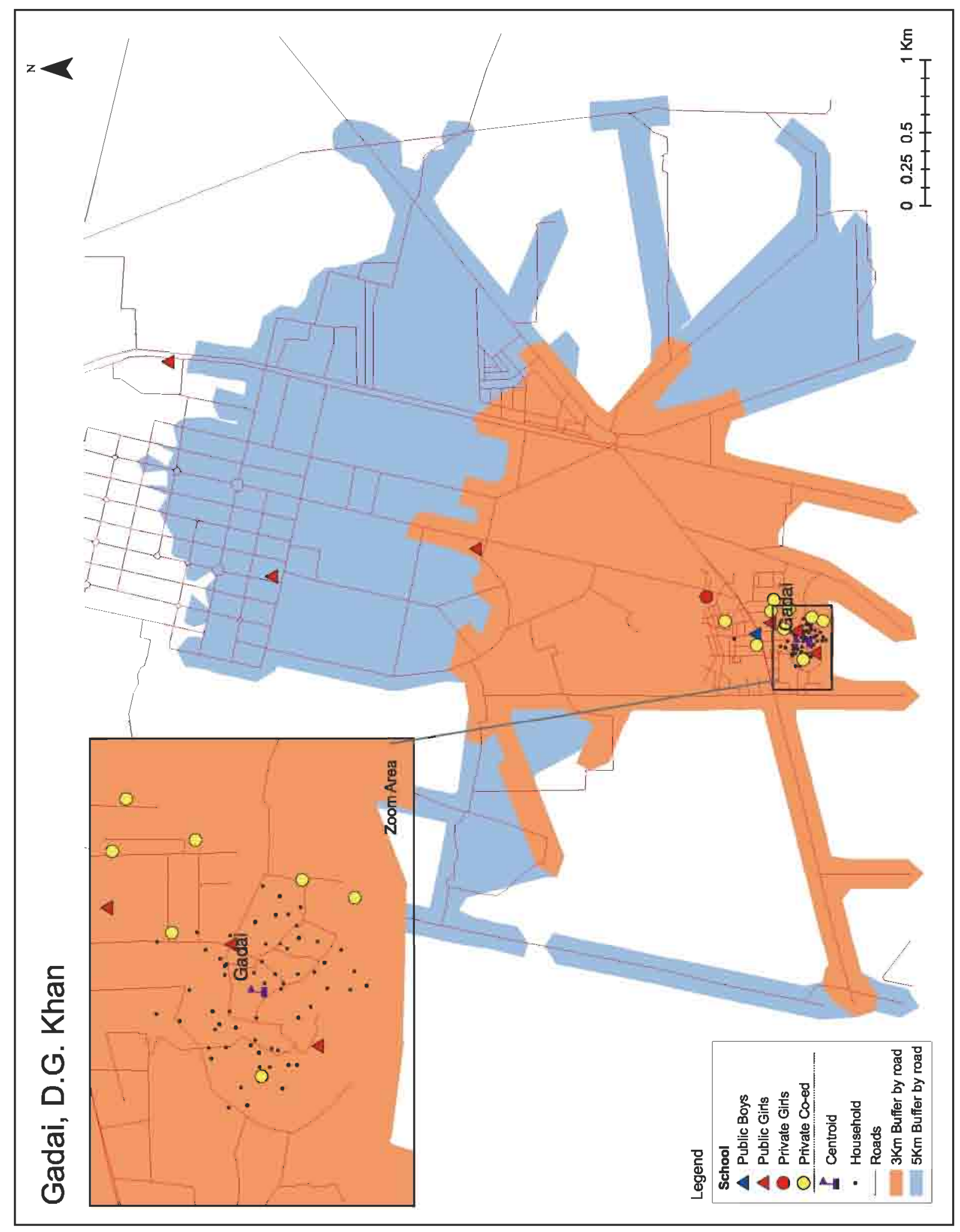




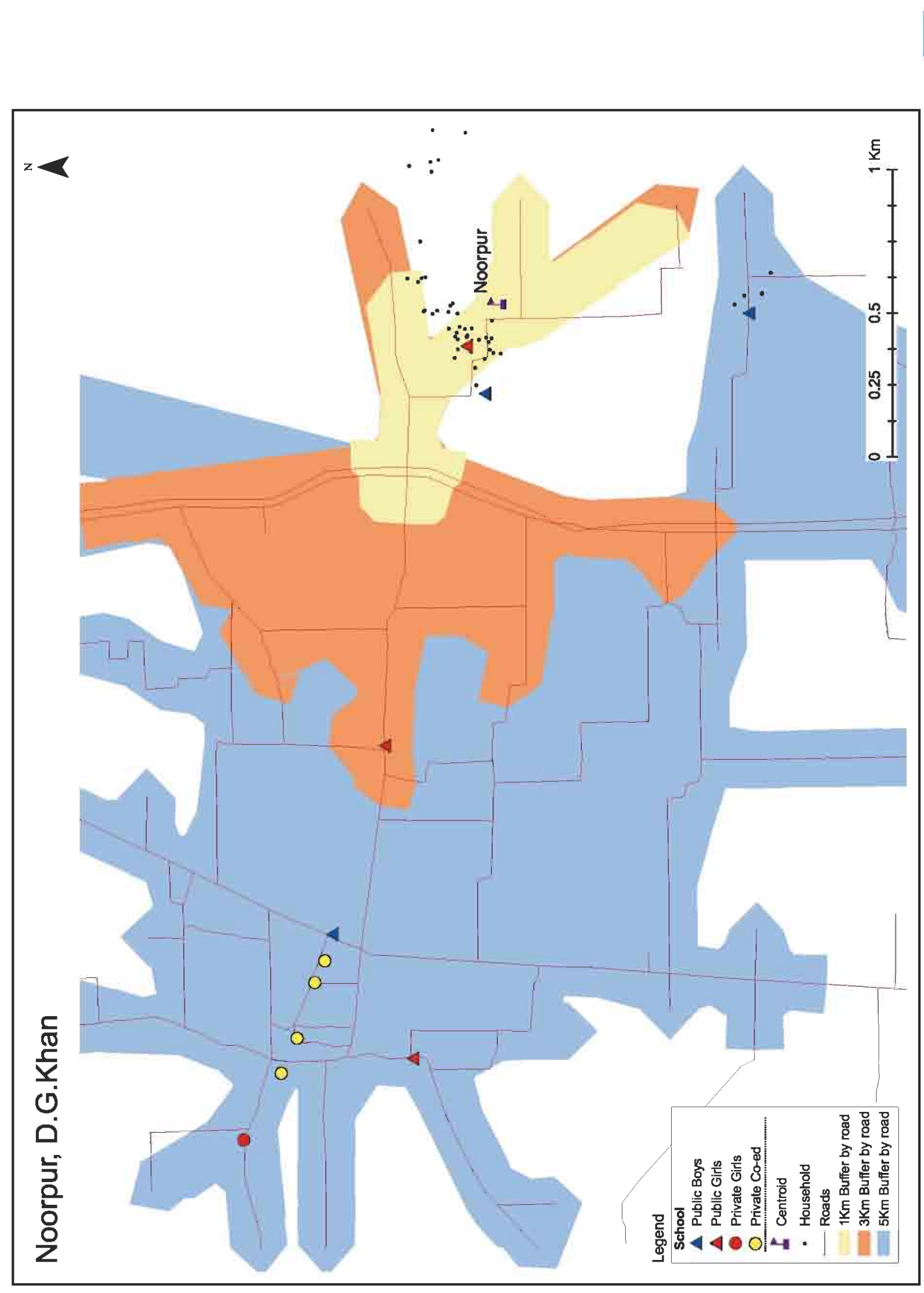




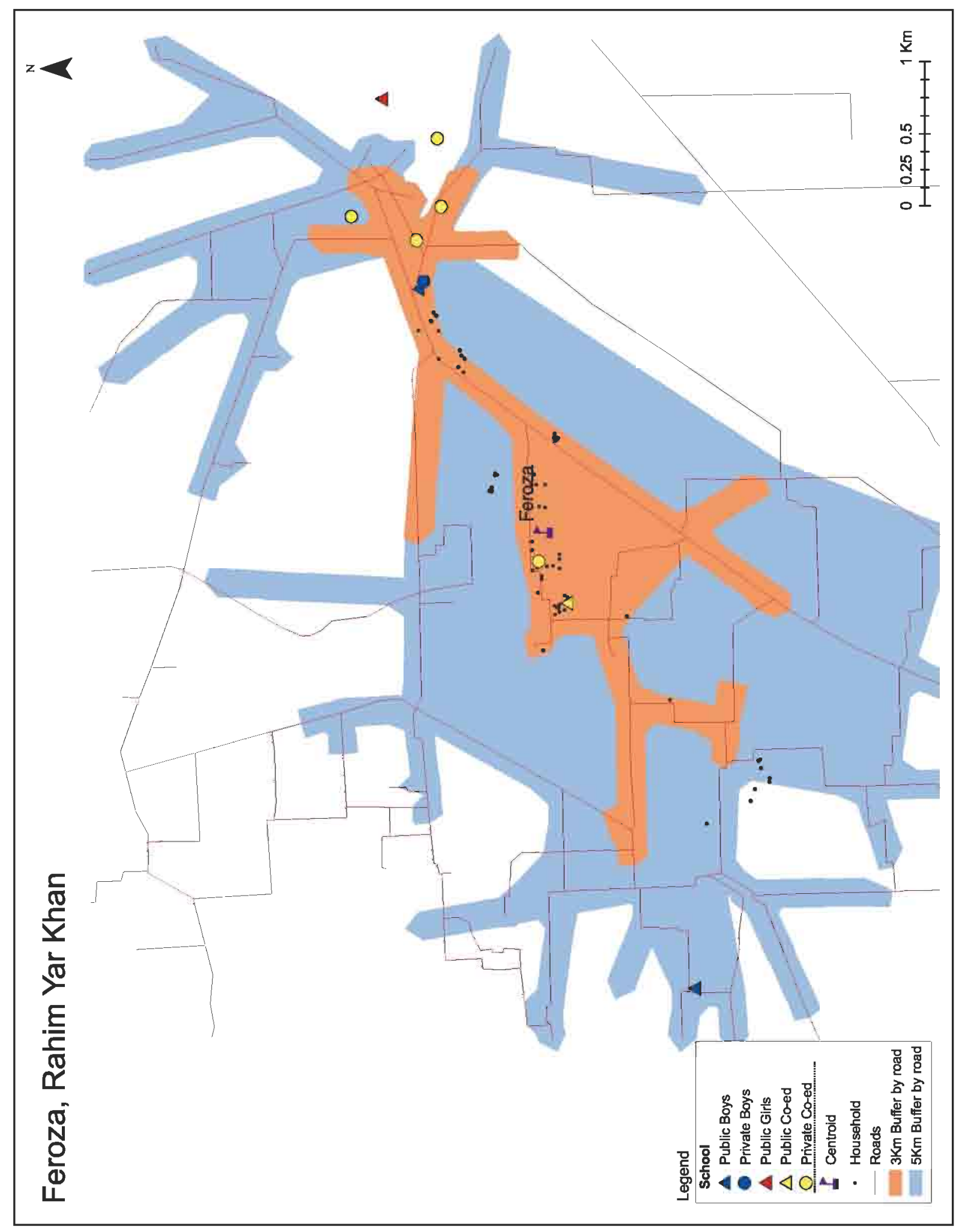




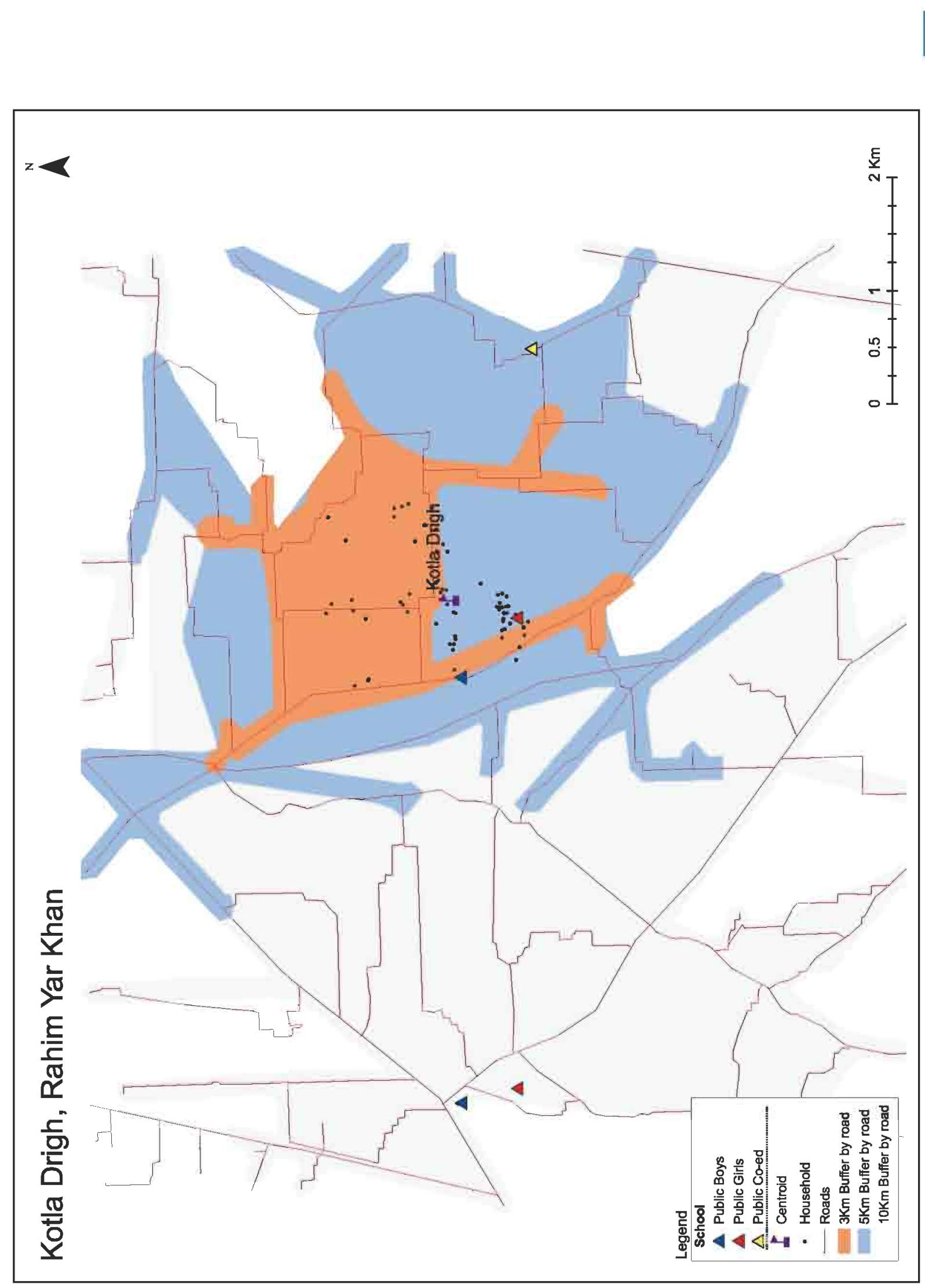




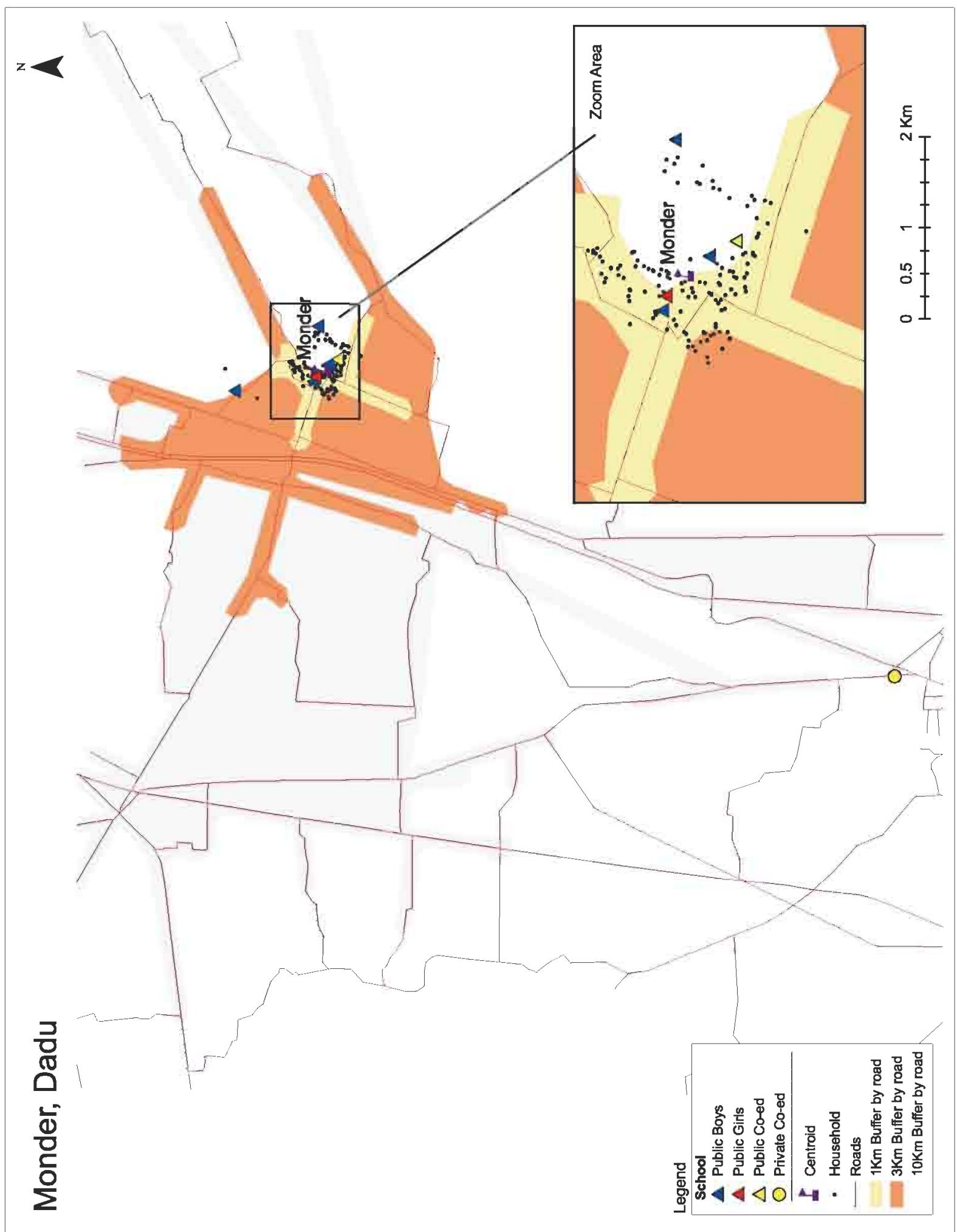




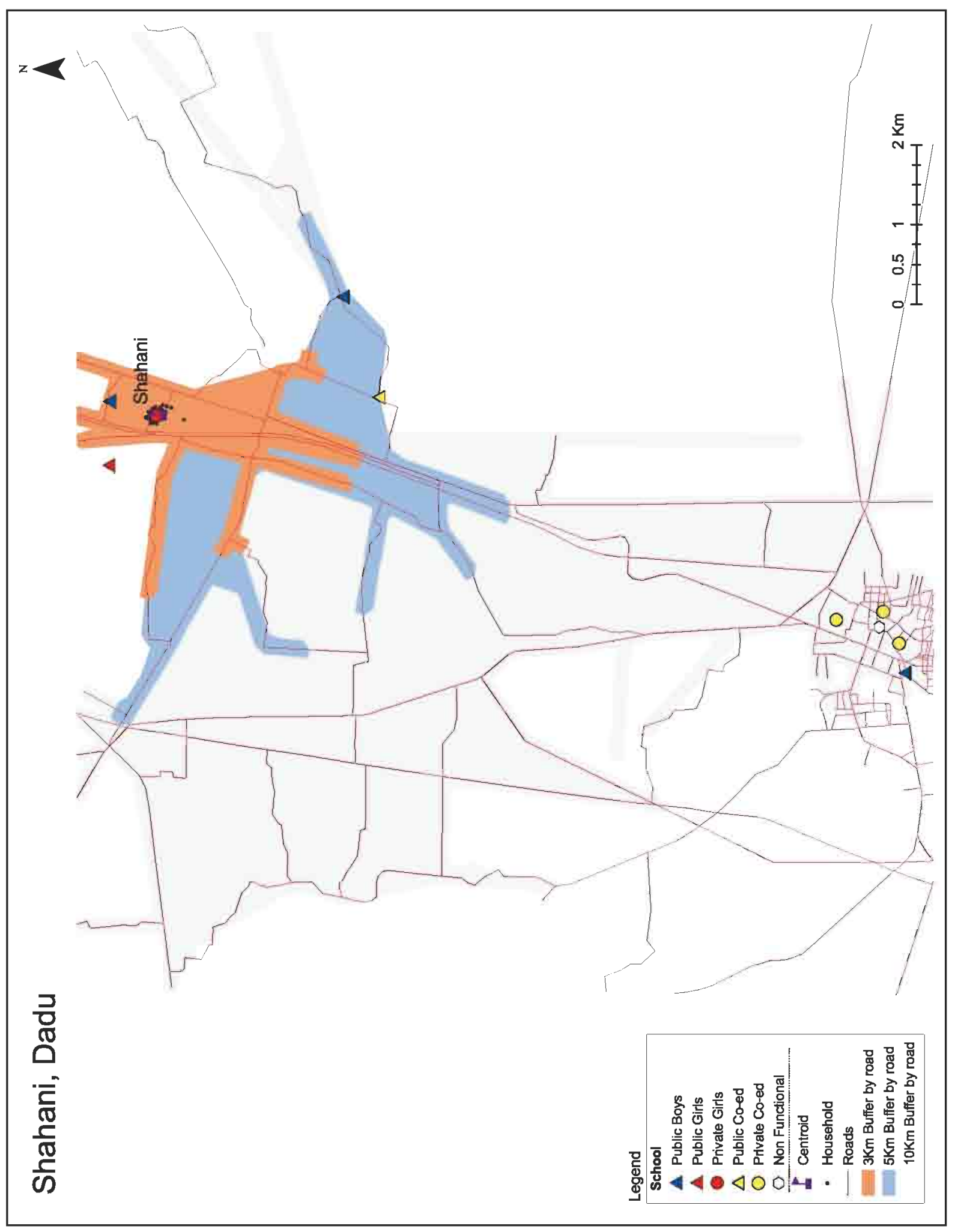




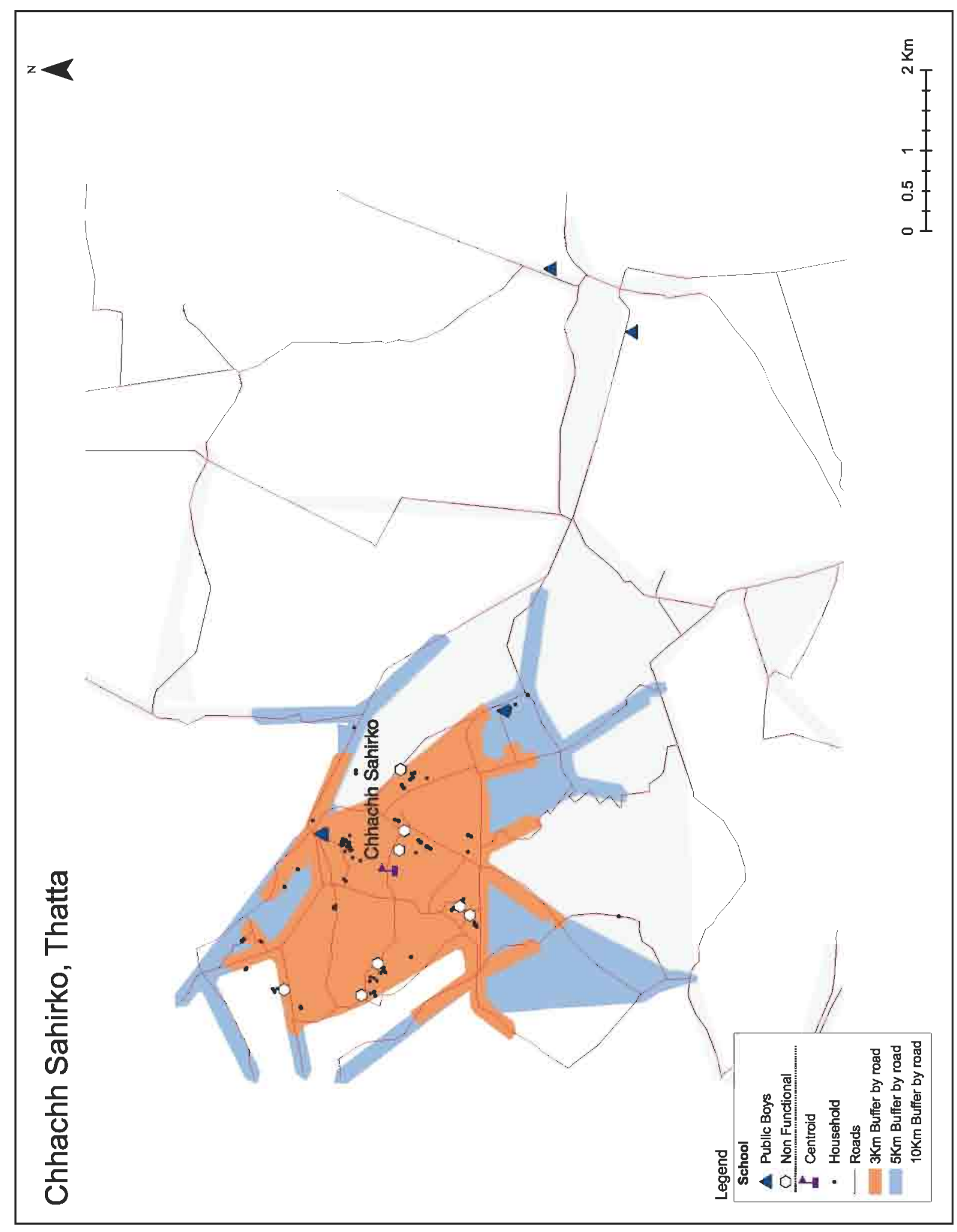




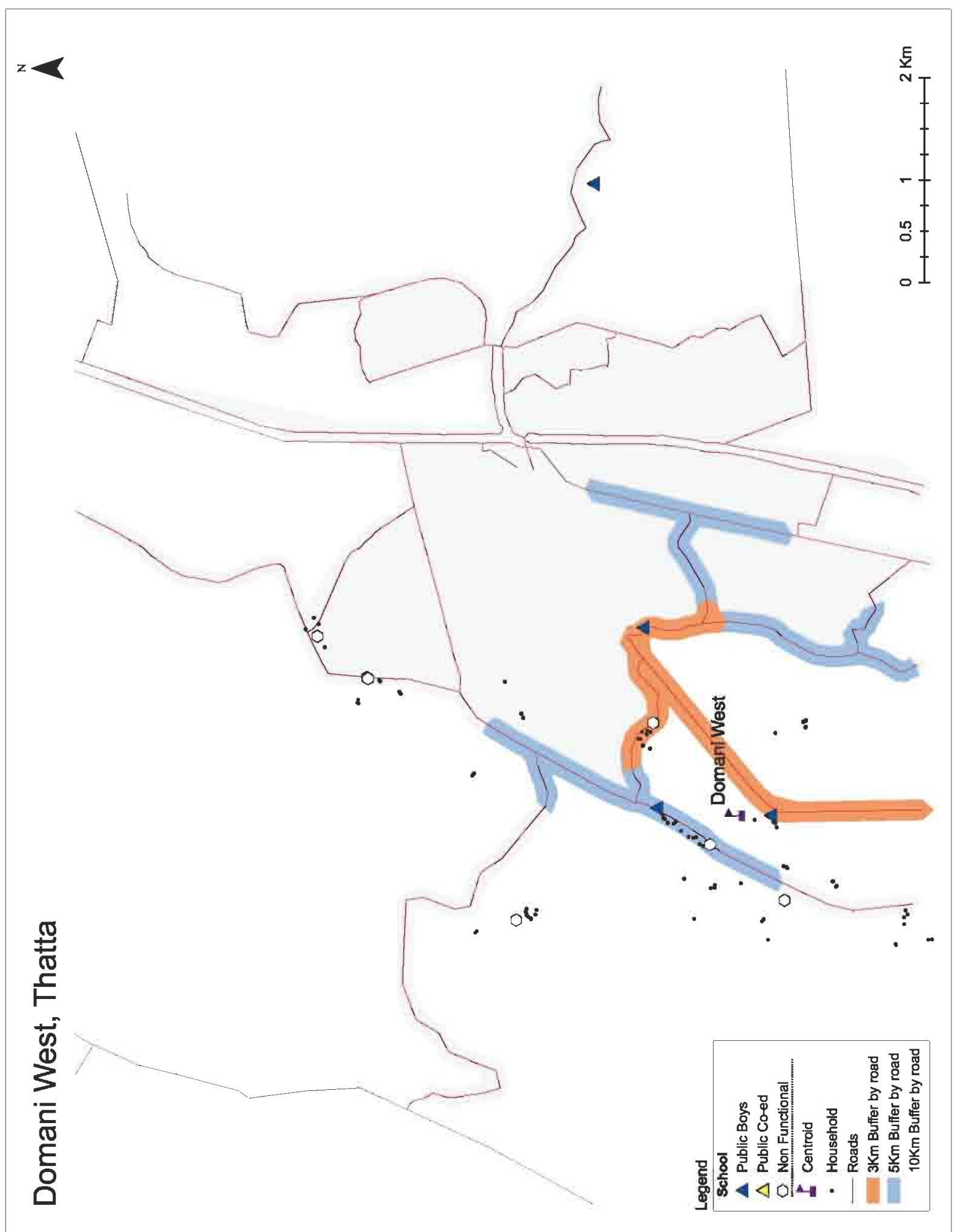




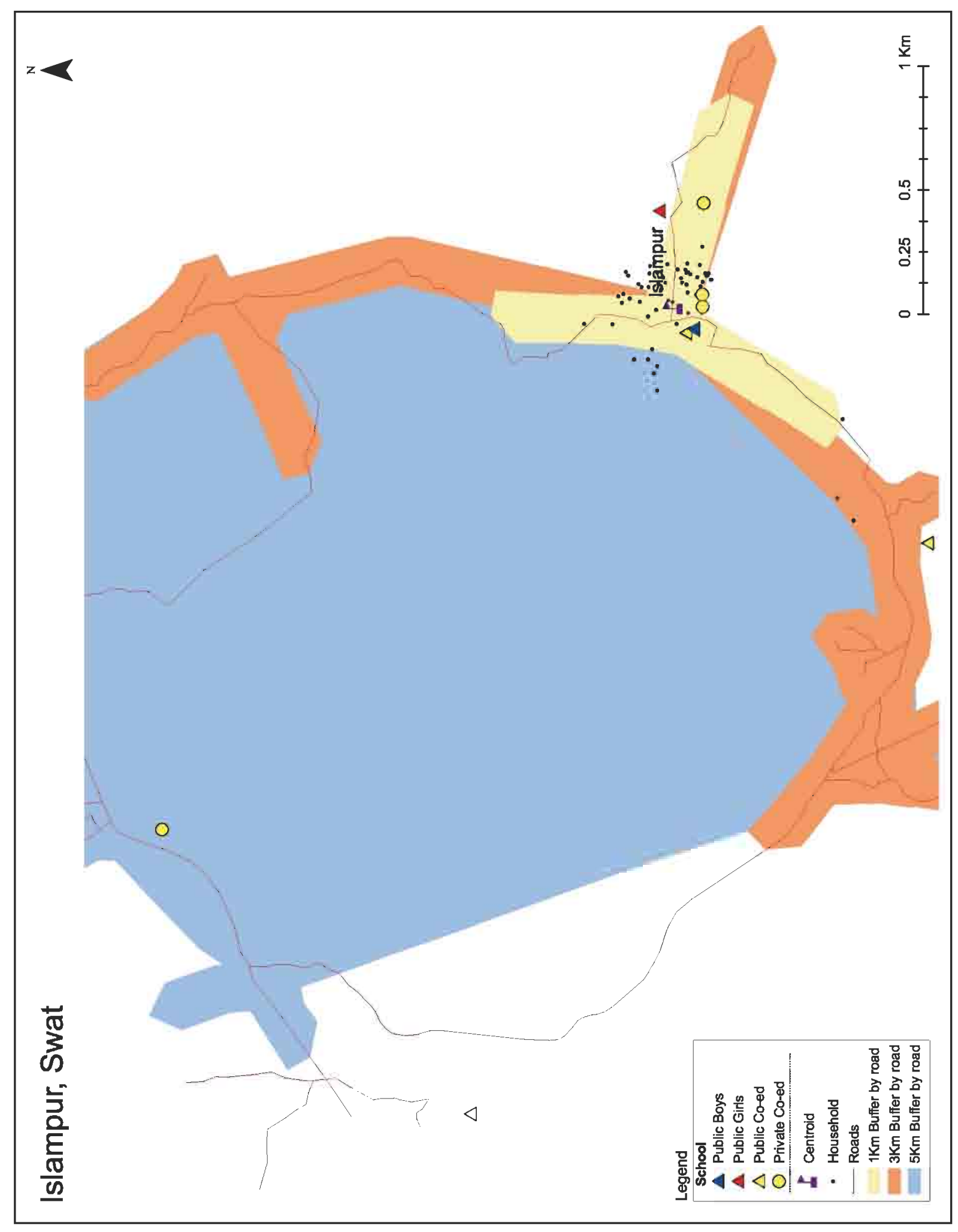




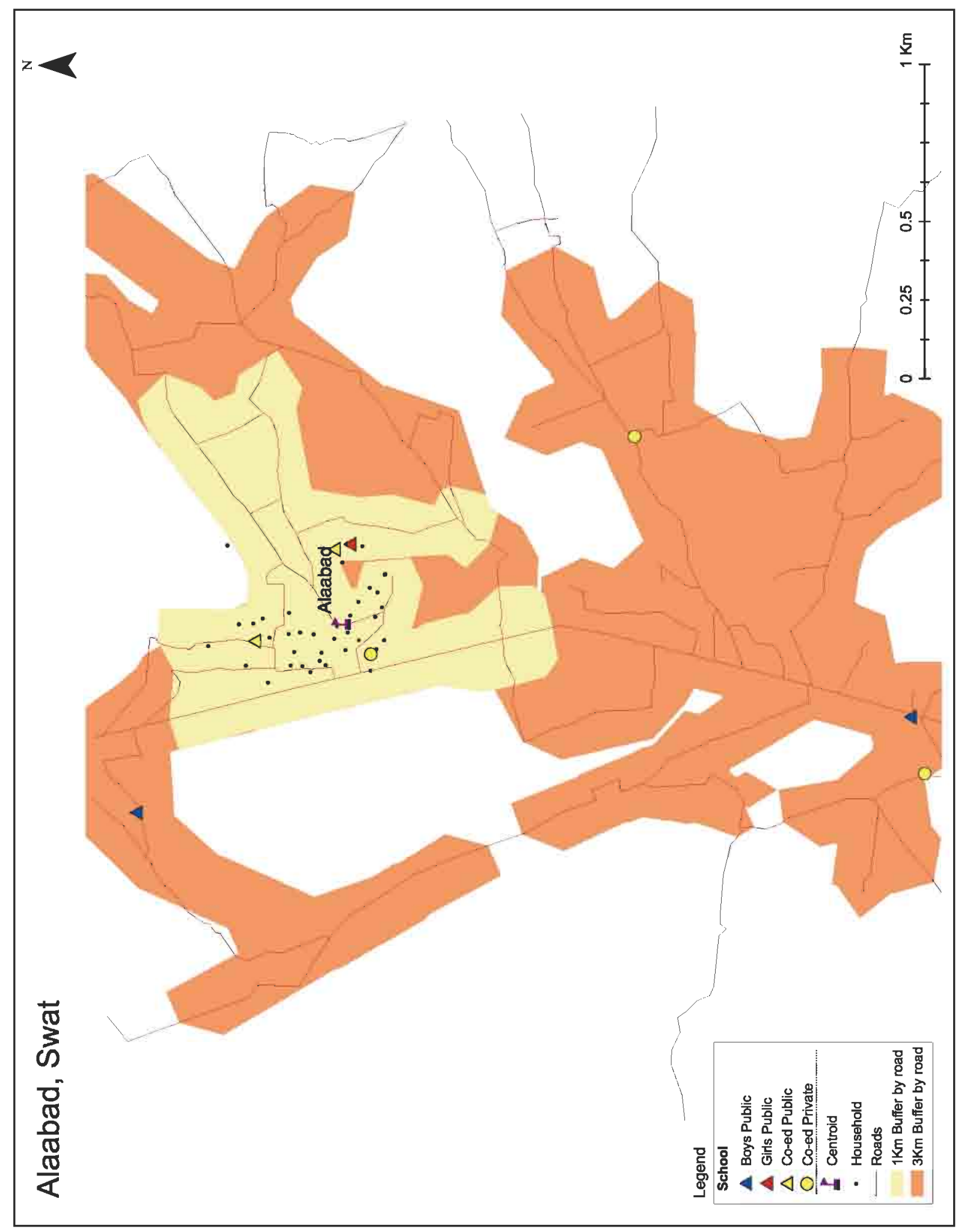




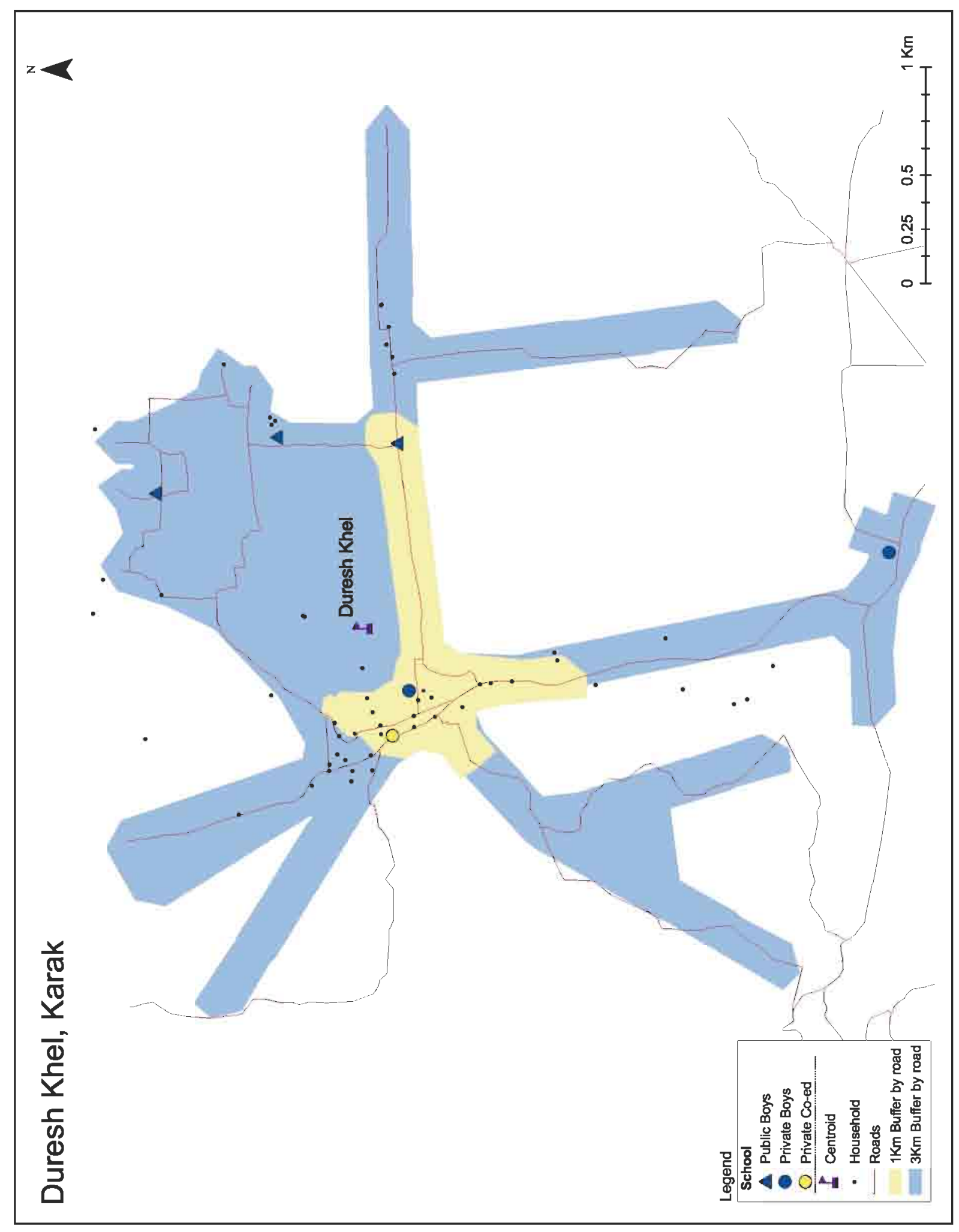




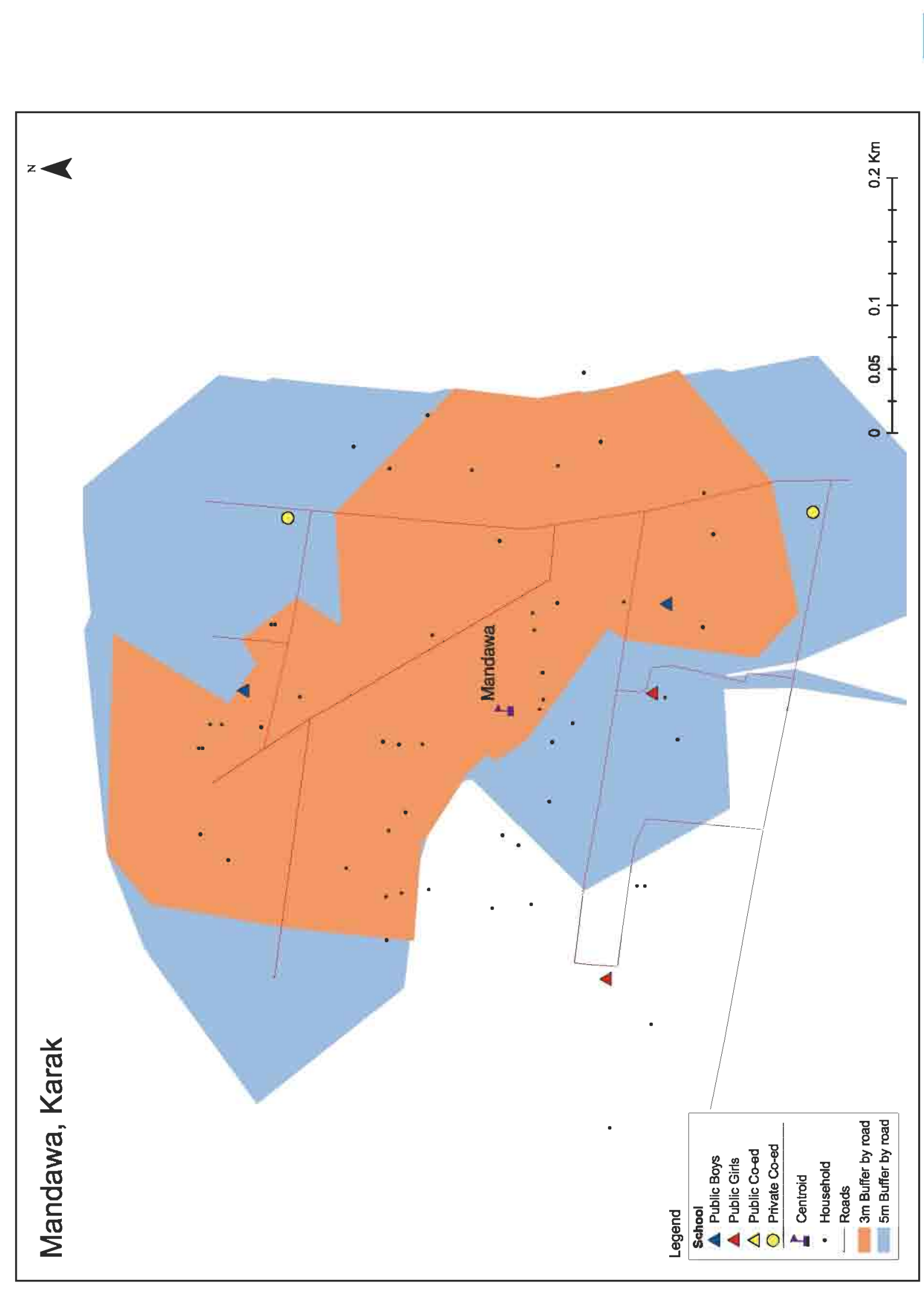




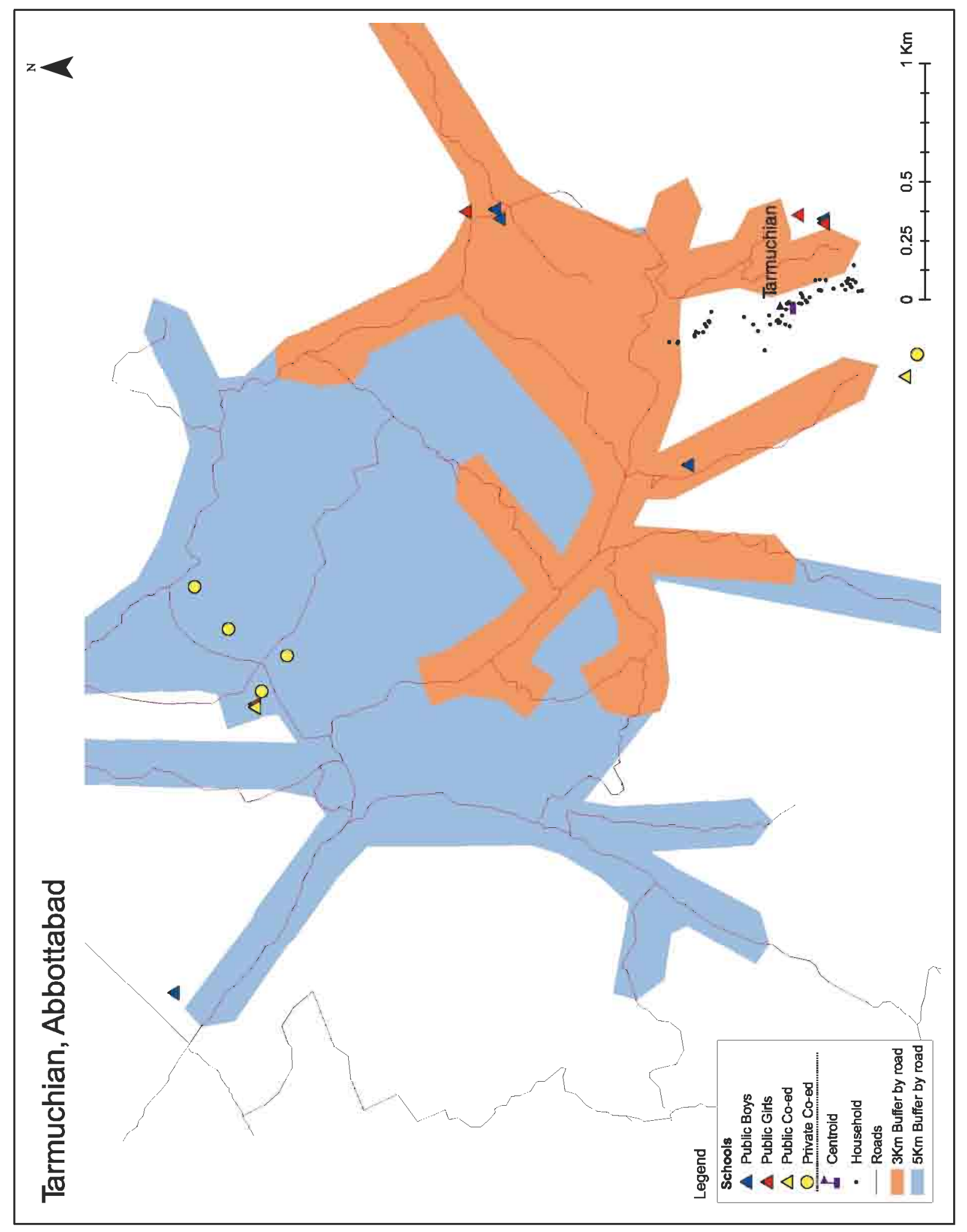




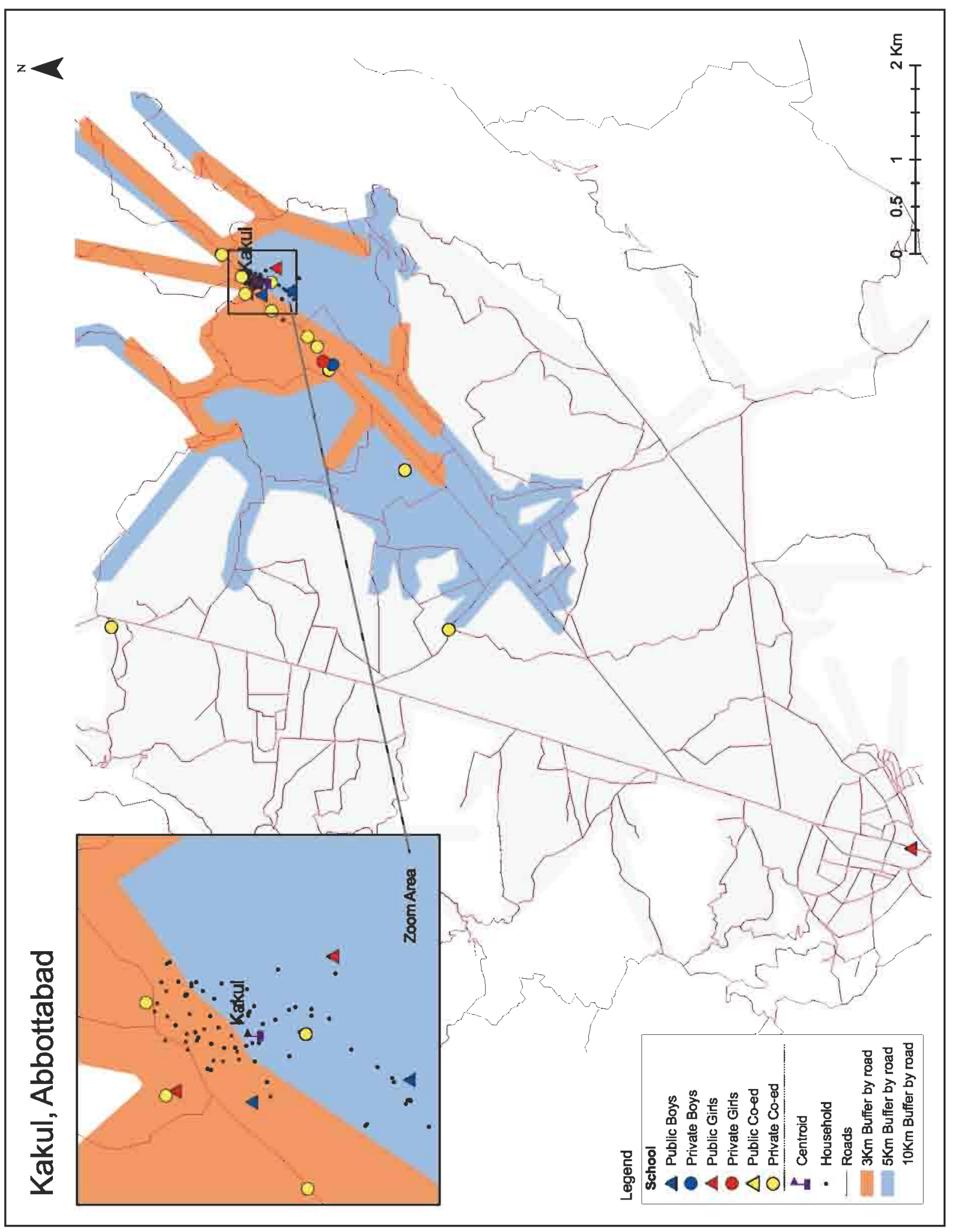

